\title{
Jupiter's auroral-related stratospheric heating and chemistry I: analysis of Voyager-IRIS and Cassini-CIRS spectra
}

\author{
J. A. Sinclair ${ }^{\mathrm{a}, *}$, G. S. Orton ${ }^{\mathrm{a}}$, T. K. Greathouse ${ }^{\mathrm{b}}$, L. N. Fletcher ${ }^{\mathrm{c}}$, J. I. Moses ${ }^{\mathrm{d}}$, V. Hue ${ }^{\mathrm{b}}$, P. G. J. Irwin ${ }^{\mathrm{e}}$ \\ ${ }^{a}$ Jet Propulsion Laboratory/California Institute of Technology, 4800 Oak Grove Dr, Pasadena, CA 91109, United States \\ ${ }^{b}$ Southwest Research Institute, 6220 Culebra Rd., San Antonio, TX 78236, United States \\ ${ }^{c}$ Department of Physics $\mathcal{E}$ Astronomy, University of Leicester, University Road, Leicester, LE1 7RH, United Kingdom \\ ${ }^{d}$ Space Science Institute, 4750 Walnut St, Suite 205, Boulder, CO 80301, United States \\ ${ }^{e}$ Atmospheric, Oceanic E Planetary Physics, University of Oxford, Parks Road, Oxford, OX1 3PU, United Kingdom
}

\begin{abstract}
Auroral processes are evident in Jupiter's polar atmosphere over a large range in wavelength (X-ray to radio). In particular, previous observations in the mid-infrared (5 to $15 \mu \mathrm{m}$ ) have shown enhanced emission from $\mathrm{CH}_{4}, \mathrm{C}_{2} \mathrm{H}_{2}$ and $\mathrm{C}_{2} \mathrm{H}_{4}$ and further stratospheric hydrocarbon species in spatial regions coincident with auroral processes observed at other wavelengths. These regions, described as auroral-related hotspots, observed at approximately $160^{\circ} \mathrm{W}$ to $200^{\circ} \mathrm{W}$ (System III) at high-northern latitudes and $330^{\circ} \mathrm{W}$ to $80^{\circ} \mathrm{W}$ at high-southern latitudes, indicate that auroral processes modify the thermal structure and composition of the neutral atmosphere. However, previous studies have struggled to differentiate whether the aforementioned enhanced emission is a result of either temperature changes and/or changes in the concentration of the emitting species. We attempt to address this degeneracy in this work by performing a retrieval analysis of Voyager 1-IRIS spectra (acquired in 1979) and Cassini-CIRS spectra (acquired in 2000/2001) of Jupiter. Retrievals of the vertical temperature profile in Cassini-CIRS spectra covering the auroral-related hotspots indicate the presence of two discrete vertical regions of heating at the 1-mbar level and at pressures of 10- $\mu$ bar and lower. For example, in Cassini-CIRS $2.5 \mathrm{~cm}^{-1}$ 'MIRMAP' spectra at $70^{\circ} \mathrm{N}$ (planetographic) $180^{\circ} \mathrm{W}$ (centred on the auroral oval), we find temperatures at the 1-mbar level and $10-\mu$ bar levels are enhanced by $15.3 \pm 5.2 \mathrm{~K}$ and $29.6 \pm 15.0 \mathrm{~K}$ respectively, in comparison to results at $70^{\circ} \mathrm{N}, 60^{\circ} \mathrm{W}$ in the same dataset. High temperatures at $10-\mu \mathrm{bar}$ and lower pressures were considered indicative of joule heating, ion and/or electron precipitation, ion-drag and energy released form exothermic ion-chemistry. However, we conclude that the heating at the 1-mbar level is the result of either a layer of aurorally-produced haze particles, which are heated by incident sunlight and/or adiabatic heating by downwelling within the auroral hot-spot region. The former mechanism would be consistent with the vertical profiles of polycyclic aromatic hydrocarbons (PAHs) and haze particles predicted in auroral-chemistry models (Wong et al., 2000, 2003). Retrievals of $\mathrm{C}_{2} \mathrm{H}_{2}$ and $\mathrm{C}_{2} \mathrm{H}_{6}$ were also performed and indicate $\mathrm{C}_{2} \mathrm{H}_{2}$ is enriched but $\mathrm{C}_{2} \mathrm{H}_{6}$ is depleted in auroral regions relative to quiescent regions. For example, using $\mathrm{CIRS} \Delta \tilde{v}=2.5 \mathrm{~cm}^{-1}$ spectra, we determined that $\mathrm{C}_{2} \mathrm{H}_{2}$ at 0.98 mbar increases by $175.3 \pm 89.3 \mathrm{ppbv}$ while $\mathrm{C}_{2} \mathrm{H}_{6}$ at 4.7 mbar decreases by $0.86 \pm 0.59$ ppmv in comparing results at $70^{\circ} \mathrm{N}, 180^{\circ} \mathrm{W}$ and $70^{\circ} \mathrm{N}, 60^{\circ} \mathrm{W}$. These results represent a mean of values retrieved from different initial assumptions and thus we believe they are robust. We believe these contrasts in $\mathrm{C}_{2} \mathrm{H}_{2}$ and $\mathrm{C}_{2} \mathrm{H}_{6}$ between auroral and quiescent regions can be explained by a coupling of auroral-driven chemistry and horizontal advection. Ion-neutral and electron recombination chemistry in the auroral region enriches all $\mathrm{C}_{2}$ hydrocarbons but in particular, the unsaturated $\mathrm{C}_{2} \mathrm{H}_{2}$ and $\mathrm{C}_{2} \mathrm{H}_{4}$ hydrocarbons. Once advected outside of the auroral region, the unsaturated $\mathrm{C}_{2}$ hydrocarbons are converted into $\mathrm{C}_{2} \mathrm{H}_{6}$ by neutral photochemistry thereby enriching $\mathrm{C}_{2} \mathrm{H}_{6}$ in quiescent regions, which gives the impression it is depleted inside the auroral region.
\end{abstract}

Keywords:

\section{Introduction}

The polar atmosphere of Jupiter is highly coupled to the external magnetospheric environment. Energetic charged particles of the solar wind and from the tori of the galilean satellites such as Io and Europe penetrate the atmosphere at polar latitudes. Gases in the Jovian atmosphere are bombarded by high energy electrons and ions, resulting in the auroral glow of the atmosphere at X-ray (e.g. Gladstone et al. 2002, Branduardi-Raymont et al. 2007, Kharchenko et al. 2006, Ozak et al. 2010), ultraviolet (e.g. Gerard et al. 1993, Nichols et al. 2007, Gérard et al. 2013), near-infrared $\left(\mathrm{H}_{3}^{+}\right.$emission at 3 to 5- $\mu \mathrm{m}$, e.g. Baron et al. 1991, Morioka et al. 2004, Stallard et al. 2012, O'Donoghue et al. 2014, Giles et al.

\footnotetext{
${ }^{*}$ Corresponding Author

Email address: james.sinclair@jpl.nasa.gov (J. A. Sinclair)
}

2016) and radio wavelengths (Gurnett et al. 2002). Correlated observations at these different wavelengths reveal three distinct features that form the Jovian aurora: 1) the main oval feature, a filament/ring-like structure centred on the magnetic pole, which appears approximately fixed in System III longitude, 2) extended, transient aurora that fill the oval feature (Mauk et al., 2002) and 3) discrete spots that correspond to the footprints of magnetic field lines to Io, Ganymede and Europa (Clarke et al., 2002).

Jupiter's aurora also appear in the mid-infrared (5- to 15- $\mu \mathrm{m}$ ). Caldwell et al. $(1980,1983)$ first reported the presence of discrete bright regions at Jupiter's high latitudes at $8-\mu \mathrm{m}$, which is sensitive to stratospheric $\mathrm{CH}_{4}$ emission. These features in $\mathrm{CH}_{4}$ emission, which will henceforth be described as auroral-related hotspots, have been observed numerous times since (Kim et al., 1985; Kunde et al., 1996; Flasar et al., 
2004) and are considered to be a result of auroral-related heating. Similar hotspots, coincident with those observed in $\mathrm{CH}_{4}$, are also observed in the emission features of other hydrocarbon species in Jupiter's stratosphere. Using IRIS (Infrared Interferometer Spectrometer (Hanel et al., 1981) spectra on Voyager 1), Kim et al. (1985) observed a similar brightening of $\mathrm{CH}_{4}$ emission towards Jupiter's poles but also observed enhanced emission (and in cases, the first detection) of $\mathrm{CH}_{3} \mathrm{D}$ (deuterated methane), $\mathrm{C}_{2} \mathrm{H}_{2}$ (acetylene), $\mathrm{C}_{2} \mathrm{H}_{4}$ (ethylene), $\mathrm{C}_{2} \mathrm{H}_{6}$ (ethane), $\mathrm{C}_{3} \mathrm{H}_{4}$ (methylacetylene) and $\mathrm{C}_{6} \mathrm{H}_{6}$ (benzene). Kim et al. (1985) concluded that these observations indicated an enhancement of these molecules in the polar regions as a result of the aurora, which would suggest auroral processes also modify the stratospheric chemistry as well as the thermal structure. However, their analysis did not discriminate between temperature and composition. Several subsequent studies used neutral molecular emission features to probe the auroral regions though similarly struggled to constrain how much of this enhanced emission was a result of 1) elevated temperatures and/or 2) enhanced volume mixing ratios of the emitting molecular species being viewed. For example, Livengood et al. (1993) and Kostiuk et al. (1993) used very high-resolution spectroscopy $(\mathrm{R}=60000)$ to measure the emission features of $\mathrm{C}_{2} \mathrm{H}_{6}$ and $\mathrm{C}_{2} \mathrm{H}_{4}$ respectively but, without independent constraints on temperature, were only able to conclude a range of temperature enhancements or an upper limit on the concentrations of $\mathrm{C}_{2} \mathrm{H}_{4}$ and $\mathrm{C}_{2} \mathrm{H}_{6}$ in Jupiter's auroral regions.

In breaking this degeneracy and quantifiying changes in temperature and composition across Jupiter's auroral region, we hope to gain improved understanding of how auroral processes modify the thermal structure and composition. In Earth's lower stratosphere, auroral processes have been observed to induce 1 $3 \mathrm{~K}$ temperature changes, anti-correlated with changes in ozone concentration over the course of the 11-year solar cycle (e.g. Zubov et al. 2005). Jupiter's magnetosphere is significantly stronger than Earth's and thus the interaction of the atmosphere with the magnetosphere is considerably higher. The influx of ions and electrons increases the importance of ion-neutral and electron recombination chemistry with respect to neutral photochemistry, which yields increased production of larger hydrocarbons (Gladstone et al., 1996). This is also thought to enrich aromatic hydrocarbons in the polar regions such as $\mathrm{C}_{6} \mathrm{H}_{6}$ and larger PAHs (polycyclic aromatic hydrocarbons), which are important building blocks in the production of polar haze particles (Wong et al., 2000; Friedson et al., 2002; Wong et al., 2003). Such hazes have been observed as dark regions in the ultraviolet (West, 1988; Pryor and Hord, 1991) in Jupiter's polar regions, coincident with regions of auroral emissions (Carlson, 1997; Grodent et al., 2015). A similar effect has also been observed at Saturn's poles (Gérard et al., 1995; Karkoschka and Tomasko, 2005) and recent analyses by Guerlet et al. (2015) and Koskinen et al. (2016) confirm the presence of $\mathrm{C}_{6} \mathrm{H}_{6}$ and aerosols in Saturn's polar atmosphere.

In summary, there are several motivations for this study. Firstly, we aim to break the degeneracy between temperature and composition that has presented a challenge in previous work (detailed above). Both Voyager-IRIS and Cassini-CIRS spectra measure $\mathrm{CH}_{4}$ emission from approximately 1230 $1380 \mathrm{~cm}^{-1}$. $\mathrm{CH}_{4}$ has been assumed to be vertically and horizontally well-mixed below its homopause in the jovian atmospheres (Moses et al., 2005). Extensive work on Voyager-IRIS, Cassini-CIRS and ground-based data of Saturn has utilised this assumption to allow an independent constraint on stratospheric temperature allowing subsequent retrievals of gas concentrations such as $\mathrm{C}_{2} \mathrm{H}_{2}$ and $\mathrm{C}_{2} \mathrm{H}_{6}$ to be determined (e.g. Greathouse et al. 2005; Guerlet et al. 2009; Fletcher et al. 2012; Sinclair et al. 2013). While we cannot rule out modification of the $\mathrm{CH}_{4}$ concentration, in particular at high altitudes in the polar atmosphere, we plan on adopting a similar technique in this study such that the magnitude of temperature and composition changes induced by the aurora can be better disentangled and constrained.

Secondly, previous analyses of Cassini-CIRS data of Jupiter acquired during its 2000/2001 flyby have not focussed on the auroral regions. Simon-Miller et al. (2006) compared Voyager-IRIS and Cassini-CIRS spectra but focused their analysis on the tropospheric to lower stratospheric pressure ranges. Nixon et al. (2007) and Nixon et al. (2010) used Cassini-CIRS and Voyager-IRIS zonally-averaged data to determine meridional variations in stratospheric temperature, $\mathrm{C}_{2} \mathrm{H}_{2}$ and $\mathrm{C}_{2} \mathrm{H}_{6}$ but avoided using spectra covering the auroral regions such that quiescent and auroral conditions were not averaged together. Kunde et al. (1996) presented comparisons of observed and synthetic Cassini-CIRS spectra and used radiance contrasts between non-auroral and auroral regions to calculate the power emitted from auroral-related hotspots. Flasar et al. (2004) presented brightness temperature variations and by comparing the morphology of the auroral-related hotspots at different wavenumbers that sounded different pressure regions, constrained that auroral heating must not penetrate below the 4-mbar level. Fletcher et al. (2016) have performed a similar analysis of Cassini-CIRS and IRTF-TEXES (observations from the Texas Echelon Cross Echelle Spectrograph on NASA's Infrared Telescope Facility, Lacy et al. 2002) spectra where near-global maps of temperatures, composition and aerosol abundance were retrieved. However, in this work, we have focussed only on high-latitude regions to observe auroral behaviour in the Voyager-IRIS and Cassini-CIRS datasets.

The structure of the paper is as follows. In Section 2, we detail the Voyager-IRIS and Cassini-CIRS observations and the spatial averaging adopted to compute spectra representative of auroral and quiescent regions. The model atmosphere of Jupiter adopted in forward modelling and retrievals is presented in Section 3. In Section 4, we provide a contextual summary of the results of forward modelling and retrievals of test synthetic spectra that are included in greater detail in the Appendix. The results of retrievals of temperature, $\mathrm{C}_{2} \mathrm{H}_{2}$ and $\mathrm{C}_{2} \mathrm{H}_{6}$ from the observations are presented in Section 5 and a discussion of the results is given in Section 6. 


\section{Observations}

\subsection{Voyager-IRIS}

The closest approaches of the Voyager 1 and 2 spacecraft to Jupiter occurred in March and July, 1979 respectively. Both spacecraft included the IRIS (Infrared Interferometer Spectrometer) instrument, which measured thermal infrared emission from 180 to $2500 \mathrm{~cm}^{-1}$ at a spectral resolution of $4.3 \mathrm{~cm}^{-1}$ (Hanel et al., 1980). However, we only use Voyager 1-IRIS data in this study since Voyager 2-IRIS spectra were far less sensitive due to a misalignment of the interferometer (Hanel et al., 1980; Sinclair et al., 2014).

Voyager 1-IRIS spectra of Jupiter were obtained several days before and after closest approach and thus the fields-of-view on the planet of individual spectra varied significantly and in some cases, mixed dark space with on-disk regions. In order to remove such spectra, we omitted Voyager 1-IRIS spectra obtained at spacecraft distances of greater than $4 \times 10^{6} \mathrm{~km}$ or $60 \mathrm{R}_{J}$ (Jupiter radii). The remaining spectra correspond to a field-of-view of approximately $10^{\circ}$ in latitude and longitude at the sub-spacecraft point. Voyager 1-IRIS did not sample high enough in southern-latitude to capture the southern auroral region centred at approximately $75^{\circ} \mathrm{S}, 330-80^{\circ} \mathrm{W}$. However, the northern auroral region is situated at a comparably lower latitude $\left(60^{\circ} \mathrm{N}-80^{\circ} \mathrm{N}\right)$ and was sampled by Voyager 1-IRIS. Due to the large field-of-view on the planet, the sparse sampling in both latitude and longitude, and in order to reduce the effective noise equivalent spectral radiance or NESR on the spectra, we computed two spatial averages of Voyager 1-IRIS spectra. We averaged spectra in two spatial ranges, similar to the 'N1' and 'N2' ranges adopted in Kim et al. (1985), which respectively capture areas of high-northern latitudes affected by the aurora and areas that are quiescent. The effective noise on the measurements was calculated by scaling the NESR spectrum by a factor of $1 / \sqrt{N_{\text {coadd }}}$, where $N_{\text {coadd }}$ is the number of target spectra averaged (as in Sinclair et al. (2014)). The properties of these spectral averages are detailed in Table 1 and the full spectra are compared in Figure 1. These two spatial-averaged observations will henceforth be described as 'Voyager-NA' and 'Voyager-NQ'.

It should be noted that the Voyager-NQ spectrum (quiescent) is approximately $15^{\circ}$ higher in emission angle than the Voyager-NA (auroral) spectrum and thus stratospheric emission features in quiescent regions are limb-brightened to a greater extent relative to auroral regions. Nevertheless, the enhanced emission of $\mathrm{CH}_{4}$ from 1230 to $1380 \mathrm{~cm}^{-1}$ and $\mathrm{C}_{2} \mathrm{H}_{2}$ at $730 \mathrm{~cm}^{-1}$ were highly evident in the auroral region (NA), with respect to the quiescent region (NQ). There was also elevated emission from $\mathrm{C}_{2} \mathrm{H}_{6}$ in the auroral region compared to quiescent longitudes however: this was to a lesser extent than $\mathrm{C}_{2} \mathrm{H}_{2}$ and $\mathrm{CH}_{4}$. Although not evident in the spectra alone, subtracting the NA and NQ spectra revealed the emission features of several other hydrocarbon species, as detailed in Kim et al. (1985). $\quad \mathrm{C}_{3} \mathrm{H}_{4}$ and $\mathrm{C}_{4} \mathrm{H}_{2}$ appeared at 630-634 $\mathrm{cm}^{-1}$ (both emission features are convolved into one feature by
Voyager-IRIS's $4.3 \mathrm{~cm}^{-1}$ spectral resolution), $\mathrm{C}_{6} \mathrm{H}_{6}$ appeared at $674 \mathrm{~cm}^{-1}$ (and is possibly blended with the $\mathrm{CO}_{2}$ emission feature at $667 \mathrm{~cm}^{-1}$ at this spectral resolution), and $\mathrm{C}_{2} \mathrm{H}_{4}$ appeared at $950 \mathrm{~cm}^{-1}$.

\subsection{Cassini-CIRS}

During its journey to Saturn, the Cassini spacecraft performed a flyby of Jupiter in late 2000/early 2001 and the remote sensing payload performed several thousand measurements of the Jupiter system. Cassini-CIRS (Composite Infrared Spectrometer, Kunde et al. 1996; Flasar et al. 2004) is one such instrument, which measures mid-to-far infrared light from approximately 10 to $1600 \mathrm{~cm}^{-1}$. Using a Michelson interferometer design, CIRS measures a spectrum of its target across three focal planes - FP1 $\left(10-600 \mathrm{~cm}^{-1}\right)$, FP3 (600 $\left.1100 \mathrm{~cm}^{-1}\right)$ and FP4 $\left(1100-1400 \mathrm{~cm}^{-1}\right)$ - and can operate at different spectral resolutions from $0.5 \mathrm{~cm}^{-1}$ to $15.0 \mathrm{~cm}^{-1}$. In this work, we have focused on the FP3 and FP4 data, measured at spectral resolutions of $0.5 \mathrm{~cm}^{-1}$ (Section 2.2.2) and $2.5 \mathrm{~cm}^{-1}$ (Section 2.2.1) respectively. Once Cassini arrived at Saturn in 2004, observations of these spectral resolutions become known as the 'COMPSIT' and 'MIRMAP' observations. For labelling purposes, we have adopted these names to describe these spectra throughout this paper.

\subsection{1. $\Delta \tilde{v}=2.5 \mathrm{~cm}^{-1}$ spectra}

During Cassini's 2000/2001 flyby of Jupiter, four maps of 2.5 $\mathrm{cm}^{-1}$ 'MIRMAP' observations - 'ATMOS02A', 'ATMOS02B', 'ATMOS02C' and 'ATMOS02D' - were acquired from January 1st to Jan 11th. ATMOS02A (January 1st) spectra were chosen for analysis since they were acquired at the shortest spacecraft distance from Jupiter (ranging from approximately 137 to $139 \mathrm{R}_{J}$ ), providing the highest spatial resolution of the four maps of approximately $3^{\circ}$. All individual spectra from the ATMOS02A map were sorted and coadded into spatial bins of $5^{\circ}$ in latitudinal width, nyquist sampled in steps of $2.5^{\circ}$, and $20^{\circ}$ in longitudinal width, nyquist sampled in steps of $10^{\circ}$. The resultant noise on these spatially-binned observations was assumed to be the largest of either: 1) the standard deviation of the average or 2) the noise-equivalent spectral radiance (NESR) spectrum of CIRS by a factor of $(0.5 / \Delta \tilde{v})(1 /(\sqrt{N})+$ $1 /(\sqrt{M}))$, where $\Delta \tilde{\nu}$ is the spectral resolution of the target spectra $\left(2.5 \mathrm{~cm}^{-1}\right.$ in this case), $\mathrm{N}$ is the number of averaged target spectra and $\mathrm{M}$ is the number of deep-space spectra. Deep space observations from CIRS are used to calculate and subtract background radiance and thus the noise on the target spectra depends both on the number of target observations and deep-space observations.

Figure 2 shows the resultant distribution of these coadded observations and the brightness temperatures at $730 \mathrm{~cm}^{-1}, 822$ $\mathrm{cm}^{-1}$ and $1305 \mathrm{~cm}^{-1}$, which are sensitive to $\mathrm{C}_{2} \mathrm{H}_{2}, \mathrm{C}_{2} \mathrm{H}_{6}$ and $\mathrm{CH}_{4}$ emission, respectively. The distributions of brightness temperatures show enhanced emission from $\mathrm{C}_{2} \mathrm{H}_{2}, \mathrm{CH}_{4}$ and to a lesser extent $\mathrm{C}_{2} \mathrm{H}_{6}$ emission, at approximately $70^{\circ} \mathrm{N}$ and $180^{\circ} \mathrm{W}$ (Kunde et al., 1996; Flasar et al., 2004), coincident with 

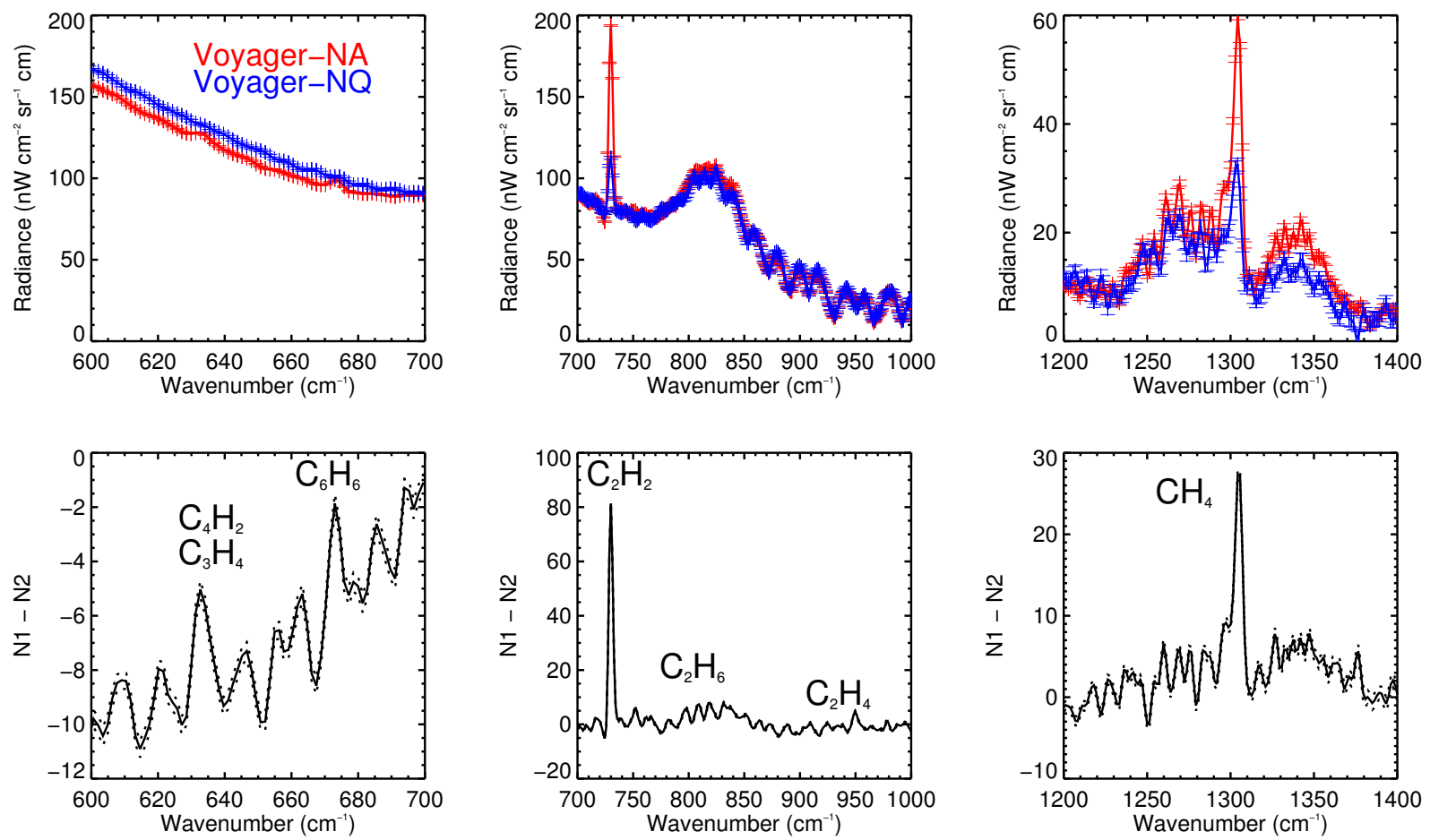

Figure 1: The 'Voyager-NA' and 'Voyager-NQ' coadded spectra, and their differences, representing an auroral and quiescent region respectively. On the upper plots, the 1- $\sigma$ noise levels are shown as error bars, calculated by scaling the NESR spectrum of Voyager 1-IRIS by a factor of $1 / \sqrt{N}$ where $\mathrm{N}$ is the number of spectra averaged (Hanel et al., 1980; Sinclair et al., 2014). On the lower plots, the dotted lines show the uncertainty on the difference spectra, computed by adding the noise levels of the spectra themselves in quadrature.

\begin{tabular}{|c|c|c|c|c|c|c|c|}
\hline $\begin{array}{l}\text { Coadd } \\
\text { Name }\end{array}$ & $\begin{array}{c}\text { Min. } \\
\text { Latitude } \\
\left(^{\circ}\right)\end{array}$ & $\begin{array}{c}\text { Max. } \\
\text { Latitude } \\
\left(^{\circ}\right)\end{array}$ & $\begin{array}{c}\text { Min. } \\
\text { Longitude } \\
\left(^{\circ}\right)\end{array}$ & $\begin{array}{c}\text { Max. } \\
\text { Longitude } \\
\left(^{\circ}\right)\end{array}$ & $\begin{array}{l}\text { Min. } \\
\text { emission } \\
\text { angle } \\
\left(^{\circ}\right)\end{array}$ & $\begin{array}{l}\text { Max. } \\
\text { emission } \\
\text { angle } \\
\left(^{\circ}\right)\end{array}$ & $\begin{array}{c}\text { Number } \\
\text { of } \\
\text { spectra }\end{array}$ \\
\hline Voyager-NA & 52 & 71 & 122 & 237 & 30 & 40 & 210 \\
\hline Voyager-NQ & 52 & 71 & 0 & 30 & 46 & 61 & 48 \\
\hline
\end{tabular}

Table 1: Details of the Voyager-N1 and Voyager-N2 coadded spectra averaged over the latitude and longitude ranges indicate to respectively capture an auroral and non-auroral region at high-northern latitudes respectively. All latitudes are planetographic and longitudes are System III West.

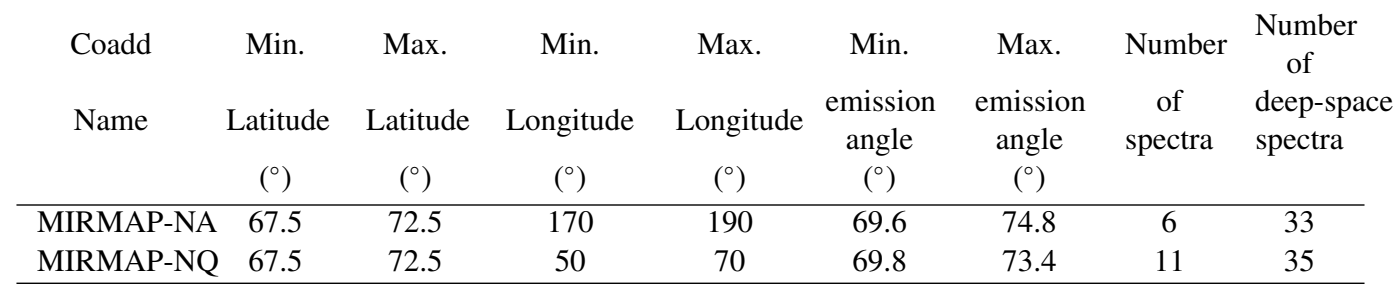

Table 2: Details of the MIRMAP-NA and MIRMAP-NQ coadded spectra averaged over the latitude and longitude ranges indicate to respectively capture an auroral and non-auroral region at high-northern latitudes respectively. All latitudes are planetographic and longitudes are System III West.

auroral features observed at shorter wavelengths (discussed previously). Although we performed a retrieval analysis of all MIRMAP spectra to generate a map of atmospheric results, we have further analysed the MIRMAP observations at $70^{\circ} \mathrm{N}, 60^{\circ} \mathrm{W}$ and $70^{\circ} \mathrm{N}, 180^{\circ} \mathrm{W}$, which respectively capture quiescent and auroral regions at high-northern latitudes. For labelling purposes, we will henceforth identify these observations as 'MIRMAP-NQ' and 'MIRMAP-NA'. Their geometry information is shown in Table 2. 

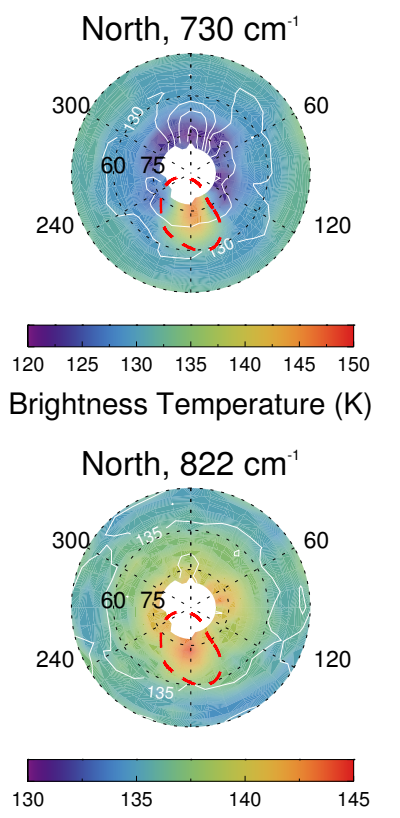

Brightness Temperature $(\mathrm{K})$

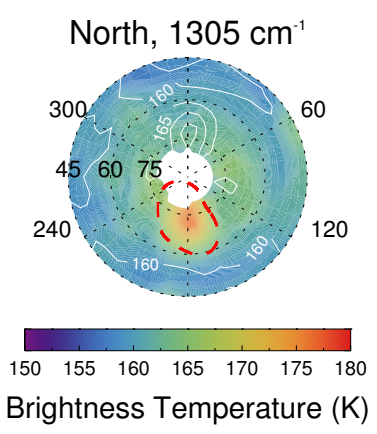

North, Number spectra coadded

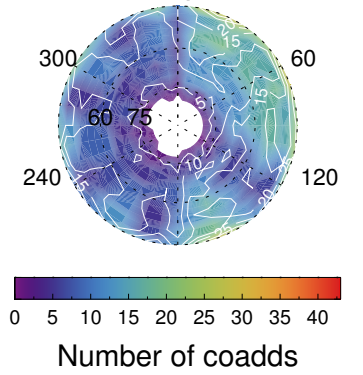

North, Emission angle range

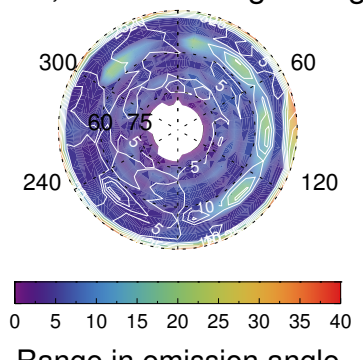

\section{South, $730 \mathrm{~cm}^{-1}$}

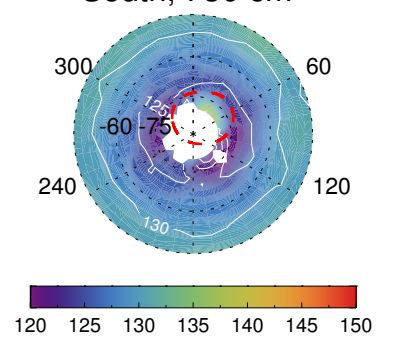

Brightness Temperature (K)

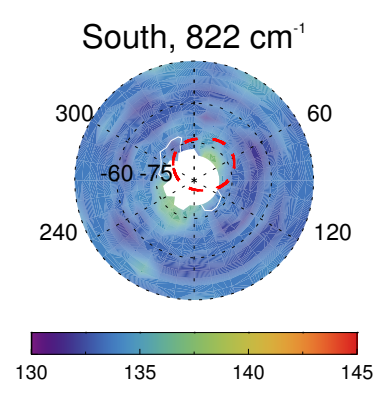

Brightness Temperature (K)

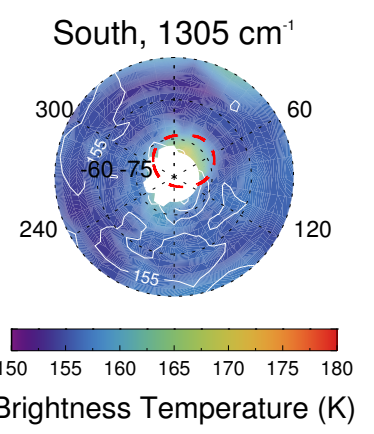

South, Number spectra coadded

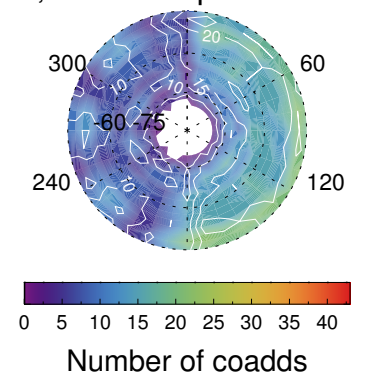

South, Emission angle range

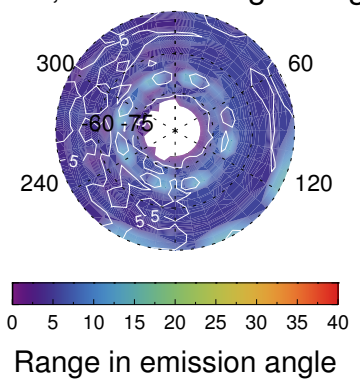

Figure 2: Polar-projected distributions in north (left) and south (right) of brightness temperature at $730 \mathrm{~cm}^{-1}\left(\mathrm{C}_{2} \mathrm{H}_{2} \mathrm{emission}\right), 822 \mathrm{~cm}^{-1}\left(\mathrm{C}_{2} \mathrm{H}_{6}\right.$ emission), $1305 \mathrm{~cm}^{-1}\left(\mathrm{CH}_{4}\right.$ emission), the number of spectra averaged and the range in emission angle averaged for Cassini-CIRS $\Delta \tilde{v}=2.5$ $\mathrm{cm}^{-1}$ ATMOS02A observations. The red lines show the positions of the ultraviolet auroral ovals as measured by Bonfond et al. (2012). 


\subsection{2. $\Delta \tilde{v}=0.5 \mathrm{~cm}^{-1}$ spectra}

Our selection of $\Delta \tilde{v}=0.5 \mathrm{~cm}^{-1}$ 'COMPSIT' observations of Jupiter was based on those used by Lellouch et al. (2006), which were acquired by Cassini-CIRS from November 15th 2000 to February 15th 2001. The distance of the spacecraft from Jupiter varied significantly over this time frame and thus the field-of-view of the majority of the spectra are large, in particular at high latitudes where the $0.273-\mathrm{mrad}$ footprint corresponds to a latitude range as high as $20^{\circ}$. Due to the large footprint on the planet and since averaging of a large number of individual spectra is required to sufficiently improve the signal-to-noise ratio of these observations, we computed large spatial averages of these spectra in the ranges detailed in Table 3. The 'NA' and 'SA' latitude and longitude ranges were chosen in order to cover the regions of auroral emission observed at 2.5 $\mathrm{cm}^{-1}$ whilst incorporating a sufficient number of observations to reduce the noise. The same latitude range, but remaining longitude range, were chosen to reflect 'quiescent' regions outside the auroral regions. The standard deviation of the average was assumed as the noise on the observations.

Figure 3 shows these coadded spectra at high-southern and high-northern latitudes. As was observed with the Voyager-IRIS spectra of high-northern latitudes (Figure 1), there is stronger emission from $\mathrm{CH}_{4}, \mathrm{C}_{2} \mathrm{H}_{2}, \mathrm{C}_{2} \mathrm{H}_{4}, \mathrm{C}_{2} \mathrm{H}_{6}$, $\mathrm{C}_{3} \mathrm{H}_{4}$ and/or $\mathrm{C}_{4} \mathrm{H}_{2}$ and $\mathrm{C}_{6} \mathrm{H}_{6}$ in the auroral region with respect to quiescent longitudes in the same latitude band. Similar contrasts are seen at high-southern latitudes in $\mathrm{CH}_{4}$, $\mathrm{C}_{2} \mathrm{H}_{2}$ and $\mathrm{C}_{6} \mathrm{H}_{6}$ however there negligible differences between $\mathrm{C}_{2} \mathrm{H}_{6}, \mathrm{C}_{3} \mathrm{H}_{4}$ and $\mathrm{C}_{4} \mathrm{H}_{2}$ between southern-auroral and quiescent regions.

We have employed a retrieval analysis in an attempt to constrain temperatures, $\mathrm{C}_{2} \mathrm{H}_{2}$ and $\mathrm{C}_{2} \mathrm{H}_{6}$ in observations from Voyager-IRIS and Cassini-CIRS. Although the emission features of further hydrocarbons such as $\mathrm{C}_{2} \mathrm{H}_{4}, \mathrm{C}_{3} \mathrm{H}_{4}, \mathrm{C}_{4} \mathrm{H}_{2}$ and $\mathrm{C}_{6} \mathrm{H}_{6}$ are visible in the observations of auroral regions, we do not present a retrieval analysis of these species. This analysis will be instead will be presented in future work.

\section{Radiative transfer modelling}

\subsection{Spectroscopic line data}

Radiative transfer forward modelling and retrievals were performed using NEMESIS (Irwin et al., 2008). While NEMESIS can operate using both the line-by-line and correlated-k methods (e.g. Lacis and Oinas 1991), the latter was chosen due to its computation efficiency and its suitability for the moderate to low spectral resolution used in this work. Using the sources of line data detailed in Fletcher et al. (2012), k-distributions were computed for $\mathrm{NH}_{3}, \mathrm{PH}_{3}, \mathrm{CH}_{4}$, $\mathrm{CH}_{3} \mathrm{D},{ }^{13} \mathrm{CH}_{4}, \mathrm{C}_{2} \mathrm{H}_{2}, \mathrm{C}_{2} \mathrm{H}_{6}$. Three sets of k-distibutions were generated in order to model the spectra of different spectral resolutions in this work: the first using a triangular instrument function with a FWHM $=0.5 \mathrm{~cm}^{-1}$, the second using a triangular instrument function of $2.5 \mathrm{~cm}^{-1}$ and the third using a triangular instrument function of $4.3 \mathrm{~cm}^{-1}$. Although both Voyager-IRIS and Cassini-CIRS instruments exhibit Hamming line functions, a triangle function is a very good approximation of the Hamming function at these lower spectral resolutions and sufficiently fits the datasets as demonstrated in this work.

\subsection{Model Atmosphere}

\subsubsection{Thermal structure}

Our model Jovian atmosphere is defined on 120 pressure levels equally spaced in logarithmic pressure from 10 bar to $10^{-8}$ bar. The reference vertical temperature profile at pressures higher than 50 mbar was computed using a mean of temperature results from $30^{\circ} \mathrm{S}$ to $30^{\circ} \mathrm{N}$ retrieved in Fletcher et al. (2009). From 50 mbar to $1 \mu$ bar, a mean over the same latitude range was computed using retrieved temperature results from Nixon et al. (2007). The lapse rate at $1 \mu$ bar was used to extrapolate the temperature profile to the $0.01-\mu$ bar level providing a near-isothermal temperature profile in this pressure range. This reference temperature profile was adopted as our nominal $a$ priori profile in performing retrievals of temperature.

We note that our reference vertical temperature profile in

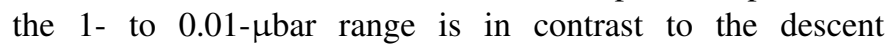
profile measured by Galileo (Seiff et al., 1998), which shows a strong temperature gradient associated with Jupiter's thermosphere. However, there is little/negligible sensitivity of mid-infrared radiances to this pressure range with respect to the temperature profile at higher pressures (see Figure 5 in Section 5.1). We instead explored the effect of upper stratospheric temperatures by modifying the reference temperature profile at pressures lower than 0.1 mbar. We derived 6 alternative vertical temperature profiles by imposing an isothermal temperature profile at pressures lower than 10 - $\mu$ bar of $180 \mathrm{~K}, 200 \mathrm{~K}, 220 \mathrm{~K}, 240 \mathrm{~K}, 260 \mathrm{~K}, 280 \mathrm{~K}$ and $300 \mathrm{~K}$. The temperature profile intermediate of the 0.1-mbar and 0.01-mbar level was derived by a cubic interpolation. These alternative temperature-pressure profiles will henceforth be described as the auroral-180K, auroral-200K, auroral-220K, auroral-240K, auroral-260K, auroral-280K and auroral-300K. For all seven alternative profiles, the composition of the atmosphere remained fixed, as detailed in Section 3.2. The top-panel of Figure 4 shows the reference temperature profile and the seven alternative temperature profiles.

\subsubsection{Composition}

$\mathrm{H}_{2}$ and $\mathrm{He}$ were assumed to be vertically well-mixed with volume mixing ratios of 0.863 and 0.134 respectively. The vertical profiles of $\mathrm{NH}_{3}$ and $\mathrm{PH}_{3}$ were parameterised by a well-mixed 'deep' value, $x_{0}$ up to a 'knee' pressure, $\mathrm{p}_{0}$, followed by a decrease in concentration, $x$, to lower pressures, $p$ given by the equation $x=x_{0}\left(p / p_{0}\right)^{(1-f) / f}$ where ' $f$ ' is the fractional scale height (Irwin et al., 2004). For $\mathrm{NH}_{3}$, we adopted $x_{0}=2.19 \times 10^{-4}, p_{0}=0.7$ bar and $f=0.15$ while for $\mathrm{PH}_{3}$, we adopted $\mathrm{x}_{0}=6 \times 10^{-7}, p_{0}=0.5$ bar and $f=0.5$, as in Nixon 

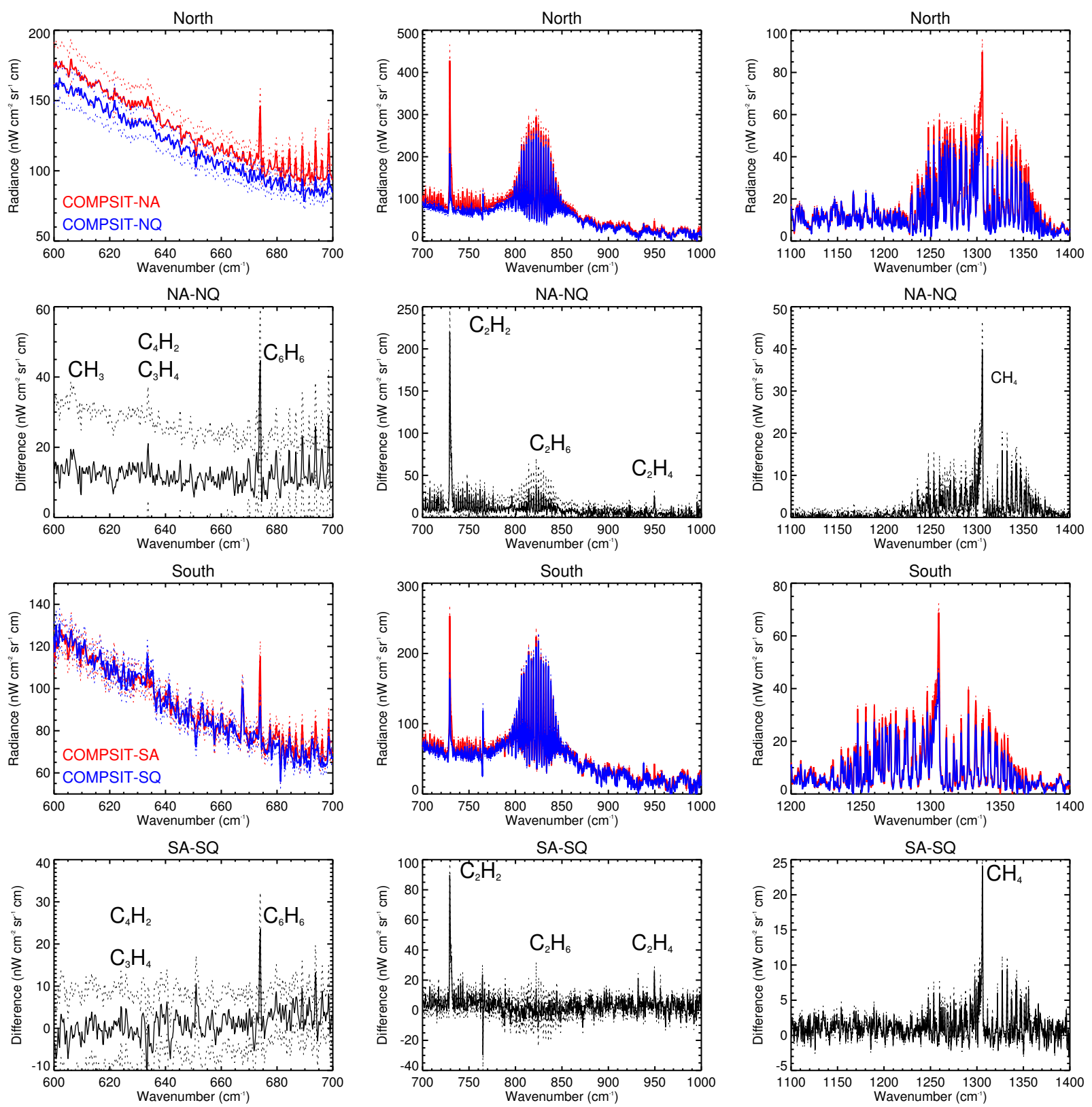

Figure 3: Top row: coadded $\Delta \tilde{v}=0.5 \mathrm{~cm}^{-1}$ spectra (solid) at $600-700 \mathrm{~cm}^{-1}$ (left), $700-1000 \mathrm{~cm}^{-1}$ (middle) and $1100-1400 \mathrm{~cm}^{-1}$ (right) at high-northern latitudes, averaged over an auroral (red) and quiescent (blue) region as detailed in Table 3. Dotted lines show the corresponding noise levels. The $1000-1100 \mathrm{~cm}^{-1}$ has been omitted due to the high noise levels of the observations and the absence of any target spectral features in this region. The third and fourth rows show similar plots for high-southern latitude regions covering the auroral regions.

\begin{tabular}{|c|c|c|c|c|c|c|c|c|}
\hline Coadd & Min. & Max. & Min. & Max. & Average & $\begin{array}{c}\text { Range } \\
\text { in }\end{array}$ & Number & Number \\
\hline Name & $\begin{array}{l}\text { Latitude } \\
\quad\left({ }^{\circ}\right)\end{array}$ & $\begin{array}{l}\text { Latitude } \\
\left({ }^{\circ}\right)\end{array}$ & $\begin{array}{c}\text { Longitude } \\
\left({ }^{\circ}\right)\end{array}$ & $\begin{array}{c}\text { Longitude } \\
\left({ }^{\circ}\right)\end{array}$ & $\begin{array}{c}\text { emission } \\
\text { angle } \\
\left({ }^{\circ}\right)\end{array}$ & $\begin{array}{c}\text { emission } \\
\text { angle } \\
\left({ }^{\circ}\right)\end{array}$ & $\begin{array}{c}\text { of target } \\
\text { spectra }\end{array}$ & $\begin{array}{l}\text { deep-space } \\
\text { spectra }\end{array}$ \\
\hline COMPSIT-NA & A 65 & 85 & 140 & 230 & 68 & 18 & 308 & 7 \\
\hline COMPSIT-NQ & Q 65 & 85 & 230 & 140 & 69 & 16 & 271 & 7 \\
\hline COMPSIT-SA & A $\quad-85$ & -70 & 330 & 80 & 71 & 11 & 162 & 9 \\
\hline COMPSIT-SQ & $2 \quad-85$ & -70 & 80 & 330 & 72 & 9 & 138 & 9 \\
\hline
\end{tabular}

Table 3: Details of the $\Delta \tilde{v}=0.5 \mathrm{~cm}^{-1}$ 'COMPSIT' spectral averages for FP3 observations (with results for FP4 being very similar). The names of each coadd are denoted with 'COMPSIT' followed by either an ' $N$ ' or ' $S$ ' to denote whether the average is at high-northern or high-southern latitudes and an 'A' or 'Q' to denote 'auroral' or 'quiescent'. All latitudes are planetographic and longitudes are System III West. 

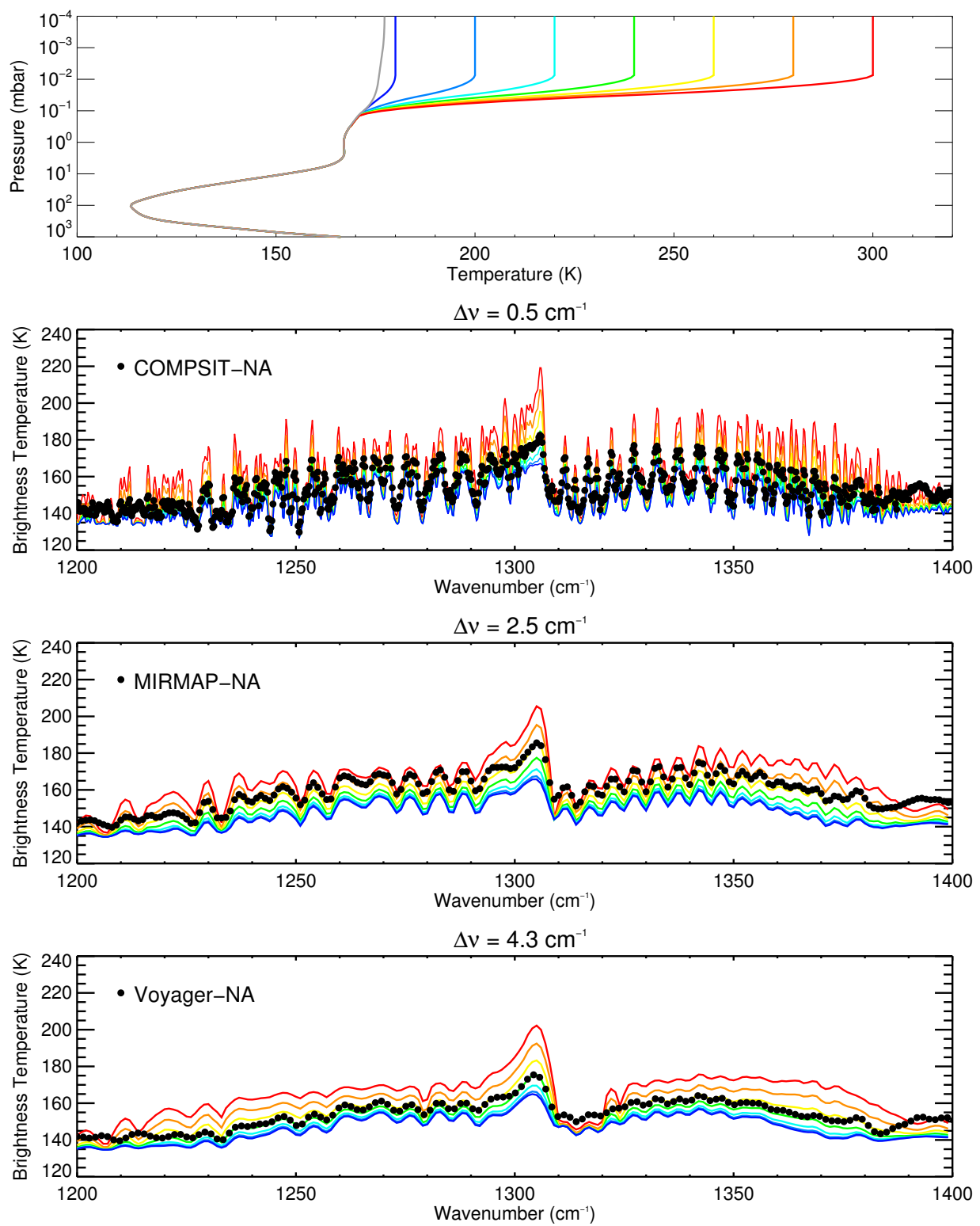

Figure 4: The top panel shows the reference vertical temperature profile (grey) and the seven alternative temperature profiles with varying upper stratospheric isotherms, calculated as detailed in the text. The 2nd, 3rd and 4th panels show the corresponding synthetic spectra in brightness temperature scale (without random noise) coloured accordingly at the spectral resolutions of Voyager-IRIS, Cassini-CIRS $(\Delta \tilde{v}=0.5$ $\left.\mathrm{cm}^{-1}\right)$ and Cassini-CIRS $\left(\Delta \tilde{v}=2.5 \mathrm{~cm}^{-1}\right)$ respectively. The black points show the observed radiances of the Voyager-NA, MIRMAP-NA and COMPSIT-NA spectra as detailed in Section 2 for comparison.

et al. (2010). While these values do change with both latitude and time (Fletcher et al., 2014, 2016), the assumed values of the $\mathrm{NH}_{3}$ and $\mathrm{PH}_{3}$ parameters have negligible effect in fitting the stratospheric emission features used in this study. For $\mathrm{CH}_{4}$, the vertical profile was based on a photochemical model by Romani (1996) but with a 5\% increase in deep concentrations in order to match the results of Galileo's Neutral Mass Spectrometer experiment (Niemann et al., 1998). The vertical profiles of the isotopologues, ${ }^{13} \mathrm{CH}_{4}$ and $\mathrm{CH}_{3} \mathrm{D}$, were respectively calculated assuming the terrestrial ${ }^{13} \mathrm{C} /{ }^{12} \mathrm{C}$ ratio of 0.011 and the $\mathrm{D} / \mathrm{H}$ ratio in $\mathrm{CH}_{4}$ of $7.79 \times 10^{-5}$ assumed by the Cassini-CIRS team (private communication). The vertical profiles of all remaining hydrocarbons were adopted from 'Model A' of the photochemical model detailed in Moses et al. (2005), which is representative of a mid-northern latitude region.

We have not included any profiles of haze/aerosols in our radiative transfer model. Trial forward models and retrievals where a single layer or multiple layers of aerosols were placed in the troposphere at varying pressures from 0.5 to 0.8 bar had negligible effect on the fits of modelled spectra to observed spectra and if anything, degraded the quality of the fits. Although we find evidence of an auroral-produced haze layer in 
the stratosphere by its effect on the retrieved thermal structure (Section 5.2), we suggest these haze layers are too optically thin in the thermal infrared to have any significant effect on our radiative transfer calculations.

\section{Synthetic observations and test retrievals}

At an emission angle of $60^{\circ}$ (which is representative of the typical emission angle of Cassini-CIRS and Voyager-IRIS observations at high latitudes), the seven alternative temperature profiles described in Section 3.2.1 were forward-modelled at spectral resolutions of $\Delta \tilde{v}=0.5 \mathrm{~cm}^{-1}$, $\Delta \tilde{v}=2.5 \mathrm{~cm}^{-1}$ and $\Delta \tilde{v}=4.3 \mathrm{~cm}^{-1}$ to generate synthetic Cassini-CIRS observations (at both spectral resolutions) and Voyager-IRIS spectra respectively. These synthetic spectra are shown in the latter three panels in Figure 4. In addition, the observed radiances from the COMPSIT-NA, MIRMAP-NA and Voyager-NA observations are shown for comparison. As shown, observed radiances do not exceed those forward-modelled using the auroral-240 K profile and so we do not believe temperatures can exceed $240 \mathrm{~K}$ at the 10- $\mu$ bar level.

While retrievals of temperature, $\mathrm{C}_{2} \mathrm{H}_{2}$ and $\mathrm{C}_{2} \mathrm{H}_{6}$ have previously been performed on Cassini-CIRS and Voyager-IRIS data on Jupiter (e.g. Nixon et al. 2007, 2010) and extensively on Saturn (e.g. Hesman et al. 2009; Fletcher et al. 2012; Sinclair et al. 2014), these retrievals did not cover regions where auroral heating was present at higher altitudes. In order to test the reliability and limitations of the IRIS and CIRS observations in resolving upper stratospheric heating, we performed test retrievals of synthetic observations. The auroral-200 K temperature profile was adopted as a plausible, test temperature profile of the auroral regions. Random noise was added to the forward models of this temperature profile to simulate an observation and a retrieval of temperature, $\mathrm{C}_{2} \mathrm{H}_{2}$ and $\mathrm{C}_{2} \mathrm{H}_{6}$ was subsequently performed. Any disagreement between the retrieved parameters with those adopted in computing the synthetic observations highlight limitations of the retrievals. These tests and results are presented in greater detail in Appendix A.

In brief summary, this analysis showed that observations of a higher spectral resolution more readily and accurately allow retrieval of the vertical temperature profile in regions where upper stratospheric temperatures are enhanced by auroral-related heating. Lower spectral resolutions, in particular the Voyager-IRIS observations at $\Delta \tilde{v}=4.3 \mathrm{~cm}^{-1}$, struggled to discriminate between lower stratospheric (10to 0.5 -mbar) and upper stratospheric (0.5-mbar to 1 - $\mu$ bar) heating, however, by testing retrievals of temperature starting from several different a priori profiles, the correct temperature profile could be retrieved within uncertainty. Errors in the temperature retrieval also affected the magnitude of retrieved concentrations of $\mathrm{C}_{2} \mathrm{H}_{2}$ and $\mathrm{C}_{2} \mathrm{H}_{6}$. However, the dominant source of uncertainty in performing retrievals of $\mathrm{C}_{2} \mathrm{H}_{2}$ and $\mathrm{C}_{2} \mathrm{H}_{6}$ was the choice of a priori profile. For these reasons, we test retrievals of temperature, $\mathrm{C}_{2} \mathrm{H}_{2}$ and $\mathrm{C}_{2} \mathrm{H}_{6}$ of the real observations by starting from several different $a$ priori profiles to determine the robustness of retrieved parameters and using the reduced $\chi^{2}$ parameter (as a measure of the quality of the fit to the spectra) to discriminate between different solutions.

\section{Retrievals of temperature, $\mathrm{C}_{2} \mathrm{H}_{2}$ and $\mathrm{C}_{2} \mathrm{H}_{6}$}

The vertical profiles of temperature, $\mathrm{C}_{2} \mathrm{H}_{2}$ and $\mathrm{C}_{2} \mathrm{H}_{6}$ were retrieved simultaneously for all datasets. Temperature was retrieved from the $600-625 \mathrm{~cm}^{-1}, 640-665 \mathrm{~cm}^{-1}$ (both collision induced absorption regions but with the emission features of $\mathrm{C}_{3} \mathrm{H}_{4}, \mathrm{C}_{4} \mathrm{H}_{2}$ and $\mathrm{C}_{6} \mathrm{H}_{6}$ omitted) and $1230-1380$ $\mathrm{cm}^{-1}\left(\mathrm{CH}_{4}\right.$ emission) regions. The vertical profiles of $\mathrm{C}_{2} \mathrm{H}_{2}$ and $\mathrm{C}_{2} \mathrm{H}_{6}$ were retrieved from their respective emission features at $710-750 \mathrm{~cm}^{-1}$ and $770-890 \mathrm{~cm}^{-1}$. Initially, the reference temperature profile and the photochemically-predicted vertical profiles of $\mathrm{C}_{2} \mathrm{H}_{2}$ and $\mathrm{C}_{2} \mathrm{H}_{6}$ (Moses et al., 2005) were adopted as the a priori.

\subsection{Vertical sensitivity}

Figure 5 show the vertical functional derivatives with respect to temperature, $\mathrm{C}_{2} \mathrm{H}_{2}$ and $\mathrm{C}_{2} \mathrm{H}_{6}$. Results are shown for the $2.5 \mathrm{~cm}^{-1}$ CIRS observations at $70^{\circ} \mathrm{N}, 60^{\circ} \mathrm{W}$ (MIRMAP-NQ) and $70^{\circ} \mathrm{N}, 180^{\circ} \mathrm{W}$ (MIRMAP-NA). The spectral resolutions used in this work range from $0.5 \mathrm{~cm}^{-1}$ to $4.3 \mathrm{~cm}^{-1}$ and the vertical resolution and sensitivity to temperature, $\mathrm{C}_{2} \mathrm{H}_{2}$ and $\mathrm{C}_{2} \mathrm{H}_{6}$ do differ across this range in spectral resolution (e.g. Sinclair et al. 2014). For the sake of brevity, we have not included plots of the vertical functional derivatives of the 0.5 $\mathrm{cm}^{-1}$ CIRS and $4.3 \mathrm{~cm}^{-1}$ IRIS observations. However, we have explored the sensitivity of these other datasets both by performing retrievals of synthetic $0.5 \mathrm{~cm}^{-1}$ CIRS and $4.3 \mathrm{~cm}^{-1}$ IRIS observations (Appendix A.1) and by testing the robustness of retrieved parameters using different a priori (Sections 5.2.3 and 5.3.3).

Temperature: The collision-induced absorption region provides the most sensitivity to the $\sim 100$-mbar level in both auroral and quiescent regions. $\mathrm{CH}_{4}$ emission provides the greatest sensitivity to temperature in the 10 - to 0.5 -mbar pressure range in both quiescent and auroral regions. The P-branch of the $\mathrm{CH}_{4}$ band alone also provides sensitivity to temperature from 0.5 mbar to $10 \mu$ bar. In auroral regions, the presence of high temperatures at $10 \mu \mathrm{bar}$ (Section 5.2) extends the sensitivity of the $\mathrm{Q}$ branch of the $\mathrm{CH}_{4}$ band up to this pressure level. Thus, temperatures retrieved in the 10 to 0.5 mbar pressure range can be directly compared between quiescent and auroral regions in order to assess contrasts. At lower pressures from 0.5 mbar to $5 \mu \mathrm{bar}$, where there is less sensitivity to temperature in quiescent regions, we will explore the robustness of temperature constrasts in this pressure range by testing different a priori profiles.

$\mathrm{C}_{2} \mathrm{H}_{2}, \mathrm{C}_{2} \mathrm{H}_{6}$ : In quiescent regions, there is sensitivity to $\mathrm{C}_{2} \mathrm{H}_{2}$ from approximately 20 to $0.1 \mathrm{mbar}$ and to $\mathrm{C}_{2} \mathrm{H}_{6}$ from 

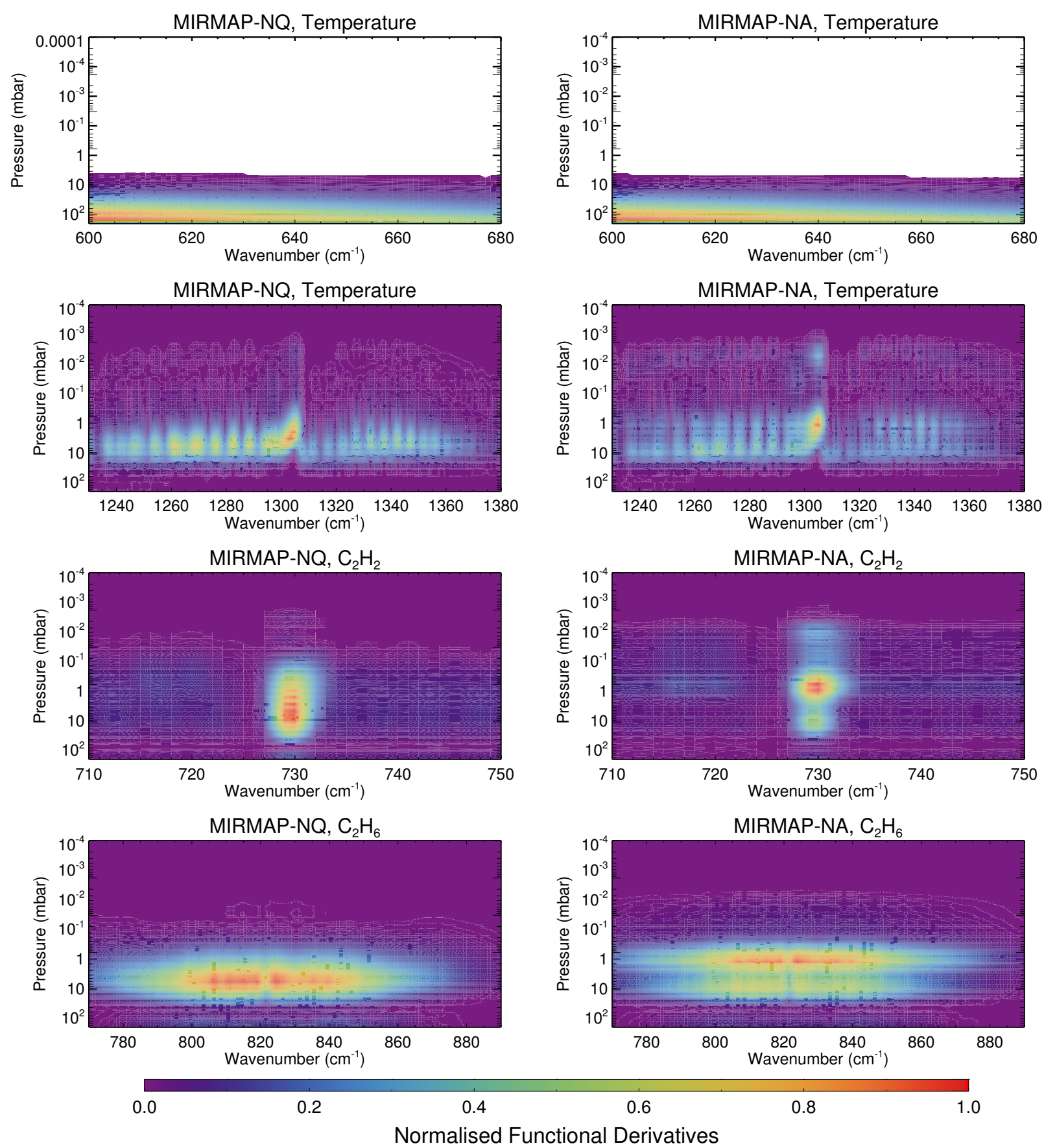

Figure 5: The vertical functional derivatives with respect to temperature from $600-680 \mathrm{~cm}^{-1}$ (top row), $1230-1380 \mathrm{~cm}^{-1}$ (2nd row), with respect to $\mathrm{C}_{2} \mathrm{H}_{2}$ from $710-750 \mathrm{~cm}^{-1}$ (3rd row) and $\mathrm{C}_{2} \mathrm{H}_{6}$ from $770-890 \mathrm{~cm}^{-1}$ (4th row). Results are shown for MIRMAP-NQ (the $2.5 \mathrm{~cm}^{-1}$ CIRS spectrum centred at $\left.70^{\circ} \mathrm{N}, 60^{\circ} \mathrm{W}\right)$ on the left and for MIRMAP-NA $\left(70^{\circ} \mathrm{N}, 180^{\circ} \mathrm{W}\right)$ on the right using the nominal temperature $a$ priori profile.

approximately 10 to 1 mbar. The altitude of peak sensitivity of $\mathrm{C}_{2} \mathrm{H}_{2}$ changes from approximately 5 mbar in quiescent regions to 1 mbar in auroral regions and there is sensitivity to $\mathrm{C}_{2} \mathrm{H}_{2}$ over a much larger vertical range in the latter region. Similarly, the altitude of peak sensitivity of $\mathrm{C}_{2} \mathrm{H}_{6}$ changes from approximately 8 mbar to $1 \mathrm{mbar}$ between quiescent and auroral regions. Retrieved concentrations of $\mathrm{C}_{2} \mathrm{H}_{2}$ at $1 \mathrm{mbar}$ and $\mathrm{C}_{2} \mathrm{H}_{6}$ at 5 mbar will be used to assess spatial variations of $\mathrm{C}_{2} \mathrm{H}_{2}$ and $\mathrm{C}_{2} \mathrm{H}_{6}$ between quiescent and auroral regions.

We note that spectra in auroral regions can probe temperatures and concentrations at low pressures, where non-LTE effects may begin affecting the observed spectrum. The introduction of non-LTE effects into the NEMESIS forward model and retrieval software has not been conducted in this work and 

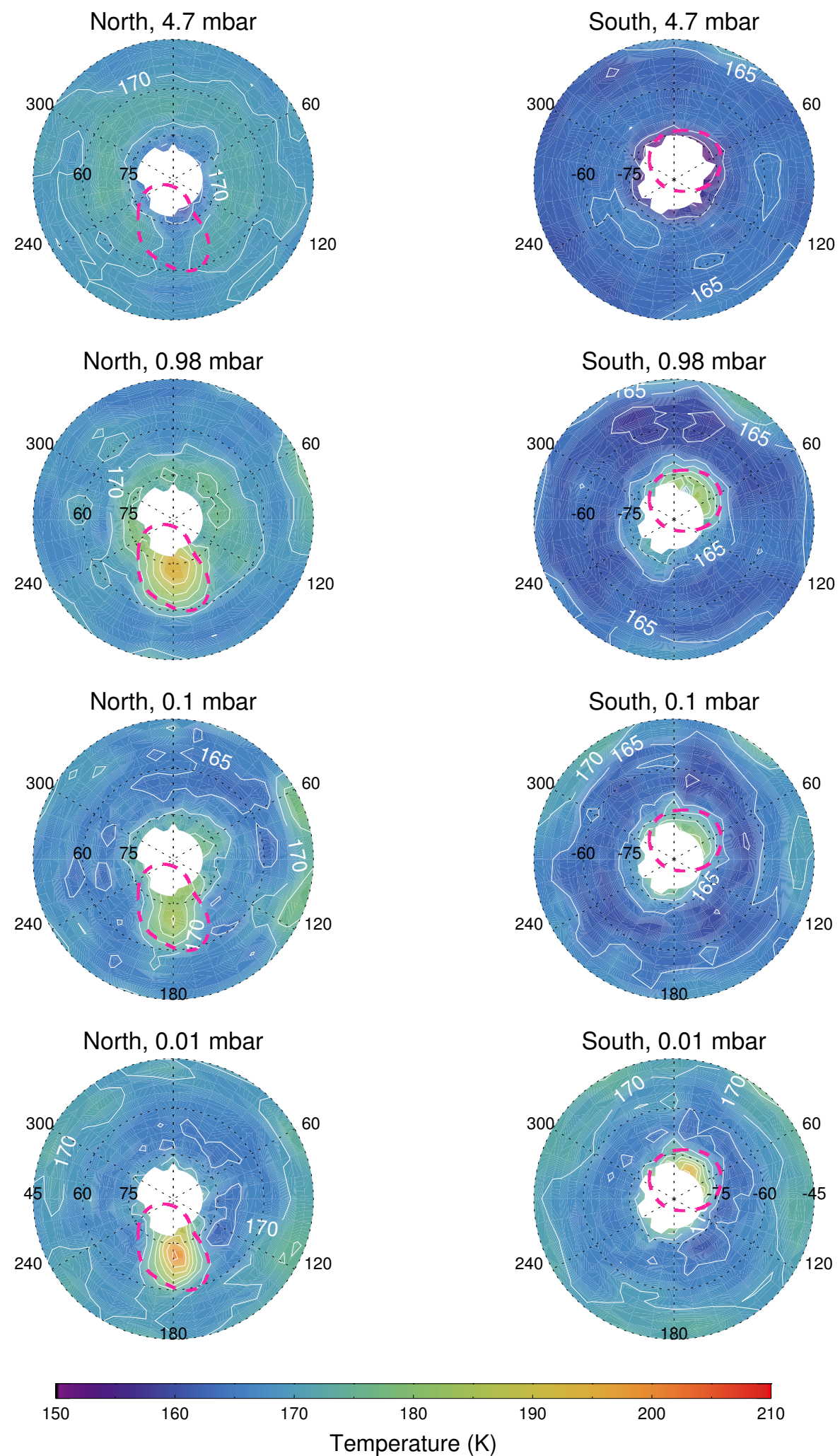

Figure 6: Polar-projections of the retrieved temperature distributions in the north (left) and south (right) $4.7 \mathrm{mbar}$ (top), $1 \mathrm{mbar}$ ( $2 \mathrm{nd} \mathrm{row),0.1}$ mbar (3rd row) and 0.01 mbar (4th row) as retrieved from Cassini-CIRS $\Delta \tilde{v}=2.5 \mathrm{~cm}^{-1}$ observations acquired in 2000. White line contours mark $5 \mathrm{~K}$ intervals in temperature and the conversion from colour to temperature is also shown in the bottom colour bar. The results correspond to temperatures retrieved starting from the nominal temperature a priori. The positions of the main auroral ovals are shown as dashed red lines using the results from Bonfond et al. (2012). 
thus, we note a minor caution to the reader in the interpretation of upper-stratospheric results. The introduction of non-LTE parameterisations into NEMESIS will be addressed in future work.

\subsection{Temperature results}

Since the $\Delta \tilde{v}=2.5 \mathrm{~cm}^{-1}$ CIRS observations provide the best latitude and longitudinal sampling, we initially present the results of retrievals of temperature, $\mathrm{C}_{2} \mathrm{H}_{2}$ and $\mathrm{C}_{2} \mathrm{H}_{6}$ from these observations.

\subsubsection{CIRS $\Delta \tilde{v}=2.5 \mathrm{~cm}^{-1}$}

Figure 6 respectively shows distributions of the retrieved temperatures in north-polar and south-polar projections. Warmer temperatures are retrieved at high-northern latitudes at longitudes centred on $180^{\circ} \mathrm{W}$ coincident with the auroral oval features observed at shorter wavelengths (Bonfond et al., 2012). The lack of sampling of the $2.5 \mathrm{~cm}^{-1}$ observations at high-southern latitudes and the relatively higher latitude of the southern auroral oval makes warm temperatures associated with the southern aurora less evident.

Figure 7 shows variations in the retrieved temperature distributions at all longitudes at $70^{\circ} \mathrm{N}$. As shown, at 4.7-mbar, there is no temperature enhancement at $180^{\circ} \mathrm{W}$ with respect to adjacent longitudes: in fact, temperatures at this altitude are warmer by approximately $4 \mathrm{~K}$ at $60^{\circ} \mathrm{W}$ in comparison to $180^{\circ} \mathrm{W}$. In contrast to the temperatures at 0.98 mbar to 0.01 mbar, the lack of any temperature enhancement at $70^{\circ} \mathrm{N}, 180^{\circ} \mathrm{W}$ at 4.7 mbar indicates that auroral-related heating does not penetrate to pressures higher than 1 - 4-mbar. This is consistent with the conclusions of Flasar et al. (2004).

Over the pressure range sounded by CIRS, the strongest temperature enhancement between quiescent and auroral regions occurs at the $10-\mu$ bar level. We cannot rule out even stronger enhancements at pressures lower than $10-\mu b a r$ level, where the observations have no sensitivity (Figure 5). Temperatures are also elevated at $0.98 \mathrm{mbar}$ in the auroral region with respect to quiescent regions, however, there is comparably less heating at intermediate pressures. We find this result to be consistent in using CIRS spectra of the higher, 0.5 $\mathrm{cm}^{-1}$ spectral resolution (Section 5.2.2) and when starting the retrievals of both $0.5 \mathrm{~cm}^{-1}$ and $2.5 \mathrm{~cm}^{-1}$ CIRS spectra from different temperature a priori profiles (Section 5.2.3). This is nominally counter-intuitive: auroral processes are the result of charged particles penetrating and precipitating from the top of the atmosphere to higher pressures and thus, any effect of the aurora on the neutral atmosphere would be expected to be a vertically-continuous top-down effect. This perhaps indicates that the auroral energy is not deposited continuously as a function of height but instead into two discrete pressure regions or that heating at the higher, 1-mbar pressure level is driven by a different mechanism (albeit auroral-related) compared to the heating observed at pressures of $10-\mu$ bar and lower.
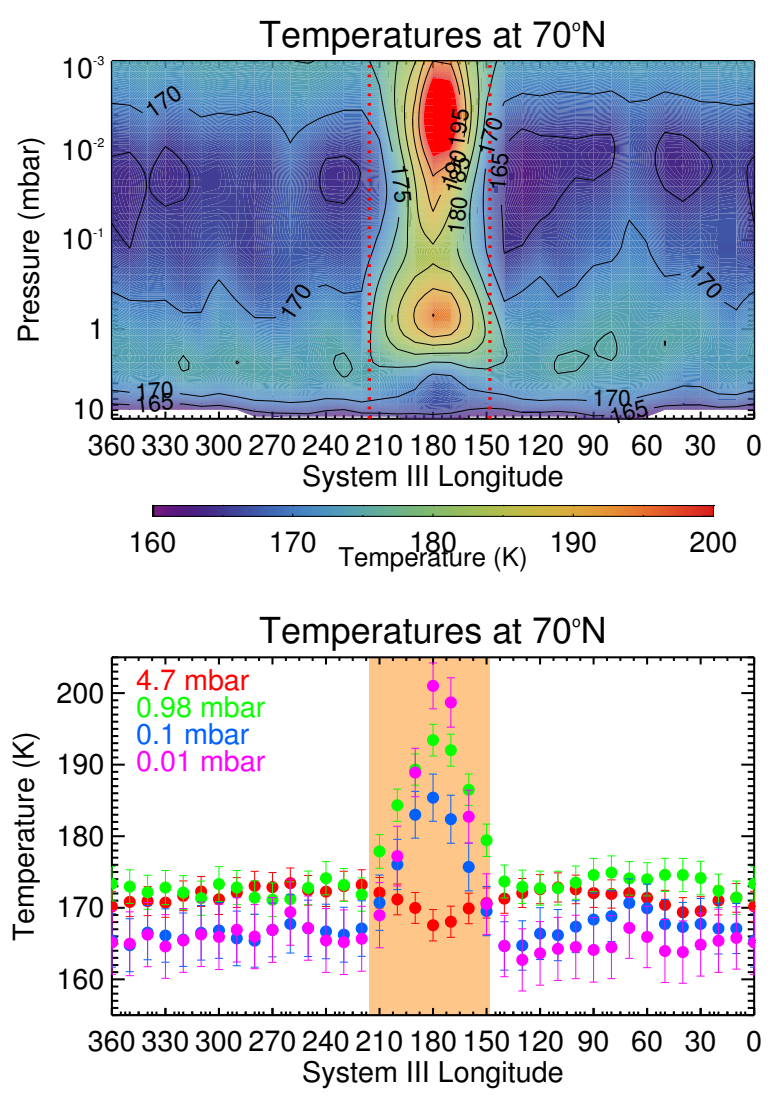

Figure 7: Longitudinal variations of retrieved temperatures at $70^{\circ} \mathrm{N}$ from Cassini-CIRS $\Delta \tilde{v}=2.5 \mathrm{~cm}^{-1}$ observations acquired in 2000 . The top plot shows a longitude-pressure contour cross-section, coloured as indicated in the colourbar and the bottom plot shows points with error bars at 4 representative pressure levels: 4.7-mbar (red), 0.98-mbar (green), 0.1-mbar (blue) and 0.01-mbar(purple). As in Figure 6, these temperatures were retrieved starting from the reference temperature $a$ priori. The filled, orange regions outline the longitude range of the main auroral oval at $70^{\circ} \mathrm{N}$ using the results from Bonfond et al. (2012).

In order to test the robustness of these features in the vertical temperature profile on the aurora, we have performed temperature retrievals of the CIRS $0.5 \mathrm{~cm}^{-1}$ and IRIS $4.3 \mathrm{~cm}^{-1}$ spectra (Section 5.2.2). This includes observations of the 0.5 $\mathrm{cm}^{-1}$ observations in the south, which do sample more of the southern auroral region than the $2.5 \mathrm{~cm}^{-1}$ spectra and also show the presence of two discrete pressure regions of heating. For all datasets, we have also tested alternative temperature a priori in all datasets (Section 5.2.3) to test the robustness of the retrieved profiles.

\subsubsection{CIRS $\Delta \tilde{v}=0.5 \mathrm{~cm}^{-1}$, IRIS $\Delta \tilde{v}=4.3 \mathrm{~cm}^{-1}$ results}

Temperature, $\mathrm{C}_{2} \mathrm{H}_{2}$ and $\mathrm{C}_{2} \mathrm{H}_{6}$ were retrieved using the same method as for $2.5 \mathrm{~cm}^{-1}$ spectra. Figure 8 shows the results of temperature retrievals performed on the Voyager spectra and the $0.5 \mathrm{~cm}^{-1}$ COMPSIT CIRS spectra at both high-southern and high-northern latitudes. The results from the $\Delta \tilde{v}=0.5 \mathrm{~cm}^{-1}$ observations at both poles also indicate the presence of two 

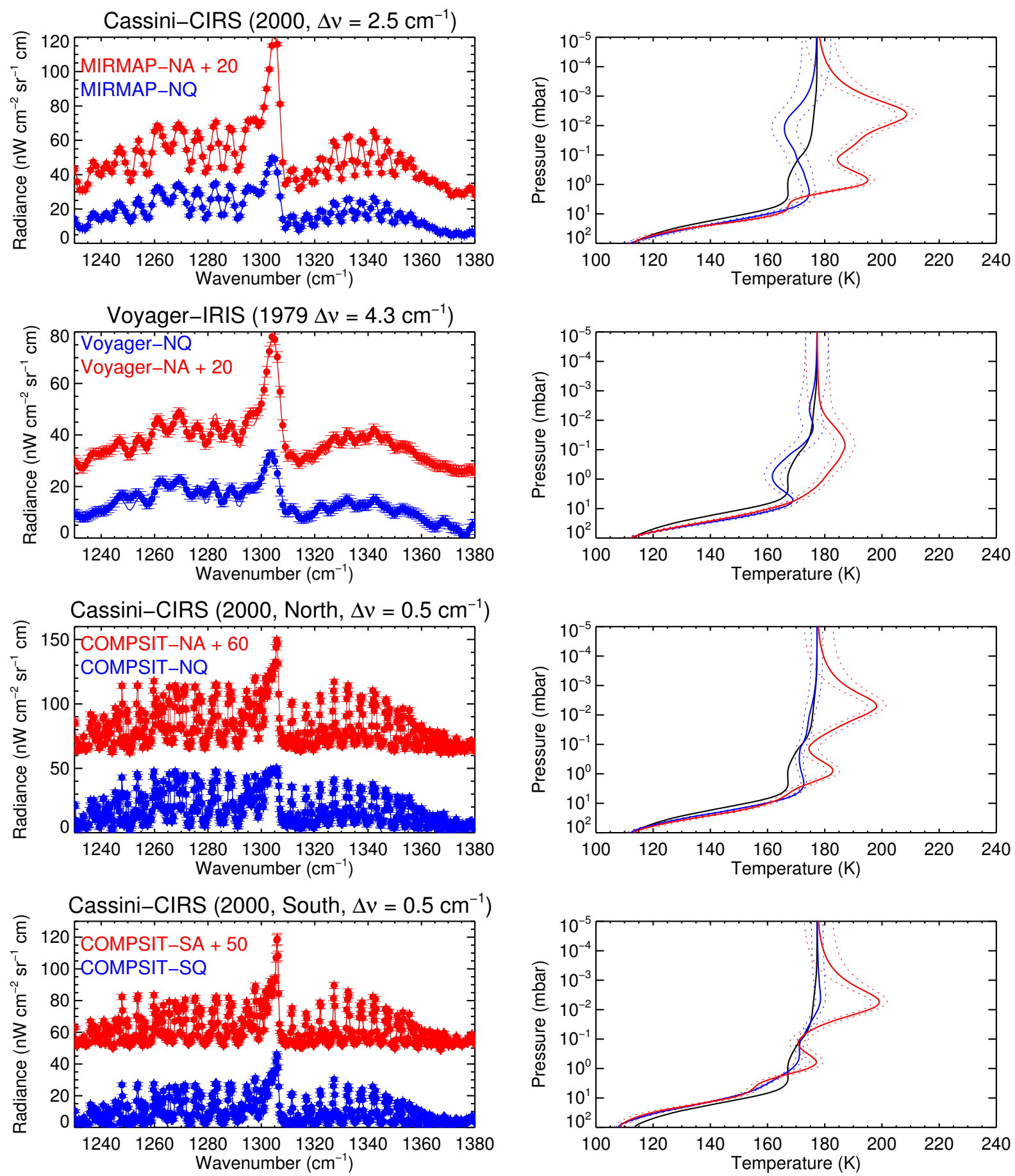

Figure 8: Comparisons of retrieved temperature profiles from Cassini-CIRS, $\Delta \tilde{v}=2.5 \mathrm{~cm}^{-1}$ spectra (top row) in the north in 2000, Voyager-IRIS $\Delta \tilde{v}=4.3 \mathrm{~cm}^{-1}$ spectra in the north in 1979 (2nd row), Cassini-CIRS, $\Delta \tilde{v}=0.5 \mathrm{~cm}^{-1}$ spectra (top) in the north in 2000 and Cassini-CIRS, $\Delta \tilde{v}=0.5 \mathrm{~cm}^{-1}$ spectra (top) in the south in 2000. Red spectra/results are for the auroral regions while blue spectra/results are for a quiescent region outside the auroral region. 1- $\sigma$ error bars on the retrieved temperatures are shown as dotted lines. Solid black lines show the $a$ priori temperature profiles.

discrete pressure regions of auroral heating at the 0.98-mbar and 10- $\mu$ bar levels. The magnitude of the temperature maxima do differ between the results from the $\Delta \tilde{v}=2.5 \mathrm{~cm}^{-1}$ spectra at $70^{\circ} \mathrm{N}, 180^{\circ} \mathrm{W}$ and the $\Delta \tilde{v}=0.5 \mathrm{~cm}^{-1}$ COMPSIT-NA result, which we have attributed to differences in the spatial sampling of both datasets, with the COMPSIT-NA observation representing an average of individual spectra over a larger latitude/longitude range.

The results from the Voyager-NA $\left(\Delta \tilde{v}=4.3 \mathrm{~cm}^{-1}\right)$ spectra however show only a single temperature maximum at 

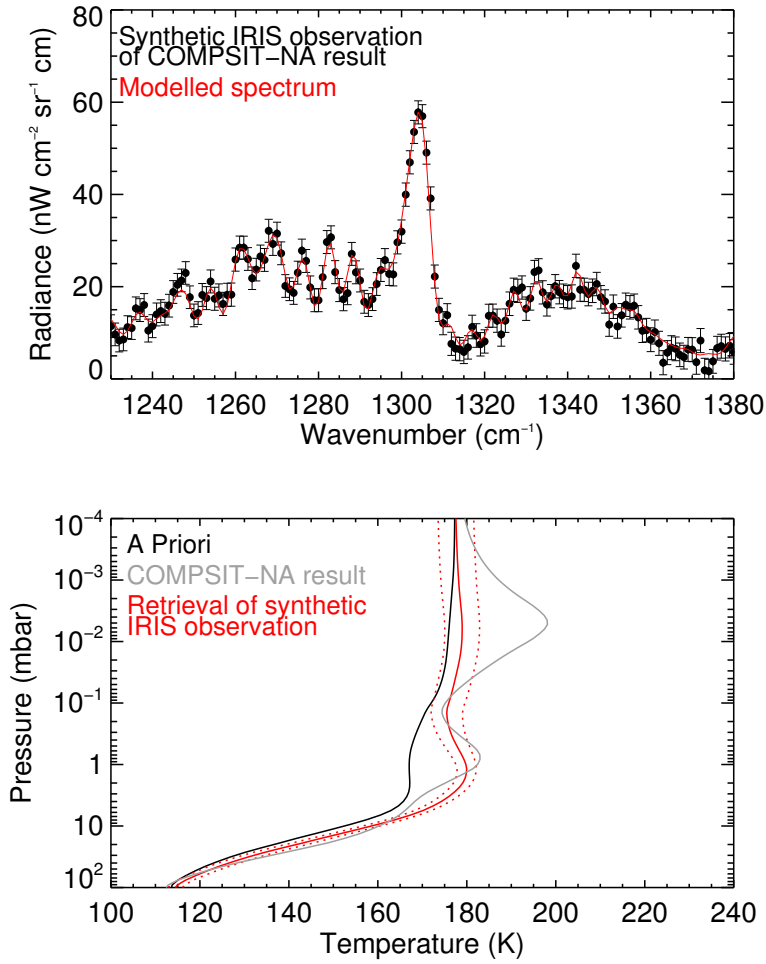

Figure 9: Top plot: black points with error bars show the synthetic IRIS spectrum (computed assuming the COMPSIT-NA (grey) temperature profile in the lower plot) with noise added and the solid red line shows the modelled spectrum associated with the retrieved temperature profile. Bottom plot: the black profile indicates the $a$ priori profile, the grey indicates the correct, COMPSIT-NA result and the red indicates the retrieved temperature profile from the synthetic IRIS spectrum.

approximately 0.1 -mbar, which contrasts the shape of the profile retrieved from the Cassini-CIRS data at both spectral resolutions and in the north and south. We attributed this discrepancy to one or more of the following reasons: 1) the differences in spatial sampling between the CIRS and IRIS spectra with the latter capturing less of the area affected by the auroral-related heating, 2) differences in vertical sensitivity of the two datasets due to their different spectral resolutions and 3) possible differences in the auroral input energy and the resultant auroral-related heating between the Voyager encounter in 1979 and Cassini's flyby in 2000. In order to determine the extent to which the second reason could be a possible source of discrepancy, we forward modelled the vertical temperature profile retrieved from the COMPSIT-NA observation (Figure 8) at the same spectral resolution and emission angle as the Voyager-NA spectrum. Subsequently, we added noise to the forward model to simulate an observation and then performed a retrieval of temperature. Figure 9 shows the results of this test. As shown, a retrieval of the temperature profile from the synthetic IRIS spectrum does not reproduce the correct, double-peaked temperature profile but instead a single maximum in temperature at the 1 mbar level. This demonstrates that the lower spectral resolution of Voyager-IRIS observations do struggle to resolve the vertical thermal structure induced by the auroral processes, at least as determined by Cassini-CIRS observations. This is in agreement with our analysis of synthetic observations in Appendix A.1.

\subsubsection{Testing alternative temperature a priori}

As noted in Appendix A, the retrieval of temperature relies, in part, upon the choice of the a priori profile. In order to test the robustness of the retrieved vertical temperature profiles shown in Section 5.2.1 and 5.2.2, we repeated retrievals of temperature of the Voyager-NQ, Voyager-NA, MIRMAP-NQ, MIRMAP-NA, COMPSIT-NQ, COMPSIT-NA, COMPSIT-SQ and COMPSIT-SA spectra starting from different temperature a priori. In contrast to the retrievals presented in Section 5.2.1 and 5.2.2, only temperature was retrieved from the 600 $680 \mathrm{~cm}^{-1}$ (collision-induced absorption) and $1230-1380 \mathrm{~cm}^{-1}$ $\left(\mathrm{CH}_{4}\right.$ emission) regions. The emission features of $\mathrm{C}_{2} \mathrm{H}_{2}$ and $\mathrm{C}_{2} \mathrm{H}_{6}\left(710-750 \mathrm{~cm}^{-1}\right.$ and $770-890 \mathrm{~cm}^{-1}$ respectively) were not modelled and their vertical profiles were kept constant. We have explored retrievals of $\mathrm{C}_{2} \mathrm{H}_{2}$ and $\mathrm{C}_{2} \mathrm{H}_{6}$ from different $a$ priori in Section 5.3.3.

Figure 10 shows the results of temperature retrievals from quiescent and auroral spectra of all datasets starting from different a priori. We tested retrievals from the nominal temperature profile, isotherms of $160 \mathrm{~K}$ and $200 \mathrm{~K}$ above the levels where these temperatures are reached and an isotherm of $200 \mathrm{~K}$ above the $10-\mu$ bar level (the auroral-200K profile).

For Voyager-NA, temperature profiles retrieved from the different a priori all indicate a temperature maximum at pressures intermediate between 1- and 0.1-mbar. We demonstrated in Section 5.2.2 that this single temperature maximum feature could be explained by IRIS's lower spectral resolution and therefore reduced vertical sensitivity in the atmosphere. Nevertheless, temperatures retrieved from the Voyager-NA spectrum in the $10-0.1$ mbar pressure range are significantly higher than the range in temperatures retrieved from the Voyager-NQ observation.

At high-northern latitudes, temperatures retrieved in both quiescent and auroral regions from CIRS spectra at both 0.5 $\mathrm{cm}^{-1}$ and $2.5 \mathrm{~cm}^{-1}$ spectral resolutions converge in the $10-$ to $1-$ mbar region. This is expected given the observations are sensitive over this pressure range (Figure 5). In particular, retrievals from the the MIRMAP-NA, COMPSIT-NA and COMPSIT-SA spectra continue to indicate a temperature maximum at approximately 1 mbar and a minimum at 0.1 mbar, regardless of the temperature a priori that was used. We note that there is less sensitivity to temperature at the $0.1-\mathrm{mbar}$ pressure level in comparison to the 1-mbar and 10- $\mu$ bar levels (Figure 5). However, temperature retrievals of auroral spectra using different a priori converge on temperatures (within $5 \mathrm{~K}$ ) even when starting from a priori that are colder or hotter than the final temperature. This demonstrates that the temperature maximum at $1 \mathrm{mbar}$ and temperature minimum 

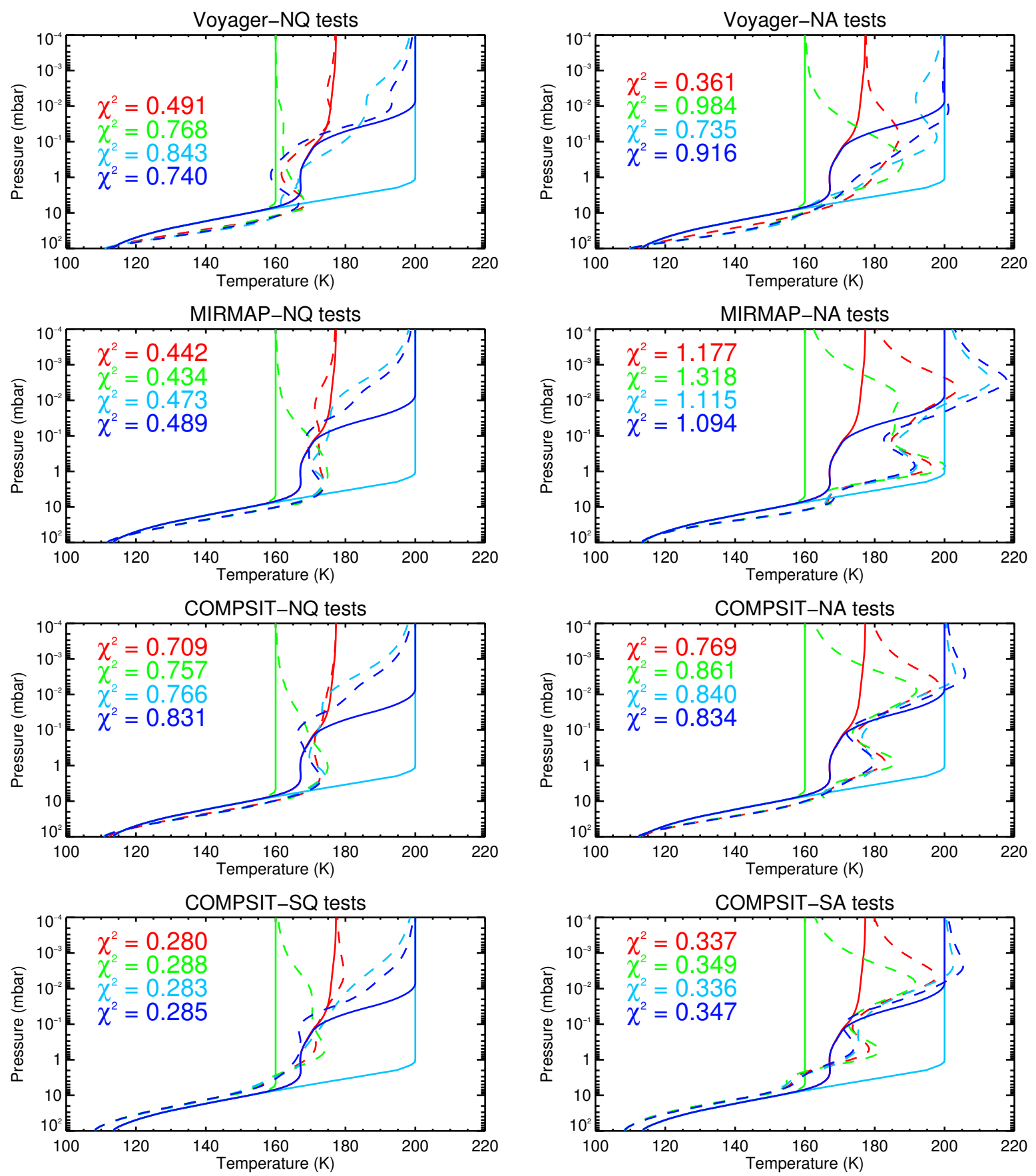

Figure 10: Retrievals of temperature from Voyager (top row), MIRMAP (2nd row) and COMPSIT observations in the north and south (3rd and 4th row respecitvely) starting from different temperature a priori. Tests for quiescent observations are shown in the left-hand column, those for observations covering the auroral region are shown on the right. A priori profiles are shown as solid, coloured lines and the corresponding retrievals are shown as dashed lines. The corresponding reduced $\chi^{2} / n$ values of each retrieval are also shown.

at 0.1 mbar in the retrieved vertical profiles of temperature from the MIRMAP-NA, COMPSIT-NA and COMPSIT-SA spectra are robust features and not an artefact of the vertical sensitivity.

In quiescent regions (MIRMAP-NQ, COMPSIT-NQ and COMPSIT-SQ), retrieved temperatures diverge and tend back to a priori values at pressures lower than 0.1 mbar since the observations are not sensitive above this altitude. Temperature retrievals of auroral regions indicate a robust increase of temperature with height up to pressures of $10 \mu \mathrm{bar}$ and then similarly diverge and tend back to a priori levels at pressure below this level. We believe the appearance of

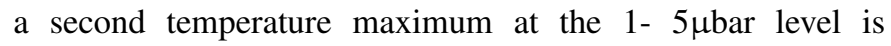
most likely an artefact of the lack of sensitivity of lower pressure and the retrieved profile tending back to the cooler 


\begin{tabular}{ccccc} 
Observation & \multicolumn{3}{c}{ Temperature at } \\
& $4.7 \mathrm{mbar}$ & $0.98 \mathrm{mbar}$ & $0.1 \mathrm{mbar}$ & $0.01 \mathrm{mbar}$ \\
\hline Voyager-NQ & $166.7 \pm 3.4$ & $162.8 \pm 4.8$ & $168.7 \pm 6.6$ & $178.6 \pm 13.5$ \\
Voyager-NA & $166.3 \pm 3.3$ & $178.6 \pm 3.3$ & $188.7 \pm 5.4$ & $185.5 \pm 12.9$ \\
\hline MIRMAP-NQ & $169.7 \pm 3.0$ & $173.9 \pm 3.7$ & $169.9 \pm 5.7$ & $169.9 \pm 9.9$ \\
MIRMAP-NA & $167.6 \pm 3.4$ & $189.2 \pm 3.7$ & $185.8 \pm 5.3$ & $199.5 \pm 11.3$ \\
\hline COMPSIT-NQ & $167.7 \pm 2.4$ & $172.2 \pm 3.0$ & $173.1 \pm 4.3$ & $175.4 \pm 9.1$ \\
COMPSIT-NA & $165.9 \pm 2.6$ & $180.3 \pm 2.9$ & $178.7 \pm 4.1$ & $187.6 \pm 10.1$ \\
\hline COMPSIT-SQ & $154.5 \pm 2.5$ & $167.7 \pm 2.8$ & $170.2 \pm 4.0$ & $178.3 \pm 5.1$ \\
COMPSIT-SA & $153.6 \pm 2.6$ & $171.9 \pm 2.9$ & $173.4 \pm 4.0$ & $189.9 \pm 3.9$ \\
\hline
\end{tabular}

Table 4: Retrieved temperatures and uncertainties from the Voyager-NQ, Voyager-NA, MIRMAP-NQ, MIRMAP-NA, COMPSIT-NQ, COMPSIT-NA, COMPSIT-SQ and COMPSIT-SA spectra at four representative pressure levels. The quoted values and uncertainties reflect a mean and error of the retrieved results from different a priori profiles as detailed in the text.

temperatures of the a priori. This is also demonstrated by the retrievals of temperature starting from the isothermal $200 \mathrm{~K}$ and auroral-200K temperature a priori, where the appearance of a temperature maximum at $5 \mu$ bar is reduced or even removed. We have no sensitivity in our measurements to make conclusions of the behaviour of temperatures at pressures below the 5- $\mu$ bar level: we suspect that temperatures increase with height towards the thermosphere.

For a single spectrum, the range of temperatures retrieved from different a priori is generally the dominant source of variance in comparison to the uncertainties on individual retrievals. This is in particular at lower pressures. In order to quote retrieved temperatures and uncertainty that best captures the range in results depending on the choice of a priori, we computed a weighted average and error and the weighted standard deviation of temperature retrieved at each pressure level from the four different a priori. The weighted average, $\bar{y}$, was calculated as in Equation 1.

$$
\bar{y}=\frac{\sum_{i=1}^{n} w_{i} y_{i}}{\sum_{i=1}^{n} w_{i}}, w_{i}=\frac{\chi_{\min }^{2}}{\chi_{i}^{2}}
$$

$y_{i}$ is the retrieved value (in this case, temperature) using the $i^{\text {th }}$ a priori. Each retrieval is weighted by $w_{i}$ (also shown in Equation 1) and ensures that the result of retrievals yielding a better fit to the observations are weighted relatively higher than those with a poorer fit. The uncertainty on this weighted value was assumed to be the larger of 1) the error on the weighted average (Equation 2), where the uncertainties of the $i^{\text {th }}$ retrieval are similarly weighted and combined in quadrature or 2) the weighted standard deviation of the retrieved values also weighted by the $\chi^{2}$ (Equation 3 ).

$$
\begin{gathered}
\sigma_{\bar{y}}=\sqrt{\sum_{i=1}^{n} w_{i} \sigma_{i}^{2}} \\
\sigma_{\mathrm{SD}}=\sqrt{\frac{\sum_{i=1}^{n} w_{i}\left(y_{i}-\bar{y}\right)^{2}}{(n-1) / n \sum_{i=1}^{n} w_{i}}}
\end{gathered}
$$

Table 4 shows the resulting weighted mean temperatures and uncertainty for each of the datasets. Differences in temperatures at 4.7 mbar between quiescent and auroral regions are negligible with respect to the derived uncertainty. This is consistent with the retrieved temperature distributions shown in Figures 6 and 7 and with the findings of Flasar et al. (2004). At 0.98 mbar, all datasets indicate statistically different temperatures between quiescent and auroral regions in both the north and south. Derived temperature differences are $15.8 \pm 5.8 \mathrm{~K}, 15.3 \pm 5.2 \mathrm{~K}, 8.1 \pm 4.1 \mathrm{~K}$ and 4.2 $\pm 4.0 \mathrm{~K}$ for the Voyager, CIRS-MIRMAP, CIRS-COMPSIT in the north and CIRS-COMPSIT in the south respectively. We believe differences in the derived temperature contrasts between northern auroral and quiescent regions from the CIRS-COMPSIT and -MIRMAP observations can be explained by differences in the spatial sampling of the two spectra, as discussed previously.

At 0.1 mbar, Voyager results indicate a temperature contrast of $20.0 \pm 8.5 \mathrm{~K}$ between quiescent and auroral regions in the north. This is the largest temperature contrast at this pressure level with respect to those indicated by the CIRS datasets. At the same pressure level, the MIRMAP spectra indicate a temperature difference of $15.9 \pm 7.8 \mathrm{~K}$ while the COMPSIT observations of both the north and south indicate yield negligible difference in temperature at this pressure level with respect to uncertainty. As noted in Section 5.2.2, we believe the lower spectral resolution of Voyager-IRIS spectra might hinder the retrieval of the thermal structure indicated by the Cassini data and so the large temperature contrast at 0.1 mbar may be an artefact of this issue.

At 0.01 mbar, the MIRMAP observations of the north and the COMPSIT observations of the south indicate statistically-significant temperature differences of $30.0 \pm 15.0$ $\mathrm{K}$ and $11.6 \pm 6.4 \mathrm{~K}$ respectively. However, temperature differences between auroral and quiescent regions indicated by the Voyager results and the COMPSIT observations of the north are negligible with respect to uncertainties $(6.9 \pm 18.7 \mathrm{~K}$ and $12.2 \pm 13.5 \mathrm{~K}$ respectively). As noted above, the lack of significant contrast in the Voyager results may be an artefact of the lower spectral resolution of IRIS though differences between auroral forcing in 1979 and 2001 and it effect on the atmosphere cannot be ruled out. The lack of contrast indicated 


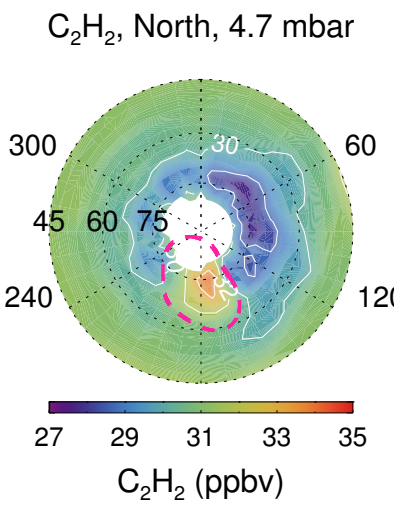

$\mathrm{C}_{2} \mathrm{H}_{2}$, North, 0.98 mbar

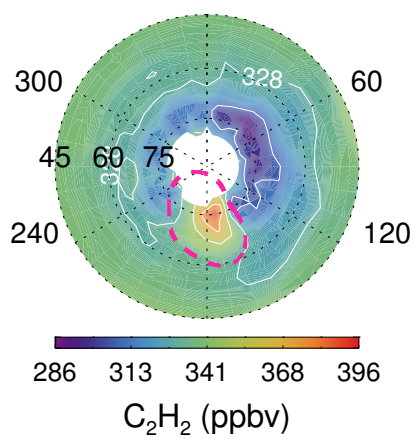

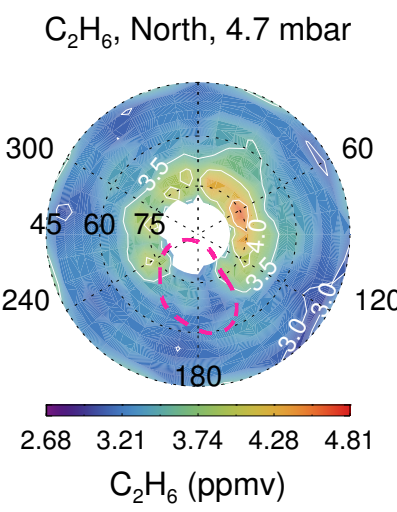

$\mathrm{C}_{2} \mathrm{H}_{6}$, North, 0.98 mbar

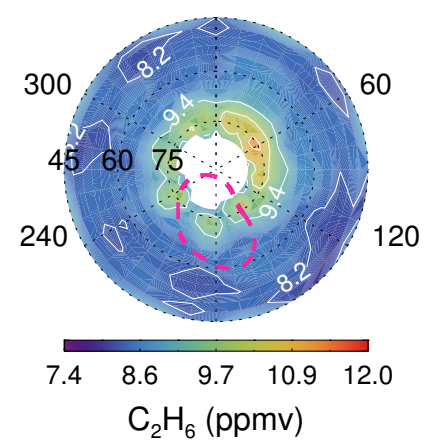

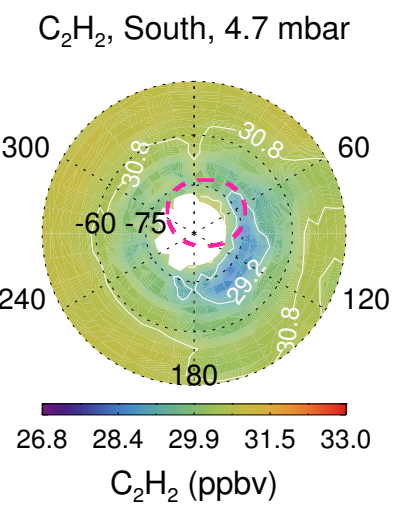

$\mathrm{C}_{2} \mathrm{H}_{2}$, South, 0.98 mbar

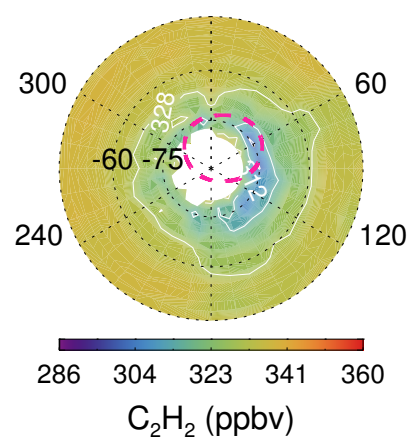

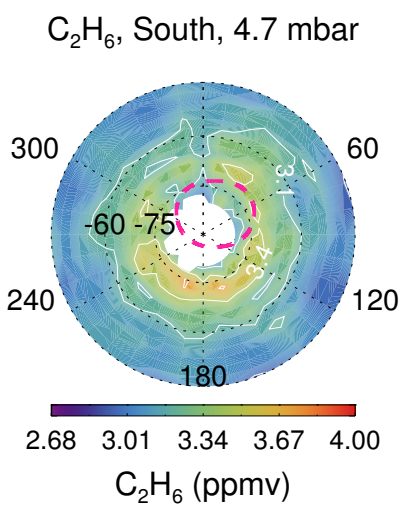

$\mathrm{C}_{2} \mathrm{H}_{6}$, South, 0.98 mbar

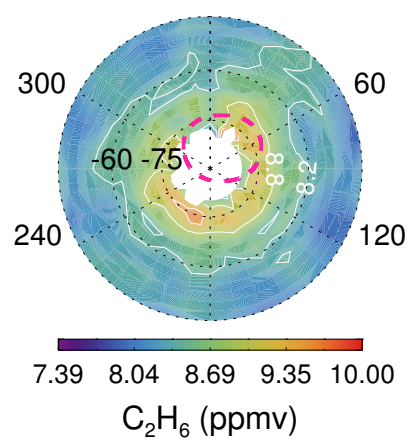

Figure 11: Polar-projected distributions of retrieved $\mathrm{C}_{2} \mathrm{H}_{2}$ and $\mathrm{C}_{2} \mathrm{H}_{6}$ concentration in the north (1st, 2nd columns) and in the south (3rd, 4th columns). Concentrations are shown at $4.7 \mathrm{mbar}$ (top row) and $1 \mathrm{mbar}$ (bottom row) as retrieved from Cassini-CIRS $\Delta \tilde{v}=2.5 \mathrm{~cm}^{-1}$ observations. These results were derived using the nominal temperature, $\mathrm{C}_{2} \mathrm{H}_{2}$ and $\mathrm{C}_{2} \mathrm{H}_{6}$ a priori. The positions of the main auroral ovals in the north and south (using the results from Bonfond et al. (2012)) are shown as dashed, red lines.

by the COMPSIT observations of the north likely arises from the averaging of individual observations over a large spatial range $\left(65^{\circ} \mathrm{N}\right.$ to $85^{\circ} \mathrm{N}$ and $140^{\circ} \mathrm{W}$ to $\left.230{ }^{\circ} \mathrm{W}\right)$. This was needed to reduce the noise on the observations to a sufficient level for analysis but likely mixed auroral and quiescent atmospheric together.

Thus, we believe the presence of two-vertically discrete pressure regions of heating at levels of approximately $1 \mathrm{mbar}$ and 0.01 mbar are physical and robust features of the thermal structure in the northern and southern auroral regions.

\section{3. $\mathrm{C}_{2} \mathrm{H}_{2}, \mathrm{C}_{2} \mathrm{H}_{6}$ results}

\subsubsection{CIRS $\Delta \tilde{v}=2.5 \mathrm{~cm}^{-1}$ results}

Figure 11 shows the retrieved distributions of $\mathrm{C}_{2} \mathrm{H}_{2}$ and $\mathrm{C}_{2} \mathrm{H}_{6}$ from the CIRS MIRMAP observations. These concentrations were retrieved using the nominal temperature profile and the nominal vertical profiles of $\mathrm{C}_{2} \mathrm{H}_{2}$ and $\mathrm{C}_{2} \mathrm{H}_{6}$ from Moses et al. (2005). However, we test alternative hydrocarbon profiles as $a$ priori in Sections 5.3.3. In contrast to the temperature results we presented at pressures from 4.7 to $0.01 \mathrm{mbar}$, we present the $\mathrm{C}_{2} \mathrm{H}_{2}$ and $\mathrm{C}_{2} \mathrm{H}_{6}$ results only at pressures from 4.7 to $0.98 \mathrm{mbar}$ since there is little sensitivity outside of this pressure region, even in auroral regions (Figure 5).
At high-northern latitudes, retrievals indicate an enrichment of $\mathrm{C}_{2} \mathrm{H}_{2}$ but a depletion of $\mathrm{C}_{2} \mathrm{H}_{6}$ in auroral regions with respect to quiescent longitudes. This is demonstrated further in Figure 12, which shows the variations in $\mathrm{C}_{2} \mathrm{H}_{2}$ and $\mathrm{C}_{2} \mathrm{H}_{6}$ with longitude at $70^{\circ} \mathrm{N}$ at 4.7 and 0.98 mbar. $\mathrm{C}_{2} \mathrm{H}_{2}$ at 0.98 mbar increases from $291.5 \pm 28.6 \mathrm{ppbv}$ at $70^{\circ} \mathrm{N}, 40^{\circ} \mathrm{W}$ (as a representative example of a quiescent region) to $364.8 \pm 34.9 \mathrm{ppbv}$ at $70^{\circ} \mathrm{N}$, $180^{\circ} \mathrm{W}$ (within the auroral oval). Over the same longitude range, $\mathrm{C}_{2} \mathrm{H}_{6}$ at 4.7 mbar decreases from $4.10 \pm 0.30 \mathrm{ppmv}$ to $3.30 \pm 0.27$ ppmv. In general, it appears that $\mathrm{C}_{2} \mathrm{H}_{2}$ and $\mathrm{C}_{2} \mathrm{H}_{6}$ at high-northern and high-southern latitudes are anti-correlated as a function of longitude: regions of high concentrations of $\mathrm{C}_{2} \mathrm{H}_{2}$ occur at the same longitudes as low concentrations of $\mathrm{C}_{2} \mathrm{H}_{6}$ (for example, $72^{\circ} \mathrm{N}, 60^{\circ} \mathrm{W}$ ) and vice-versa (for example, at the northern auroral oval at $70^{\circ} \mathrm{N}, 180^{\circ} \mathrm{W}$ ). This is demonstrated also in Figure 13, which shows that the normalised longitudinal distributions of $\mathrm{C}_{2} \mathrm{H}_{2}$ and $\mathrm{C}_{2} \mathrm{H}_{6}$ at $70^{\circ} \mathrm{N}$ sum to a distribution that is constant within uncertainty. As we discuss in Section 6, we believe this behaviour results from conversion of $\mathrm{C}_{2} \mathrm{H}_{2}$ into $\mathrm{C}_{2} \mathrm{H}_{6}$ outside of the auroral region.

We demonstrate the consistency of these results in the results of similar retrievals of $\mathrm{C}_{2} \mathrm{H}_{2}$ and $\mathrm{C}_{2} \mathrm{H}_{6}$ from the higher-resolution CIRS measurements and the Voyager, $4.3 \mathrm{~cm}^{-1}$ observations in Section 5.3.2. We also tested retrievals of $\mathrm{C}_{2} \mathrm{H}_{2}$ and $\mathrm{C}_{2} \mathrm{H}_{6}$ 

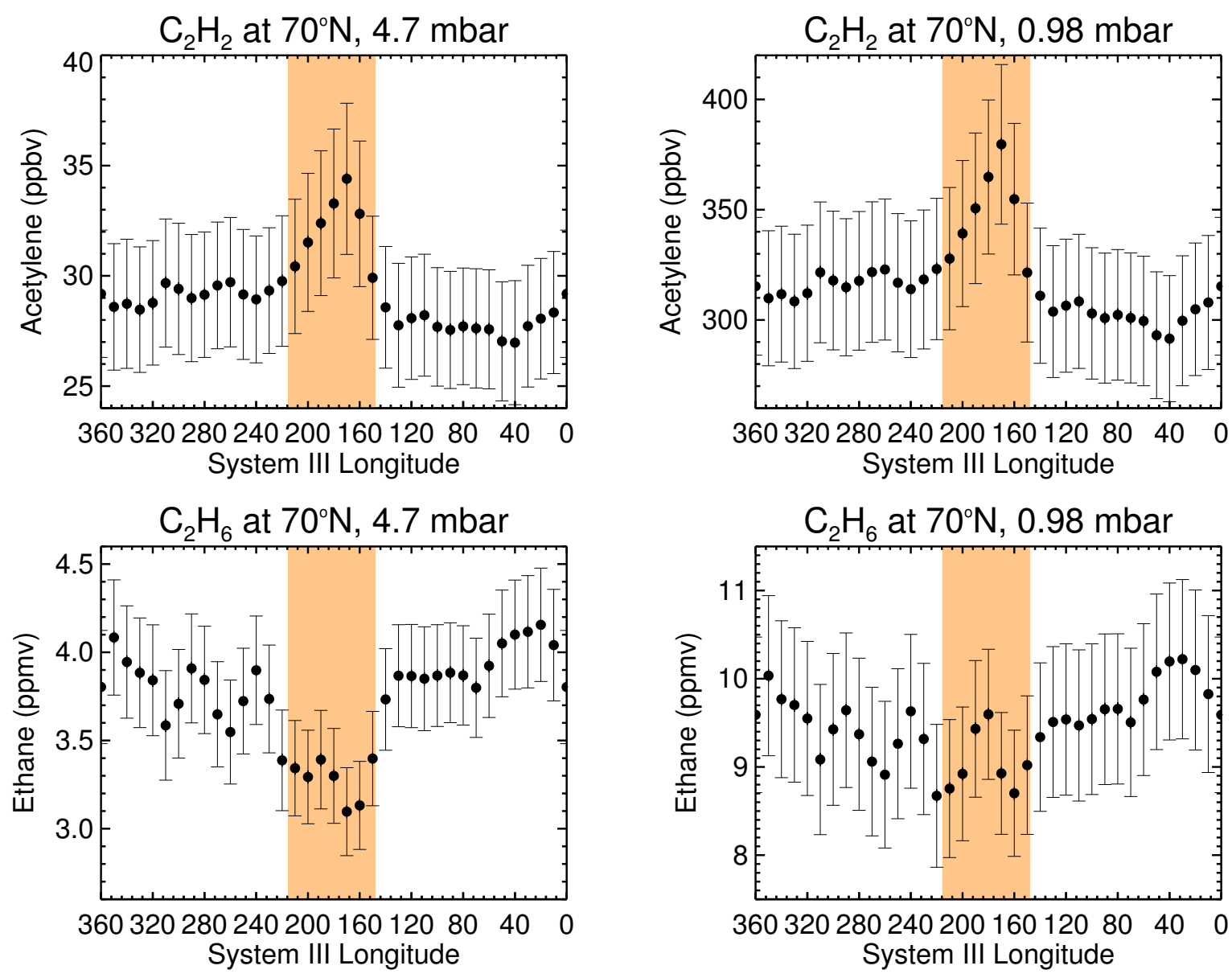

Figure 12: The retrieved concentrations of $\mathrm{C}_{2} \mathrm{H}_{2}$ (top row) and $\mathrm{C}_{2} \mathrm{H}_{6}$ (bottom row) at $70^{\circ} \mathrm{N}$ at $4.7 \mathrm{mbar}$ (left) and $0.98 \mathrm{mbar}$ (right). The orange-filled box indicates the longitudinal extent of the main auroral oval at this latitude (using the results from Bonfond et al. (2012)). These retrievals were computed using the nominal temperature profile and the nominal vertical profiles of $\mathrm{C}_{2} \mathrm{H}_{2}$ and $\mathrm{C}_{2} \mathrm{H}_{6}$.

of all datasets by starting from different a priori in Section 5.3 .3

\subsubsection{CIRS $\Delta \tilde{v}=0.5 \mathrm{~cm}^{-1}$ and IRIS $4.3 \mathrm{~cm}^{-1}$ results}

Figure 14 shows the results of retrievals of $\mathrm{C}_{2} \mathrm{H}_{2}$ and $\mathrm{C}_{2} \mathrm{H}_{6}$ from the Voyager-NQ, Voyager-NA, COMPSIT-NQ, COMPSIT-NA, COMPSIT-SQ and COMPSIT-SA spectra using the nominal $a$ priori of temperature, $\mathrm{C}_{2} \mathrm{H}_{2}$ and $\mathrm{C}_{2} \mathrm{H}_{6}$. All datasets support the result that $\mathrm{C}_{2} \mathrm{H}_{2}$ is enhanced but $\mathrm{C}_{2} \mathrm{H}_{6}$ is depleted in auroral regions with respect to quiescent regions. In particular, the results of the COMPSIT-SQ and COMPSIT-SA retrievals indicate that enhanced concentrations of $\mathrm{C}_{2} \mathrm{H}_{2}$ but depleted concentrations of $\mathrm{C}_{2} \mathrm{H}_{6}$ are also a feature of the southern auroral region with respect to quiescent longitudes. Contrasts in $\mathrm{C}_{2} \mathrm{H}_{2}$ and $\mathrm{C}_{2} \mathrm{H}_{6}$ concentrations between auroral and quiescent regions exceed the 1- $\sigma$ uncertainty level in the MIRMAP-NA and MIRMAP-NQ observations in the north and the COMPSIT-SA and COMPSIT-SQ observations in the south. In contrast, differences in the retrieved concentrations of $\mathrm{C}_{2} \mathrm{H}_{6}$ between the COMPSIT-NA and COMPSIT-NQ results are not significant with respect to the $1-\sigma$ uncertainty. As for the temperature results in Section 5.2.2, we believe differences between the COMPSIT and MIRMAP results of derived auroral-quiescent contrasts can be explained by differences in the spatial sampling of the observations.

Retrieved concentrations of $\mathrm{C}_{2} \mathrm{H}_{2}$ and $\mathrm{C}_{2} \mathrm{H}_{6}$ derived from the Voyager measurements exhibit the largest differences between auroral and quiescent regions. However, the retrieved temperature profile of the Voyager-IRIS observations in auroral regions differed greatly from those retrieved from the Cassini observations (Section 5.2). In the Cassini measurements, two discrete pressure regions of heating were retrieved at approximately the 1-mbar and 10- $\mu$ bar levels. While differences in the auroral forcing between 1979 and 2001 cannot be ruled out, we demonstrated in Section 5.2.2 that Voyager-IRIS spectra might not resolve the auroral thermal structure because of its lower spectral resolution and therefore vertical resolution in the atmosphere. This issue would also affect the retrieval of $\mathrm{C}_{2} \mathrm{H}_{2}$ and $\mathrm{C}_{2} \mathrm{H}_{6}$ since their emission features vary as a result of their mole fraction and the temperature of the line forming region. Thus, larger differences in auroral and quiescent concentrations derived from the 


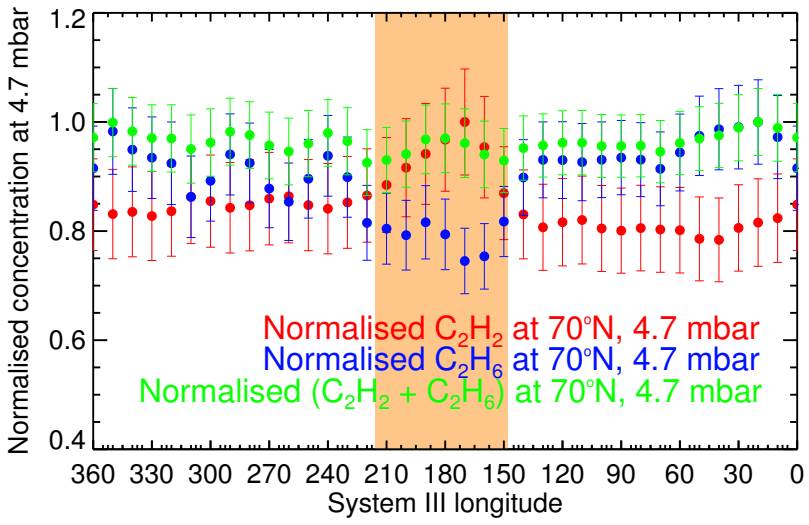

Figure 13: The concentrations at $70^{\circ} \mathrm{N}, 4.7$ mbar of $\mathrm{C}_{2} \mathrm{H}_{2}$ (red), $\mathrm{C}_{2} \mathrm{H}_{6}$ (blue) and the sum of $\mathrm{C}_{2} \mathrm{H}_{2}+\mathrm{C}_{2} \mathrm{H}_{6}$ (green). All results are normalised with respect to the maximum value in the latitude band. The orange-filled region indicates the longitudinal extent of the northern auroral oval at $70^{\circ} \mathrm{N}$.

Voyager-IRIS measurements may be an artefact of the previous temperature retrieval rather than a physical difference in auroral-qiuescent concentration contrasts between 1979 and 2001.

\subsubsection{Testing alternative hydrocarbon a priori}

As noted in Appendix A.1.3, the largest source of uncertainty in the retrieval of $\mathrm{C}_{2} \mathrm{H}_{2}$ and $\mathrm{C}_{2} \mathrm{H}_{6}$ was the variation in concentration depending on the chosen a priori. Thus, we performed additional retrievals using alternative a priori profiles of $\mathrm{C}_{2} \mathrm{H}_{2}$ and $\mathrm{C}_{2} \mathrm{H}_{6}$ in order to test the robustness of derived results.

The retrieved temperature profile and corresponding uncertainties retrieved in Section 5.2.3, starting from the temperature a priori that yielded the best fit to each observation, was adopted as the temperature profile and kept constant. Alternative a priori profiles of $\mathrm{C}_{2} \mathrm{H}_{2}$ and $\mathrm{C}_{2} \mathrm{H}_{6}$ were derived by applying scale factors of $0.4,0.7,1.5$ and 2 to their reference vertical profiles (from Moses et al. (2005)). Further retrievals of $\mathrm{C}_{2} \mathrm{H}_{2}$ and $\mathrm{C}_{2} \mathrm{H}_{6}$ using these alternative a priori were performed from the Voyager-NQ, Voyager-NA, MIRMAP-NQ, MIRMAP-NA, COMPSIT-NQ, COMPSIT-NA, COMPSIT-SQ and COMPSIT-SA spectra using the $710-750 \mathrm{~cm}^{-1}$ and $770-890 \mathrm{~cm}^{-1}$ spectral regions.

Figure 15 shows the results of these retrievals. For clarity, only the retrievals using the $a$ priori profiles scaled by 0.4 and 2 are shown and compared with a retrieval using the nominal $a$ priori. The results from all a priori were however adopted in the weighted mean calculated detailed below. In all datasets, retrieved profiles of $\mathrm{C}_{2} \mathrm{H}_{6}$ using different a priori converge on a common solution in the 10- to 1-mbar range, where the observations are sensitive (Figure 5), while tending back to $a$ priori values outside this range. Retrieved profiles of $\mathrm{C}_{2} \mathrm{H}_{2}$

\begin{tabular}{ccc} 
Observation & $\begin{array}{c}\mathrm{C}_{2} \mathrm{H}_{2} \text { at } \\
0.98 \text { mbar } \\
(\mathrm{ppbv})\end{array}$ & $\begin{array}{c}\mathrm{C}_{2} \mathrm{H}_{6} \text { at } \\
4.7 \mathrm{mbar} \\
(\mathrm{ppmv})\end{array}$ \\
\hline Voyager-NQ & $186.6 \pm 53.8$ & $4.34 \pm 0.52$ \\
Voyager-NA & $425.7 \pm 71.5$ & $2.74 \pm 0.37$ \\
\hline MIRMAP-NQ & $166.2 \pm 50.9$ & $4.44 \pm 0.44$ \\
MIRMAP-NA & $341.5 \pm 73.4$ & $3.58 \pm 0.40$ \\
\hline COMPSIT-NQ & $107.3 \pm 18.7$ & $4.05 \pm 0.24$ \\
COMPSIT-NA & $226.1 \pm 38.0$ & $3.97 \pm 0.26$ \\
\hline COMPSIT-SQ & $72.3 \pm 12.2$ & $4.99 \pm 0.32$ \\
COMPIST-SA & $121.9 \pm 20.2$ & $3.96 \pm 0.28$ \\
\hline
\end{tabular}

Table 5: Concentrations of $\mathrm{C}_{2} \mathrm{H}_{2}$ and $\mathrm{C}_{2} \mathrm{H}_{6}$ retrieved from the Voyager-NQ, Voyager-NA, MIRMAP-NQ, MIRMAP-NA, COMPSIT-NQ, COMPSIT-NA, COMPSIT-SQ and COMPSIT-SA spectra. The quoted concentrations reflect a weighted-mean of the results retrieved starting from several different hydrocarbon $a$ priori profiles, as detailed in the text.

using different a priori also exhibit some convergence in the 10- to 0.1-mbar pressure range. However, there still exists some variation in the retrieved concentrations depending on the chosen a priori: for $\mathrm{C}_{2} \mathrm{H}_{2}$ retrievals, this represents the larger source of uncertainty. However, in general, we find that retrievals of $\mathrm{C}_{2} \mathrm{H}_{2}$ in quiescent regions using the depleted $\mathrm{C}_{2} \mathrm{H}_{2}$ profiles exhibit the best fit to the observations.

In order to derive a concentration and uncertainty for $\mathrm{C}_{2} \mathrm{H}_{2}$ and $\mathrm{C}_{2} \mathrm{H}_{6}$ that captures the range retrieved from different $a$ priori, we computed a weighted mean, weighted error and the weighted standard deviation. For each spectrum, these values were calculated using the same expressions provided in Equations 1 - 3 for the temperature results in Section 5.2.3. For $\mathrm{C}_{2} \mathrm{H}_{2}$, a mean concentration, error and standard deviation were calculated of the retrieved concentrations from each $a$ priori and weighted by how well the modelled spectrum fit the observed spectrum in the $710-750 \mathrm{~cm}^{-1}$ spectral range $\left(\mathrm{C}_{2} \mathrm{H}_{2}\right.$ emission). Similar calculations were computed for $\mathrm{C}_{2} \mathrm{H}_{6}$ at 4.7 mbar weighted by the quality of the fit to the 770 to $890 \mathrm{~cm}^{-1}$ spectral range $\left(\mathrm{C}_{2} \mathrm{H}_{6}\right.$ emission). Table 5 shows the resulting averaged concentrations of $\mathrm{C}_{2} \mathrm{H}_{2}$ and $\mathrm{C}_{2} \mathrm{H}_{6}$ from each of the datasets. The quoted uncertainties were the larger of 1) the error (the individual uncertainty of each retrieval weighted and combined in quadrature (Equation 2) or 2) the standard deviation of the range in concentrations retrieved (Equation 3).

Firstly, we note quantitative differences in the concentrations of $\mathrm{C}_{2} \mathrm{H}_{2}$ quoted in Table 5 and those shown in Figures 11 and 12. Concentrations presented in Figures 11 and 12 used only the nominal a priori profiles of $\mathrm{C}_{2} \mathrm{H}_{2}$ and $\mathrm{C}_{2} \mathrm{H}_{6}$ whereas those shown in Table 5 have been calculated using a weighted-mean of concentrations retrieved from a range of different a priori. As shown in Figure 15, retrievals of $\mathrm{C}_{2} \mathrm{H}_{2}$ from quiescent observations yielded the best fit to the $710-750 \mathrm{~cm}^{-1}$ spectral range $\left(\mathrm{C}_{2} \mathrm{H}_{2}\right.$ emission) when $\mathrm{C}_{2} \mathrm{H}_{2}$-depleted a priori were used. Thus, a weighted mean of concentrations retrieved from several different a priori, where each result was weighted by the reduced $\chi^{2}$ to the spectra, resulted in a lower concentration. 

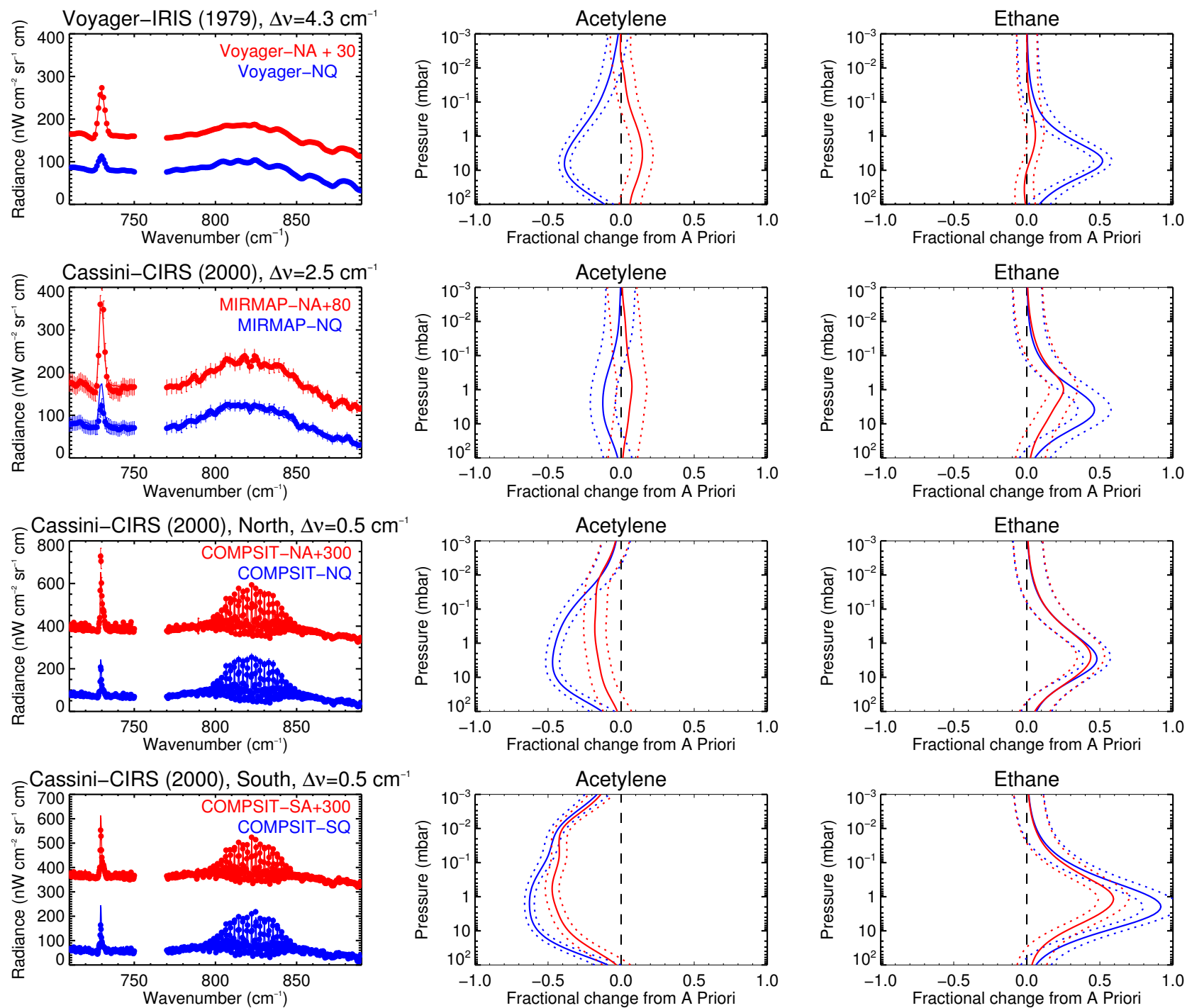

Figure 14: Results of $\mathrm{C}_{2} \mathrm{H}_{2}$ and $\mathrm{C}_{2} \mathrm{H}_{6}$ retrievals from Voyager-IRIS spectra (top row), Cassini-CIRS $\Delta \tilde{v}=2.5 \mathrm{~cm}^{-1}$ spectra (2nd row, shown here for comparison), CIRS-COMPSIT in the north (3rd row) and in the south (bottom row). The left-hand column shows observed-model comparisons of spectra with blue representing quiescent regions and red representing auroral regions with an offset in radiance added for clarity. The middle and right-hand columns respectively show the $\mathrm{C}_{2} \mathrm{H}_{2}$ and $\mathrm{C}_{2} \mathrm{H}_{6}$ results. These are shown as the fractional change of the retrieved vertical profile (coloured, solid) from the a priori profile (vertical black dashed line) in order to better highlight differences. Dotted lines show the corresponding 1- $\sigma$ uncertainties. These retrievals were computed using the nominal temperature profile and the nominal vertical profiles of $\mathrm{C}_{2} \mathrm{H}_{2}$ and $\mathrm{C}_{2} \mathrm{H}_{6}$.

The same analysis was performed for retrievals of $\mathrm{C}_{2} \mathrm{H}_{2}$ on auroral regions and although concentrations do change, the comparison of quiescent and auroral concentrations continue to indicate that concentrations of $\mathrm{C}_{2} \mathrm{H}_{2}$ derived in auroral regions are higher than those derived in quiescent regions. $\mathrm{C}_{2} \mathrm{H}_{2}$ is enriched by $239.1 \pm 89.5 \mathrm{ppbv}$ from the Voyager results, 175.3 \pm 89.3 ppbv from the CIRS-MIRMAP results, $118.8 \pm 42.4$ ppbv in the CIRS-COMPSIT results of the north and $49.6 \pm$ $23.6 \mathrm{ppbv}$ in the CIRS-COMPSIT results of the south. Thus, all derived contrasts in $\mathrm{C}_{2} \mathrm{H}_{2}$ between auroral and quiescent regions are significant with respect to the $1-\sigma$ uncertainty. In contrast, derived concentrations of $\mathrm{C}_{2} \mathrm{H}_{6}$ exhibit a decrease in auroral regions with respect to quiescent regions. $\mathrm{C}_{2} \mathrm{H}_{6}$ is depleted by $1.6 \pm 0.6$ ppmv in the Voyager results, 0.86 \pm 0.59 ppmv in the CIRS-MIRMAP results, $0.08 \pm 0.35$ ppmv in the CIRS-COMPSIT results of the north and $1.03 \pm$ 0.43 ppmv using CIRS-COMPSIT observations in the south. Thus, the contrast in $\mathrm{C}_{2} \mathrm{H}_{6}$ derived from the CIRS-COMPSIT observations in the north are not significant with respect to uncertainty.

The magnitude of changes in $\mathrm{C}_{2} \mathrm{H}_{2}$ and $\mathrm{C}_{2} \mathrm{H}_{6}$ between auroral and quiescent regions varies with each dataset. As discussed in Section 5.3.2, we believe the much larger change in concentration derived from the Voyager results can be explained by IRIS's lower spectral resolution, which hinders the retrieval of the auroral thermal structure (Section 5.2.2). This 

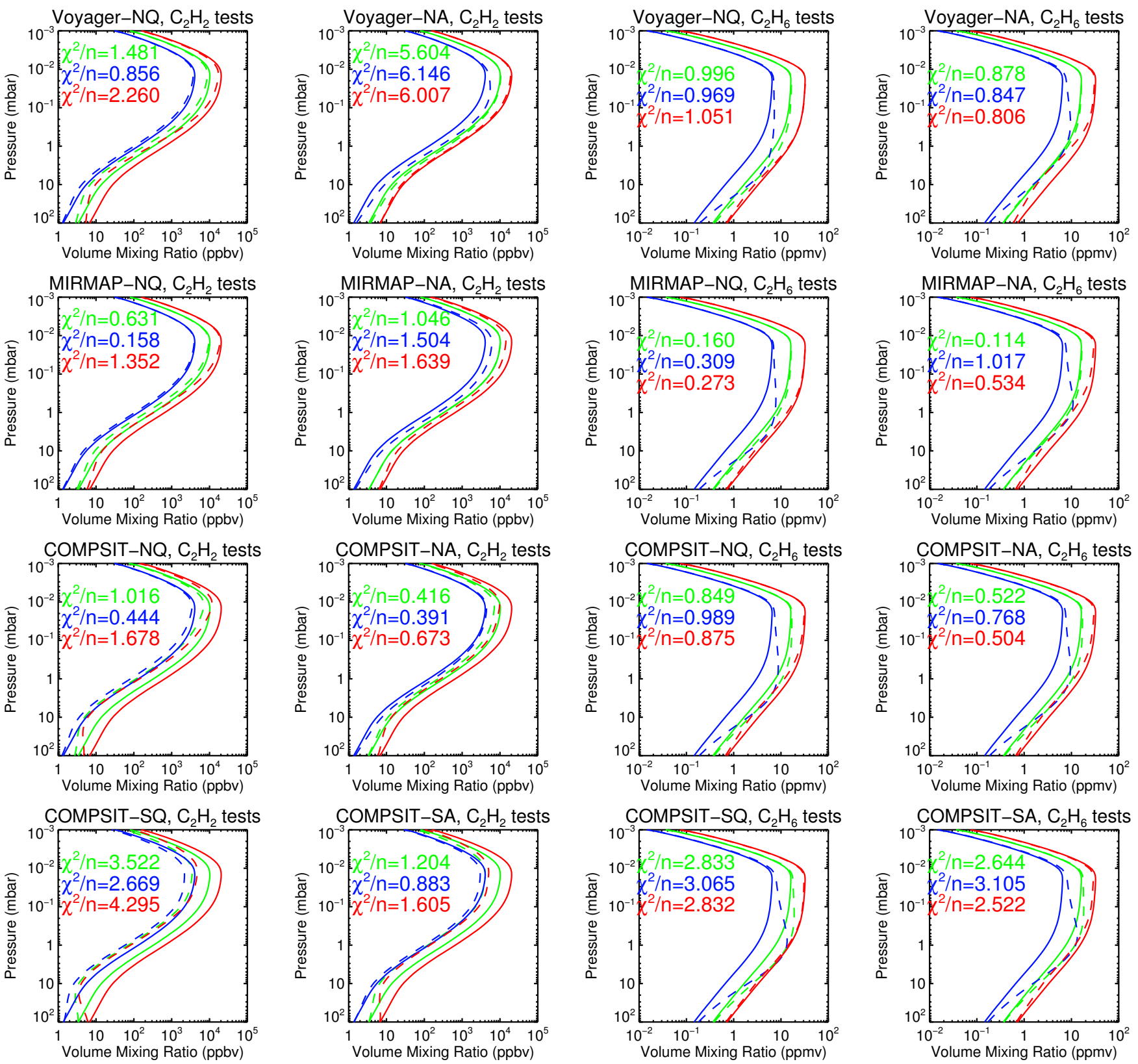

Figure 15: Results of retrievals of $\mathrm{C}_{2} \mathrm{H}_{2}$ (1st and 2nd column) and $\mathrm{C}_{2} \mathrm{H}_{6}$ (3rd and 4th column) starting from different a priori profiles. The 1st row shows the results for the Voyager observations, the 2nd row for Cassini-CIRS $\Delta \tilde{v}=2.5 \mathrm{~cm}^{-1}$ observations, the 3rd row for Cassini-CIRS $\Delta \tilde{v}=0.5 \mathrm{~cm}^{-1}$ in the north and the 4th row for Cassini-CIRS $\Delta \tilde{v}=0.5 \mathrm{~cm}^{-1}$ observations in the south. Solid, coloured profiles indicate the $a$ priori while dashed lines of the same colour show the corresponding retrieved results. The reduced $\chi^{2}$ values of each retrievals are also shown in each panel.

in turn affects the retrieval of the hydrocarbon concentrations. We believe differences between the CIRS-MIRMAP and CIRS-COMPSIT results, both of high-northern latitudes, can be explained by differences in spatial sampling, as discussed previously. From Appendix A, we also note that potential errors in the previous temperature retrieval can induce artefacts in any subsequent $\mathrm{C}_{2} \mathrm{H}_{2}$ and $\mathrm{C}_{2} \mathrm{H}_{6}$ retrievals. In particular at lower spectral resolutions, underestimated temperatures at the 10 - $\mu$ bar level resulted in overestimated temperatures in the 10to 0.1-mbar pressure range, which in turn lead to overestimated
$\mathrm{C}_{2} \mathrm{H}_{2}$ abundances and underestimated $\mathrm{C}_{2} \mathrm{H}_{6}$ abundances at the $\sim 1$-mbar level. However, these artefacts in the $\mathrm{C}_{2} \mathrm{H}_{2}$ and $\mathrm{C}_{2} \mathrm{H}_{6}$ retrievals of synthetic observations were highlighted and reduced by performing retrievals of temperature from different a priori. 


\section{Discussion \& Summary}

\subsection{Temperatures}

There is clear evidence of enhanced stratospheric temperatures in both the northern and southern auroral regions in comparison to quiescent regions (Figures 6,7 and 8). Retrieval of the vertical temperature profile from our nominal temperature $a$ priori (the temperature-pressure profile from Galileo's descent) indicated two discrete pressure regions of heating centred at approximately 1-mbar and 10- $\mu$ bar. Test retrievals of temperature from synthetic spectra (Appendix A.1) and the temperature retrievals of real observations where alternative temperature a priori were adopted do indicate that temperatures are indeed high at the 10- $\mu$ bar level. However, the subsequent cooling of temperatures at pressures lower than 10- $\mu$ bar, which gives the impression the temperatures are maximum at $10-\mu \mathrm{bar}$, is an artefact of the retrieval tending back to the a priori's cooler temperatures at higher altitudes. The temperature maximum at the 1-mbar level and the temperature minimum at $0.1 \mathrm{mbar}$ however appear robust regardless of the temperature a priori that was used. We also observe similar results in temperature retrievals of TEXES spectra, which will be presented in part II of this paper. We conclude that heating at pressures of $10-\mu$ bar and lower likely result from the interaction of precipitating electrons with atmospheric molecules, Joule heating, ion drag, energy released from exothermic ion-chemistry reactions and heat conducted from higher thermospheric altitudes (Yelle and Miller, 2004; Bougher et al., 2005). However, listed below are the possible mechanisms that readers are likely to form of heating at the 1-mbar level.

- Conduction of Joule-heating from lower pressures to the 1-mbar level.

- Precipitation of a high-energy population of charged particles at the 1-mbar level.

- Adiabatic heating produced by auroral-driven downwelling.

- Auroral-produced haze/aerosols at the 1-mbar level that are heated by short-wave radiation.

The first explanation, the conduction of joule-heating from higher altitudes, we consider unlikely due to the presence of the temperature minima at $\sim 0.1$ mbar in the vertical temperature profile retrieved in auroral regions. If the heating was driven by conduction or by other means from higher altitudes, this would be expected to induce a continuous modification of temperature with height, with the largest effect (greater heating) at lower pressures. The presence of a temperature minimum at 0.1 mbar, intermediate of the heating seen at 1-mbar and 10 - $\mu$ bar level, implies the heating at the former pressure is physically-separated and thus driven by a slightly different mechanism than the heating at the latter level.

Electrons and heavy ions precipitate in the jovian ionosphere providing the warm thermosphere temperatures at pressures lower than $1 \mu$ bar. Our second suggestion of the 1-mbar heating is a higher-energy population of charged particles that are able to precipitate deeper into the atmosphere. We note from Gérard et al. (2014) that $500 \mathrm{keV}$ represents the upper limit of auroral electron energies detected in HST-STIS observations and such electrons only precipitate as deep as the 0.1-mbar level. Thus, high-energy electrons seems less plausible as the source of 1-mbar heating. A further possibility is the precipitation of low-energy galactic cosmic rays (LGCRs). The magnetic fields of planets shield their lower-latitudes from LGCRs (e.g. Singh et al. (2011)). Thus, the effects of LGCRs may only be present at the magnetic poles where field lines intersect the atmosphere. Singh et al. (2011) show the ionisation density profiles for cosmic rays on Earth to peak in the lower stratosphere. However, a similar calculation would be required to test the viability of a similar source of energy in Jupiter's atmosphere.

The third explanation of auroral-driven downwelling and the resulting adiabatic heating could explain the high temperatures at the 1-mbar level. In addition, downwelling and the resulting advection of hydrocarbon-enriched air from higher altitudes would also explain the enhanced concentration of $\mathrm{C}_{2} \mathrm{H}_{2}$ in auroral regions. Downwelling would also advect $\mathrm{C}_{2} \mathrm{H}_{6}$-enriched air from higher in the stratosphere however, the resulting enhancement of $\mathrm{C}_{2} \mathrm{H}_{6}$ would be expected to be less than for $\mathrm{C}_{2} \mathrm{H}_{2}$ since the latter has a much higher vertical gradient in concentration (Moses et al., 2005). As discussed in Section 6.2, the higher rates of ion-neutral reactions in auroral regions would also preferentially increase concentrations of $\mathrm{C}_{2} \mathrm{H}_{2}$ compared to $\mathrm{C}_{2} \mathrm{H}_{6}$ at lower pressures, which would further increase $\mathrm{C}_{2} \mathrm{H}_{2}$ 's vertical gradient with respect to $\mathrm{C}_{2} \mathrm{H}_{6}$. If downwelling driven by the aurora and the resulting adiabatic heating is responsible for high temperatures at the 1-mbar level, the lack of similar, warm temperatures at the 0.1-mbar level would suggest the vertical advection is confined to pressures higher than the 0.1-mbar level.

Our third suggestion for the presence of heating at the 1 -mbar level is the presence of a layer of aurorally-produced complex hydrocarbon haze particles, which are heated by absorption of short-wave radiation. In the vertical profiles of polycyclic aromatic hydrocarbons (PAHs) and aerosols predicted by ion-neutral chemistry models (Wong et al., 2003), the peak in concentrations do occur at approximately the 1-mbar level, which is coincident in altitude with the maximum in temperature in this work. In addition, West et al. (2003) observed a UV-dark haze coincident with Jupiter's northern auroral region from Cassini ultraviolet data during the same flyby, which was attributed to a haze of hydrocarbon-rich particles formed by the auroral-related chemistry. We also note that UV-bright stratospheric aerosols have previously been observed at Jupiter's high-latitudes but at deeper pressures from approximately 20 to 10 mbar (Banfield et al., 1998; Rages et al., 1999; Zhang et al., 2013; Zhang et al., 2015). In particular, Zhang et al. (2013) and Zhang et al. (2015) describe these stratospheric aerosols as fluffy, fractal aggregates with an auroral hydrocarbon chemistry origin, whose heating effect is largest in the 20- to 10-mbar range (in a zonally-averaged sense). In order to reconcile these stratospheric aerosols 
observed in previous studies at deeper pressures with those inferred to be at the 1-mbar level in this work, we suggest the following. Auroral chemistry in the upper stratosphere continuously produces aerosols, which fall to lower altitudes by gravity. At auroral longitudes where aerosols are produced by the ion-neutral chemistry, their concentration and therefore heating effect is larger at lower pressures, yielding the temperature maximum at the 1 mbar level observed in this work. Upon further vertical transport to higher pressures and horizontal advection, such aerosols are then observed at deeper pressures over a large range of longitudes and therefore, in a zonal-average, their heating effect is observed to be larger at deeper pressures.

\section{2. $C_{2}$ hydrocarbons}

Retrievals of $\mathrm{C}_{2} \mathrm{H}_{2}$ from all datasets analysed indicate an enrichment in auroral regions with respect to quiescent regions (Section 5.3 and 5.3.3). With exception of the CIRS-COMPSIT observations of high-northern latitudes, we find that $\mathrm{C}_{2} \mathrm{H}_{6}$ is depleted in auroral regions with respect to quiescent regions. We believe this result is not exhibited in the CIRS-COMPSIT observations because these observations were averaged over large spatial regions.

Before presenting our conclusions of this observed hydrocarbon behaviour in the lower stratosphere $(10-0.1 \mathrm{mbar})$, we first discuss how we believe the upper stratospheric chemistry $(0.1$ mbar to $1 \mu \mathrm{bar}$ ) is modified in auroral regions. The external source of ions and electrons into the upper atmosphere in auroral regions greatly increases the importance of ion-neutral and electron recombination reactions with respect to quiescent regions where such a source is not present. As shown in De La Haye et al. (2008), the production rates of neutral species in Titan's upper atmosphere/ionosphere are significantly elevated as a result of ion-neutral and electron recombination reactions. Qualitatively, we believe a similar conclusion applies to the upper atmospheric chemistry in the Jovian auroral regions, although the fact that molecular diffusion limits the vertical extent of $\mathrm{CH}_{4}$ and other hydrocarbons near the homopause region makes this ion-chemistry source of neutrals less effective on Jupiter than on Titan. Several investigators have modeled ion chemistry in the auroral regions of Jupiter (e.g., Perry et al. 1999; Wong et al. 2003; Tao et al. 2011). However, Perry et al. (1999) and Tao et al. (2011) keep the neutrals fixed in their model and do not consider how ion chemistry affects the neutral abundances. Wong et al. (2003) fully couple the ion and neutral chemistry, but their focus is on benzene chemistry, and they do not discuss the dominant reactions affecting the neutral $\mathrm{C}_{2}$ species. We therefore look to coupled ion-neutral photochemical models of Titan for examples of how ion chemistry can influence the neutral hydrocarbon abundances (e.g., Wilson and Atreya 2004; Vuitton et al. 2008; Krasnopolsky 2009; Lavvas et al. 2011; Mandt et al. 2012), with the detailed De La Haye et al. (2008) model results and discussion being particularly useful in this regard. Based on the De La Haye et al. (2008) investigation, we expect that ion chemistry on Jupiter leads to increased production of both unsaturated $\left(\mathrm{C}_{2} \mathrm{H}_{2}, \mathrm{C}_{2} \mathrm{H}_{4}\right)$ and saturated $\left(\mathrm{C}_{2} \mathrm{H}_{6}\right)$ hydrocarbons, but the former by a greater magnitude than the latter.

As on Titan, we expect the dominant ion-chemistry pathways for the production of $\mathrm{C}_{2}$ hydrocarbons in the auroral regions Jupiter to involve the $\mathrm{C}_{2} \mathrm{H}_{5}^{+}$ion, which is produced as detailed in reactions 4-6 below.

$$
\begin{aligned}
\mathrm{H}_{2}+\mathrm{e}^{-} & \longrightarrow \mathrm{H}^{+}+\mathrm{H}+2 \mathrm{e}^{-} \\
\mathrm{H}^{+}+\mathrm{CH}_{4} & \longrightarrow \mathrm{CH}_{3}^{+}+\mathrm{H}_{2} \\
\mathrm{CH}_{3}^{+}+\mathrm{CH}_{4} & \longrightarrow \mathrm{C}_{2} \mathrm{H}_{5}^{+}+\mathrm{H}_{2}
\end{aligned}
$$

with $\mathrm{e}^{-}$representing an electron (primary auroral or secondary from the interaction of the precipitating particles with atmospheric constituents). Once $\mathrm{C}_{2} \mathrm{H}_{5}^{+}$is produced, dissociative recombination of $\mathrm{C}_{2} \mathrm{H}_{5}^{+}$with electrons can then lead to the formation of unsaturated $\mathrm{C}_{2}$ hydrocarbons, as exemplified below in reactions 7-9.

$$
\begin{aligned}
& \mathrm{C}_{2} \mathrm{H}_{5}^{+}+\mathrm{e}^{-} \longrightarrow \mathrm{C}_{2} \mathrm{H}_{2}+\mathrm{H}_{2}+\mathrm{H} \\
& \mathrm{C}_{2} \mathrm{H}_{5}^{+}+\mathrm{e}^{-} \longrightarrow \mathrm{C}_{2} \mathrm{H}_{2}+3 \mathrm{H} \\
& \mathrm{C}_{2} \mathrm{H}_{5}^{+}+\mathrm{e}^{-} \longrightarrow \mathrm{C}_{2} \mathrm{H}_{4}+\mathrm{H}
\end{aligned}
$$

Ion chemistry can also result in the production of $\mathrm{C}_{2} \mathrm{H}_{6}$ through ion-neutral charge-exchange reactions such as

$$
\begin{aligned}
\mathrm{C}_{2} \mathrm{H}_{5}^{+}+\mathrm{C}_{3} \mathrm{H}_{8} & \longrightarrow \mathrm{C}_{2} \mathrm{H}_{6}+\mathrm{C}_{3} \mathrm{H}_{7}^{+} \\
\mathrm{H}_{3}^{+}+\mathrm{C}_{4} \mathrm{H}_{10} & \longrightarrow \mathrm{C}_{2} \mathrm{H}_{5}^{+}+\mathrm{C}_{2} \mathrm{H}_{6}+\mathrm{H}_{2}
\end{aligned}
$$

De La Haye et al. (2008) suggest that dissociative recombination of $\mathrm{C}_{3} \mathrm{H}_{7}^{+}$ions will provide another important high-altitude source of $\mathrm{C}_{2} \mathrm{H}_{6}$ on Titan (and by analogy Jupiter); however, Larsson et al. (2005) have found that the ethane formation pathway from $\mathrm{C}_{3} \mathrm{H}_{7}^{+}$electron recombination (i.e., $\mathrm{C}_{3} \mathrm{H}_{7}^{+}+\mathrm{e}^{-} \longrightarrow \mathrm{C}_{2} \mathrm{H}_{6}+\mathrm{CH}$ ) is negligible, such that the ion-neutral reactions 10 and 11 would be more effective.

Although all of the above reactions are fast, the rate coefficient for electron recombination of $\mathrm{C}_{2} \mathrm{H}_{5}^{+}$in reaction pathways 7 , 8 and 9 is more than two orders of magnitude greater than the rate coefficient for reactions 10 or 11 (e.g., Aninich 2003; Florescu-Mitchell and Mitchell 2006). The electron densities in the hydrocarbon region in the Perry et al. (1999) and Tao et al. (2011) Jovian auroral models are of order $100 \mathrm{~cm}^{-3}$, which is about the same as the predicted $\mathrm{C}_{3} \mathrm{H}_{8}$ density from neutral photochemistry (Moses et al., 2005). Adopting these numbers in the production rate equations for the above reactions suggests that reactions 7-9 are, in combination, more than two orders of magnitude more effective in producing $\mathrm{C}_{2} \mathrm{H}_{2}$ and $\mathrm{C}_{2} \mathrm{H}_{4}$ than reaction 10 is in producing $\mathrm{C}_{2} \mathrm{H}_{6}$. The $\mathrm{C}_{4} \mathrm{H}_{10}$ density is even smaller where $\mathrm{H}_{3}^{+}$has its peak (again of the order $100 \mathrm{~cm}^{-3}$ ) above the methane homopause, so reaction 11 cannot compete with reactions 7-9, either, and we expect auroral ion chemistry to produce more $\mathrm{C}_{2} \mathrm{H}_{2}$ and $\mathrm{C}_{2} \mathrm{H}_{4}$ than $\mathrm{C}_{2} \mathrm{H}_{6}$. This prediction appears consistent with the De La Haye et al. (2008) model for Titan that shows peak production rates for $\mathrm{C}_{2} \mathrm{H}_{2}$ and $\mathrm{C}_{2} \mathrm{H}_{4}$ from ion-chemistry pathways that are more than 2 orders of magnitude larger than those for $\mathrm{C}_{2} \mathrm{H}_{6}$ (see Figures 6, 10, 11 
in De La Haye et al. (2008)).

Thus, auroral ion chemistry is expected to result in enhanced production of all the neutral $\mathrm{C}_{2}$ hydrocarbons at high altitudes, but especially unsaturated hydrocarbons, thereby increasing the vertical gradient of $\mathrm{C}_{2} \mathrm{H}_{2}$ and $\mathrm{C}_{2} \mathrm{H}_{4}$ by a greater magnitude with respect to $\mathrm{C}_{2} \mathrm{H}_{6}$. Vertical diffusion and/or advection would transport this hydrocarbon-richer air to the lower stratosphere. We note in Section 6.1 that downwelling at pressures higher than 0.1 mbar and the resulting adiabatic heating is one possible explanation of the high 1-mbar temperatures in the auroral region. Given $\mathrm{C}_{2} \mathrm{H}_{2}$ exhibits a stronger vertical gradients than $\mathrm{C}_{2} \mathrm{H}_{6}$, especially in auroral regions due to the ion-neutral chemistry as noted above, such vertical transport (by diffusion and/or advection) would enrich $\mathrm{C}_{2} \mathrm{H}_{2}$ to a greater extent than $\mathrm{C}_{2} \mathrm{H}_{6}$. Horizontal winds would also carry the aurorally-produced species to other longitude and latitude regions. We suggest such horizontal transport and subsequent neutral chemistry as a possible explanation of the apparent depletion of $\mathrm{C}_{2} \mathrm{H}_{6}$ in the auroral region compared with the surrounding regions. Auroral chemistry continually supplies excess $\mathrm{C}_{2} \mathrm{H}_{2}$ but once advected out of the region of auroral influence, typical neutral photochemistry processes such as sequential $\mathrm{H}$-atom addition (e.g., Moses et al. 2000, 2005) convert $\mathrm{C}_{2} \mathrm{H}_{2}$ and $\mathrm{C}_{2} \mathrm{H}_{4}$ into $\mathrm{C}_{2} \mathrm{H}_{6}$. The enrichment of $\mathrm{C}_{2} \mathrm{H}_{6}$ outside the auroral region by this process therefore gives the impression it is depleted inside the auroral region. This working explanation would explain the anti-correlation of $\mathrm{C}_{2} \mathrm{H}_{2}$ and $\mathrm{C}_{2} \mathrm{H}_{6}$ with longitude at $70^{\circ} \mathrm{N}$ (where high concentrations of one species are coincident in position with low concentrations of the other as in Figures 11, 12 and 13).

This hypothesis requires that the longitudinal transport timescales at $\sim 1$ mbar are comparable or longer than the photochemical lifetimes of $\mathrm{C}_{2} \mathrm{H}_{2}$ and $\mathrm{C}_{2} \mathrm{H}_{4}$. Adopting the 1-mbar reaction rate of the $\mathrm{C}_{2} \mathrm{H}_{2}+\mathrm{H}+\mathrm{M} \rightarrow \mathrm{C}_{2} \mathrm{H}_{3}+\mathrm{M}$ exchange reaction from Moses et al. (2005), which we believe to be the dominant reaction removing $\mathrm{C}_{2} \mathrm{H}_{2}$ at high latitudes, together with the retrieved abundances of $\mathrm{C}_{2} \mathrm{H}_{2}$ in quiescent regions (Figure 12), we calculate a lifetime of approximately 2 Earth-years or 0.16 Jupiter-years. Although we did not perform retrievals of $\mathrm{C}_{2} \mathrm{H}_{4}$ in this work, we performed a similar calculation of the lifetime of $\mathrm{C}_{2} \mathrm{H}_{4}$ at $1 \mathrm{mbar}$. Adopting the reaction rate of the $\mathrm{C}_{2} \mathrm{H}_{4}+\mathrm{H}+\mathrm{M} \rightarrow \mathrm{C}_{2} \mathrm{H}_{5}+\mathrm{M}$ reaction at 1 mbar together with the predicted abundances of $\mathrm{C}_{2} \mathrm{H}_{4}$ at this level from Moses et al. (2005), we derived a lifetime of approximately 0.26 Earth-years or 0.02 Jupiter-years. However, we believe these derived timescales of $\mathrm{C}_{2} \mathrm{H}_{2}$ and $\mathrm{C}_{2} \mathrm{H}_{4}$ are very much upper limits at high-latitudes since the reaction rates adopted in their calculation have assumed low-to-mid latitude abundances of atomic hydrogen, H, whereas Jupiter's polar regions have considerably larger abundances of atomic hydrogen due to the auroral input. In taking this into account, horizontal transport at these high-latitudes on timescales less than 0.16 Jupiter-years is plausible. However, $\mathrm{C}_{2} \mathrm{H}_{6}$ has a comparably much longer lifetime of greater than 100 Earth-years and therefore would be expected to be eventually mixed at all longitudes, yet this is not observed. A coupled dynamical-chemical model of Jupiter's high latitudes, which includes the auroral-chemistry effects, would be invaluable in interpreting these results. Such models are currently in development for both Jupiter and Saturn.

\section{Conclusions}

Retrievals of the vertical temperature profile from spectra covering auroral regions on Jupiter indicate hot temperatures at pressures lower than $10-\mu$ bar and a temperature maxima at the 1-mbar level. The former heating is likely a result of interaction of precipitating electrons with atmospheric molecules, Joule heating, ion drag, energy released from exothermic ion-chemistry reactions, heat conducted from higher thermospheric altitudes. However, we suggest the latter heating is either a result of aurorally-produced haze particles that are heated by short-wave sunlight and/or adiabatic heating induced by downwelling. The former suggestion would be consistent with the results of auroral-chemistry models (Wong et al., 2000, 2003), which predict maximums in the concentrations of polycyclic aromatic hydrocarbons and aerosols at the 1-mbar level. In retrievals of $\mathrm{C}_{2} \mathrm{H}_{2}$ and $\mathrm{C}_{2} \mathrm{H}_{6}$, we found the former to be enriched while the latter was found to be depleted in auroral regions in comparison to quiescent regions. Our suggested mechanism for this behaviour is that ion-neutral chemistry in the auroral region favours production of unsaturated $\mathrm{C}_{2}$ hydrocarbons $\left(\mathrm{C}_{2} \mathrm{H}_{2}\right.$, $\left.\mathrm{C}_{2} \mathrm{H}_{4}\right)$ with respect to saturated hydrocarbons $\left(\mathrm{C}_{2} \mathrm{H}_{6}\right)$ in the auroral region. Following vertical and horizontal advection outside the auroral region, $\mathrm{C}_{2} \mathrm{H}_{2}$ is converted into $\mathrm{C}_{2} \mathrm{H}_{6}$ by neutral photochemistry, thereby giving the impression $\mathrm{C}_{2} \mathrm{H}_{2}$ is enhanced but $\mathrm{C}_{2} \mathrm{H}_{6}$ is depleted in the auroral region. The interpretation of these results strongly advocate for the development of coupled dynamical and chemical models, which include ion chemistry.

\section{Acknowledgements}

Many thanks to the NASA Postdoctoral Program (managed by Oak Ridge Associated Universities and then Universities Space Research Administration) for funding Sinclair during this research. Orton was supported by grants from NASA to the Jet Propulsion Laboratory, California Institute of Techology. Fletcher was supported by a Royal Society Fellowship at the University of Leicester. We also thank the Cassini-CIRS team for updating the calibration of CIRS data from the Jupiter flyby. The UK authors thank the Science and Technology Facilities Council (SFTC) for their support.

\section{References}

V. G et al. Aninich. An index of the literature for bimolecular gas phase cation-molecule reaction kinetics. JPL Publications, 03(19), 2003. URL http://trs-new.jpl.nasa.gov/dspace/bitstream/ 2014/7981/1/03-2964.pdf. 
D. Banfield, B. J. Conrath, P. J. Gierasch, P. D. Nicholson, and K. Matthews. Near-IR Spectrophotometry of Jovian Aerosols's Meridional and Vertical Distributions. Icarus, 134:11-23, July 1998. doi: 10.1006/icar.1998.5942.

R. Baron, R. D. Joseph, T. Owen, J. Tennyson, S. Miller, and G. E. Ballester. Imaging Jupiter's aurorae from $\mathrm{H} 3(+)$ emissions in the 3-4 micron band. Nature, 353:539-542, October 1991. doi: 10.1038/353539a0.

B. Bonfond, D. Grodent, J.-C. Gérard, T. Stallard, J. T. Clarke, M. Yoneda, A. Radioti, and J. Gustin. Auroral evidence of Io's control over the magnetosphere of Jupiter. Geophysical Research Letters, 39:L01105, January 2012. doi: 10.1029/2011GL050253.

S. W. Bougher, J. H. Waite, T. Majeed, and G. R. Gladstone. Jupiter Thermospheric General Circulation Model (JTGCM): Global structure and dynamics driven by auroral and Joule heating. Journal of Geophysical Research (Planets), 110:E04008, April 2005. doi: 10.1029/2003JE002230.

G. Branduardi-Raymont, A. Bhardwaj, R. F. Elsner, G. R. Gladstone, G. Ramsay, P. Rodriguez, R. Soria, J. H. Waite, Jr., and T. E. Cravens. A study of Jupiter's aurorae with XMM-Newton. Astronomy $\mathcal{E}$ Asrtrophysics, 463:761-774, February 2007. doi: 10.1051/0004-6361:20066406.

J. Caldwell, F. C. Gillett, and A. T. Tokunaga. Possible infrared aurorae on Jupiter. Icarus, 44:667-675, December 1980. doi: 10.1016/0019-1035(80) 90135-9.

J. Caldwell, A. T. Tokunaga, and G. S. Orton. Further observations of 8-micron polar brightenings of Jupiter. Icarus, 53:133-140, January 1983. doi: 10. 1016/0019-1035(83)90026-X.

B. E. Carlson. Jupiter's Polar Haze. In AAS/Division for Planetary Sciences Meeting Abstracts \#29, volume 29 of Bulletin of the American Astronomical Society, page 1018, July 1997.

J. T. Clarke, J. Ajello, G. Ballester, L. Ben Jaffel, J. Connerney, J.-C. Gérard, G. R. Gladstone, D. Grodent, W. Pryor, J. Trauger, and J. H. Waite. Ultraviolet emissions from the magnetic footprints of Io, Ganymede and Europa on Jupiter. Nature, 415:997-1000, February 2002.

V. De La Haye, J. H. Waite, T. E. Cravens, I. P. Robertson, and S. Lebonnois. Coupled ion and neutral rotating model of Titan's upper atmosphere. Icarus, 197:110-136, September 2008. doi: 10.1016/j.icarus.2008.03.022.

F M Flasar, V G Kunde, M M Abbas, R K Achterberg, P Ade, A Barucci, B Bézard, G L Bjoraker, J C Brasunas, and S Calcutt. Exploring the saturn system in the thermal infrared: The composite infrared spectrometer. Space Science Reviews, 115(1-4):169-297, 2004.

F. M. Flasar, V. G. Kunde, R. K. Achterberg, B. J. Conrath, A. A. Simon-Miller, C. A. Nixon, P. J. Gierasch, P. N. Romani, B. Bézard, P. Irwin, G. L. Bjoraker, J. C. Brasunas, D. E. Jennings, J. C. Pearl, M. D. Smith, G. S. Orton, L. J. Spilker, R. Carlson, S. B. Calcutt, P. L. Read, F. W. Taylor, P. Parrish, A. Barucci, R. Courtin, A. Coustenis, D. Gautier, E. Lellouch, A. Marten, R. Prangé, Y. Biraud, T. Fouchet, C. Ferrari, T. C. Owen, M. M. Abbas, R. E. Samuelson, F. Raulin, P. Ade, C. J. Césarsky, K. U. Grossman, and A. Coradini. An intense stratospheric jet on Jupiter. Nature, 427 132-135, January 2004

L. N. Fletcher, G. S. Orton, N. A. Teanby, and P. G. J. Irwin. Phosphine on Jupiter and Saturn from Cassini/CIRS. Icarus, 202:543-564, August 2009. doi: 10.1016/j.icarus.2009.03.023.

L. N. Fletcher, B. E. Hesman, R. K. Achterberg, P. G. J. Irwin, G. Bjoraker, N. Gorius, J. Hurley, J. Sinclair, G. S. Orton, J. Legarreta, E. García-Melendo, A. Sánchez-Lavega, P. L. Read, A. A. Simon-Miller, and F. M. Flasar. The origin and evolution of saturn's 2011-2012 stratospheric vortex. Icarus, 221:560-586, November 2012. doi: 10.1016/j. icarus.2012.08.024

L. N. Fletcher, T. K. Greathouse, G. S. Orton, P. G. J. Irwin, O. Mousis, J. A. Sinclair, and R. S. Giles. The origin of nitrogen on Jupiter and Saturn from the $15 \mathrm{~N} / 14 \mathrm{~N}$ ratio. Icarus, $238: 170-190$, August 2014. doi: 10.1016/j. icarus.2014.05.007

L. N. Fletcher, T. K. Greathouse, G. S. Orton, J. A. Sinclair, R. S. Giles, P. G. J. Irwin, and T. Encrenaz. Mid-infrared mapping of Jupiter's temperatures, aerosol opacity and chemical distributions with IRTF/TEXES. Icarus, 278: 128-161, November 2016. doi: 10.1016/j.icarus.2016.06.008.

A.I. Florescu-Mitchell and J.B.A. Mitchell. Dissociative recombination. Physics Reports, 430(5-6):277 - 374, 2006. ISSN 0370-1573. doi: http://dx.doi.org/10.1016/j.physrep.2006.04.002. URL http://www . sciencedirect.com/science/article/pii/S0370157306001463.

A. J. Friedson, A.-S. Wong, and Y. L. Yung. Models for Polar Haze Formation in Jupiter's Stratosphere. Icarus, 158:389-400, August 2002. doi: 10.1006/ icar.2002.6885.
J.-C. Gerard, V. Dols, F. Paresce, and R. Prange. Morphology and time variation of the Jovian Far UV aurora: Hubble Space Telescope observations. Journal of Geophysical Research, 98:18793, October 1993. doi: 10.1029/ 93JE01334.

J. C. Gérard, V. Dols, D. Grodent, J. H. Waite, G. R. Gladstone, and R. Prangé. Simultaneous observations of the Saturnian aurora and polar haze with the HST/FOC. Geophysical Research Letters, 22:2685-2688, 1995. doi: 10. 1029/95GL02645.

J.-C. Gérard, D. Grodent, A. Radioti, B. Bonfond, and J. T. Clarke. Hubble observations of Jupiter's north-south conjugate ultraviolet aurora. Icarus, 226:1559-1567, November 2013. doi: 10.1016/j.icarus.2013.08.017.

J.-C. Gérard, B. Bonfond, D. Grodent, A. Radioti, J. T. Clarke, G. R. Gladstone, J. H. Waite, D. Bisikalo, and V. I. Shematovich. Mapping the electron energy in Jupiter's aurora: Hubble spectral observations. Journal of Geophysical Research (Space Physics), 119:9072-9088, November 2014. doi: 10.1002/ 2014JA020514.

R. S. Giles, L. N. Fletcher, P. G. J. Irwin, H. Melin, and T. S. Stallard. Detection of $\mathrm{H}_{3}^{+}$auroral emission in Jupiter's 5-micron window. ArXiv e-prints, March 2016

G. R. Gladstone, M. Allen, and Y. L. Yung. Hydrocarbon Photochemistry in the Upper Atmosphere of Jupiter. Icarus, 119:1-52, January 1996. doi: 10.1006/icar.1996.0001.

G. R. Gladstone, J. H. Waite, D. Grodent, W. S. Lewis, F. J. Crary, R. F. Elsner, M. C. Weisskopf, T. Majeed, J.-M. Jahn, A. Bhardwaj, J. T. Clarke, D. T. Young, M. K. Dougherty, S. A. Espinosa, and T. E. Cravens. A pulsating auroral X-ray hot spot on Jupiter. Nature, 415:1000-1003, February 2002.

T. K. Greathouse, J. H. Lacy, B. Bézard, J. I. Moses, C. A. Griffith, and M. J. Richter. Meridional variations of temperature, $\mathrm{C}_{2} \mathrm{H}_{2}$ and $\mathrm{C}_{2} \mathrm{H}_{6}$ abundances in Saturn's stratosphere at southern summer solstice. Icarus, 177:18-31, September 2005. doi: 10.1016/j.icarus.2005.02.016.

D. Grodent, B. Bonfond, and J. Nichols. Observing Jupiter's polar stratospheric haze with HST/STIS. An HST White Paper. ArXiv e-prints, September 2015.

S. Guerlet, T. Fouchet, B. Bézard, A. A. Simon-Miller, and F. Michael Flasar. Vertical and meridional distribution of ethane, acetylene and propane in Saturn's stratosphere from CIRS/Cassini limb observations. Icarus, 203: 214-232, September 2009. doi: 10.1016/j.icarus.2009.04.002.

S. Guerlet, T. Fouchet, S. Vinatier, A. A. Simon, E. Dartois, and A. Spiga. Stratospheric benzene and hydrocarbon aerosols detected in Saturn's auroral regions. Astronomy $\mathcal{E}$ Astrophysics, 580:A89, August 2015. doi: 10.1051/ 0004-6361/201424745.

D. A. Gurnett, W. S. Kurth, G. B. Hospodarsky, A. M. Persoon, P. Zarka, A. Lecacheux, S. J. Bolton, M. D. Desch, W. M. Farrell, M. L. Kaiser, H.-P. Ladreiter, H. O. Rucker, P. Galopeau, P. Louarn, D. T. Young, W. R. Pryor, and M. K. Dougherty. Control of Jupiter's radio emission and aurorae by the solar wind. Nature, 415:985-987, February 2002.

R. Hanel, D. Crosby, L. Herath, D. Vanous, D. Collins, H. Creswick, C. Harris, and M. Rhodes. Infrared spectrometer for voyager. Applied Optics, 19: 1391-1400, May 1980. doi: 10.1364/AO.19.001391.

R. Hanel, B. Conrath, F. M. Flasar, V. Kunde, W. Maguire, J. C. Pearl, J. Pirraglia, R. Samuelson, L. Herath, M. Allison, D. P. Cruikshank, D. Gautier, P. J. Gierasch, L. Horn, R. Koppany, and C. Ponnamperuma. Infrared observations of the Saturnian system from Voyager 1. Science, 212 192-200, April 1981. doi: 10.1126/science.212.4491.192.

B. E. Hesman, D. E. Jennings, P. V. Sada, G. L. Bjoraker, R. K. Achterberg, A. A. Simon-Miller, C. M. Anderson, R. J. Boyle, C. A. Nixon, L. N. Fletcher, and G. H. McCabe. Saturn's latitudinal $\mathrm{C}_{2} \mathrm{H}_{2}$ and $\mathrm{C}_{2} \mathrm{H}_{6}$ abundance profiles from Cassini/CIRS and ground-based observations. Icarus, 202: 249-259, July 2009. doi: 10.1016/j.icarus.2009.02.013.

P. G. J. Irwin, P. Parrish, T. Fouchet, S. B. Calcutt, F. W. Taylor, A. A. Simon-Miller, and C. A. Nixon. Retrievals of jovian tropospheric phosphine from Cassini/CIRS. Icarus, 172:37-49, November 2004. doi: 10.1016/j. icarus.2003.09.027

P. G. J. Irwin, N. A. Teanby, R. de Kok, L. N. Fletcher, C. J. A. Howett, C. C. C. Tsang, C. F. Wilson, S. B. Calcutt, C. A. Nixon, and P. D. Parrish. The NEMESIS planetary atmosphere radiative transfer and retrieval tool. Journal of Quantitative Spectroscopy and Radiative Transfer, 109: 1136-1150, April 2008.

E. Karkoschka and M. Tomasko. Saturn's vertical and latitudinal cloud structure 19912004 from HST imaging in 30 filters. Icarus, 179:195-221, December 2005. doi: 10.1016/j.icarus.2005.05.016 
V. Kharchenko, A. Dalgarno, D. R. Schultz, and P. C. Stancil. Ion emission spectra in the Jovian X-ray aurora. Geophysical Research Letters, 33: L11105, June 2006. doi: 10.1029/2006GL026039.

S. J. Kim, J. Caldwell, A. R. Rivolo, R. Wagener, and G. S. Orton. Infrared polar brightening on Jupiter. III - Spectrometry from the Voyager 1 IRIS experiment. Icarus, 64:233-248, November 1985. doi: 10.1016/ 0019-1035(85)90088-0.

T. T. Koskinen, J. I. Moses, R. A. West, S. Guerlet, and A. Jouchoux. The detection of benzene in saturn's upper atmosphere. Geophysical Research Letters, 43(15):7895-7901, 2016. ISSN 1944-8007. doi: 10.1002/ 2016GL070000. 2016GL070000.

T. Kostiuk, P. Romani, F. Espenak, and T. A. Livengood. Temperature and abundances in the Jovian auroral stratosphere. 2: Ethylene as a probe of the microbar region. Journal of Geophysical Research, 98:18823, October 1993. doi: 10.1029/93JE01332.

V. A. Krasnopolsky. A photochemical model of Titan's atmosphere and ionosphere. Icarus, 201:226-256, May 2009. doi: 10.1016/j.icarus.2008. 12.038 .

V. G. Kunde, P. A. Ade, R. D. Barney, D. Bergman, J.-F. Bonnal, R. Borelli, D. Boyd, J. C. Brasunas, G. Brown, S. B. Calcutt, F. Carroll, R. Courtin, J. Cretolle, J. A. Crooke, M. A. Davis, S. Edberg, R. Fettig, M. Flasar, D. A. Glenar, S. Graham, J. G. Hagopian, C. F. Hakun, P. A. Hayes, L. Herath, L. Horn, D. E. Jennings, G. Karpati, C. Kellebenz, B. Lakew, J. Lindsay, J. Lohr, J. J. Lyons, R. J. Martineau, A. J. Martino, M. Matsumura, J. McCloskey, T. Melak, G. Michel, A. Morell, C. Mosier, L. Pack, M. Plants, D. Robinson, L. Rodriguez, P. Romani, W. J. Schaefer, S. Schmidt, C. Trujillo, T. Vellacott, K. Wagner, and D. Yun. Cassini infrared Fourier spectroscopic investigation. In L. Horn, editor, Society of Photo-Optical Instrumentation Engineers (SPIE) Conference Series, volume 2803 of Society of Photo-Optical Instrumentation Engineers (SPIE) Conference Series, pages 162-177, October 1996.

A. A. Lacis and V. Oinas. A description of the correlated-k distribution method for modelling nongray gaseous absorption, thermal emission, and multiple scattering in vertically inhomogeneous atmospheres. Journal of Geophysical Research, 96:9027-9064, may 1991. doi: 10.1029/90JD01945.

J. H. Lacy, M. J. Richter, T. K. Greathouse, D. T. Jaffe, and Q. Zhu. Texes: A sensitive high-resolution grating spectrograph for the mid-infrared Publications of the Astronomical Society of the Pacific, 114:153-168, February 2002. doi: 10.1086/338730.

M. Larsson, A. Ehlerding, W. D. Geppert, F. Hellberg, S. Kalhori, R. D. Thomas, N. Djuric, F. sterdahl, G. Angelova, J. Semaniak, O. Novotny, S. T. Arnold, and A. A. Viggiano. Rate constants and branching ratios for the dissociative recombination of $\mathrm{c}_{3} \mathrm{~d}_{7}^{+}$and $\mathrm{c}_{4} \mathrm{~d}_{9}^{+}$. The Journal of Chemical Physics, 122(15):156101, 2005. doi: http://dx.doi.org/10.1063/1. 1872839. URL http://scitation.aip.org/content/aip/journal/ jcp/122/15/10.1063/1.1872839.

P. Lavvas, M. Galand, R. V. Yelle, A. N. Heays, B. R. Lewis, G. R. Lewis, and A. J. Coates. Energy deposition and primary chemical products in Titan's upper atmosphere. Icarus, 213:233-251, May 2011. doi: 10.1016/j.icarus. 2011.03.001.

E. Lellouch, B. Bézard, D. F. Strobel, G. L. Bjoraker, F. M. Flasar, and P. N. Romani. On the $\mathrm{HCN}$ and $\mathrm{CO}_{2}$ abundance and distribution in Jupiter's stratosphere. Icarus, 184:478-497, October 2006. doi: 10.1016/j.icarus. 2006.05.018.

T. A. Livengood, T. Kostiuk, and F. Espenak. Temperature and abundances in the Jovian auroral stratosphere. 1: Ethane as a probe of the millibar region. Journal of Geophysical Research, 98:18813, October 1993. doi: 10.1029/ 93JE01043.

K. E. Mandt, D. A. Gell, M. Perry, J. Hunter Waite, Jr., F. A. Crary, D. Young, B. A. Magee, J. H. Westlake, T. Cravens, W. Kasprzak, G. Miller, J.-E. Wahlund, K. Ågren, N. J. T. Edberg, A. N. Heays, B. R. Lewis, S. T. Gibson, V. de la Haye, and M.-C. Liang. Ion densities and composition of Titan's upper atmosphere derived from the Cassini Ion Neutral Mass Spectrometer: Analysis methods and comparison of measured ion densities to photochemical model simulations. Journal of Geophysical Research (Planets), 117(E16):E10006, October 2012. doi: 10.1029/2012JE004139.

B. H. Mauk, J. T. Clarke, D. Grodent, J. H. Waite, C. P. Paranicas, and D. J. Williams. Transient aurora on Jupiter from injections of magnetospheric electrons. Nature, 415:1003-1005, February 2002.

A. Morioka, S. Yaegashi, H. Nozawa, H. Misawa, Y. S. Miyoshi, F. Tsuchiya, and $\mathrm{S}$. Okano. $\mathrm{H}_{3}{ }^{+}$emissions in the Jovian sub-auroral region and auroral activity. Geophysical Research Letters, 31:L16806, August 2004. doi: 10. 1029/2004GL020390.

J. I. Moses, B. Bézard, E. Lellouch, G. R. Gladstone, H. Feuchtgruber, and M. Allen. Photochemistry of Saturn's Atmosphere. I. Hydrocarbon Chemistry and Comparisons with ISO Observations. Icarus, 143:244-298, February 2000. doi: 10.1006/icar.1999.6270.

J. I. Moses, T. Fouchet, B. Bézard, G. R. Gladstone, E. Lellouch, and H. Feuchtgruber. Photochemistry and diffusion in Jupiter's stratosphere: Constraints from ISO observations and comparisons with other giant planets. Journal of Geophysical Research (Planets), 110:E08001, August 2005. doi: 10.1029/2005JE002411.

J. D. Nichols, E. J. Bunce, J. T. Clarke, S. W. H. Cowley, J.-C. Gérard, D. Grodent, and W. R. Pryor. Response of Jupiter's UV auroras to interplanetary conditions as observed by the Hubble Space Telescope during the Cassini flyby campaign. Journal of Geophysical Research (Space Physics), 112:A02203, February 2007. doi: 10.1029/2006JA012005.

H. B. Niemann, S. K. Atreya, G. R. Carignan, T. M. Donahue, J. A. Haberman, D. N. Harpold, R. E. Hartle, D. M. Hunten, W. T. Kasprzak, P. R. Mahaffy, T. C. Owen, and S. H. Way. The composition of the Jovian atmosphere as determined by the Galileo probe mass spectrometer. Journal of Geophysical Research, 103:22831-22846, September 1998. doi: 10.1029/98JE01050.

C. A. Nixon, R. K. Achterberg, B. J. Conrath, P. G. J. Irwin, N. A. Teanby, T. Fouchet, P. D. Parrish, P. N. Romani, M. Abbas, A. LeClair, D. Strobel, A. A. Simon-Miller, D. J. Jennings, F. M. Flasar, and V. G. Kunde. Meridional variations of $\mathrm{C}_{2} \mathrm{H}_{2}$ and $\mathrm{C}_{2} \mathrm{H}_{6}$ in Jupiter's atmosphere from Cassini CIRS infrared spectra. Icarus, 188:47-71, May 2007. doi: 10.1016/j.icarus.2006.11.016.

C. A. Nixon, R. K. Achterberg, B. J. Conrath, P. G. J. Irwin, N. A. Teanby, T. Fouchet, P. D. Parrish, P. N. Romani, M. Abbas, A. Leclair, D. Strobel, A. A. Simon-Miller, D. J. Jennings, F. M. Flasar, and V. G. Kunde. Meridional variations of $\mathrm{C} 2 \mathrm{H} 2$ and $\mathrm{C} 2 \mathrm{H} 6$ in jupiter's atmosphere from cassini CIRS infrared spectra. Icarus, 188:47-71, May 2007. URL http: //adsabs.harvard.edu/abs/2007Icar . 188 . . 47N.

C. A. Nixon, R. K. Achterberg, P. N. Romani, M. Allen, X. Zhang, N. A. Teanby, P. G. J. Irwin, and F. M. Flasar. Abundances of Jupiter's trace hydrocarbons from Voyager and Cassini. Planetary $\mathcal{F}$ Space Science, 58: 1667-1680, November 2010. doi: 10.1016/j.pss.2010.05.008.

J. O’Donoghue, T. S. Stallard, H. Melin, S. W. H. Cowley, S. V. Badman, L. Moore, S. Miller, C. Tao, K. H. Baines, and J. S. D. Blake. Conjugate observations of Saturn's northern and southern H3+ aurorae. Icarus, 229: 214-220, February 2014. doi: 10.1016/j.icarus.2013.11.009.

N. Ozak, D. R. Schultz, T. E. Cravens, V. Kharchenko, and Y.-W. Hui. Auroral X-ray emission at Jupiter: Depth effects. Journal of Geophysical Research (Space Physics), 115(A14):A11306, November 2010. doi: 10. 1029/2010JA015635.

J. J. Perry, Y. H. Kim, J. L. Fox, and H. S. Porter. Chemistry of the Jovian auroral ionosphere. Journal of Geophysical Research, 104:16541-16566, July 1999. doi: 10.1029/1999JE900022.

W. R. Pryor and C. W. Hord. A study of photopolarimeter system UV absorption data on Jupiter, Saturn, Uranus, and Neptune - Implications for auroral haze formation. Icarus, 91:161-172, May 1991. doi: 10.1016/ 0019-1035(91)90135-G.

K. Rages, R. Beebe, and D. Senske. Jovian Stratospheric Hazes: The High Phase Angle View from Galileo. Icarus, 139:211-226, June 1999. doi: 10.1006/icar.1999.6103.

P. N. Romani. Recent Rate Constant and Product Measurements of the Reactions $\mathrm{C}_{2} \mathrm{H}_{3}+\mathrm{H}_{2}$ and $\mathrm{C}_{2} \mathrm{H}_{3}+\mathrm{H}$ - Importance for Photochemical Modeling of Hydrocarbons on Jupiter. Icarus, 122:233-241, August 1996. doi: 10.1006/icar.1996.0122.

A. Seiff, D. B. Kirk, T. C. D. Knight, R. E. Young, J. D. Mihalov, L. A. Young, F. S. Milos, G. Schubert, R. C. Blanchard, and D. Atkinson. Thermal structure of Jupiter's atmosphere near the edge of a $5-\mu \mathrm{m}$ hot spot in the north equatorial belt. Journal of Geophysical Research, 103:22857-22890, September 1998. doi: 10.1029/98JE01766.

A. A. Simon-Miller, B. J. Conrath, P. J. Gierasch, G. S. Orton, R. K. Achterberg, F. M. Flasar, and B. M. Fisher. Jupiter's atmospheric temperatures: From Voyager IRIS to Cassini CIRS. Icarus, 180:98-112, jan 2006. doi: 10.1016/ j.icarus.2005.07.019

J. A. Sinclair, P. G. J. Irwin, L. N. Fletcher, J. I. Moses, T. K. Greathouse, A. J. Friedson, B. Hesman, J. Hurley, and C. Merlet. Seasonal variations of temperature, acetylene and ethane in Saturn's atmosphere from 2005 to 
2010, as observed by Cassini-CIRS. Icarus, 225:257-271, July 2013. doi: 10.1016/j.icarus.2013.03.011.

J. A. Sinclair, P. G. J. Irwin, L. N. Fletcher, T. Greathouse, S. Guerlet, J. Hurley, and C. Merlet. From Voyager-IRIS to Cassini-CIRS: Interannual variability in Saturn's stratosphere? Icarus, 233:281-292, May 2014.

A.K. Singh, Devendraa Siingh, and R.P. Singh. Impact of galactic cosmic rays on earth's atmosphere and human health. Atmospheric Environment, 45(23):3806 - 3818, 2011. ISSN 1352-2310. doi: http://dx.doi.org/10. 1016/j.atmosenv.2011.04.027. URL http://www. sciencedirect.com/ science/article/pii/S1352231011004055.

T. S. Stallard, A. Masters, S. Miller, H. Melin, E. J. Bunce, C. S. Arridge, N. Achilleos, M. K. Dougherty, and S. W. H. Cowley. Saturn's auroral/polar $\mathrm{H}_{3}{ }^{+}$infrared emission: The effect of solar wind compression. Journal of Geophysical Research (Space Physics), 117(A16):A12302, December 2012. doi: 10.1029/2012JA018201.

C. Tao, S. V. Badman, and M. Fujimoto. UV and IR auroral emission model for the outer planets: Jupiter and Saturn comparison. Icarus, 213:581-592, June 2011. doi: 10.1016/j.icarus.2011.04.001.

V. Vuitton, R. V. Yelle, and J. Cui. Formation and distribution of benzene on Titan. Journal of Geophysical Research (Planets), 113:E05007, May 2008. doi: 10.1029/2007JE002997.

R. A. West. Voyager 2 imaging eclipse observations of the Jovian high altitude haze. Icarus, 75:381-398, September 1988. doi: 10.1016/0019-1035(88) 90152-2.

R. A. West, D. Griswold, and C. Porco. Jupiter's Polar UV Great Dark Spot. In AAS/Division for Planetary Sciences Meeting Abstracts 35, volume 35 of Bulletin of the American Astronomical Society, page 1009, May 2003.

E. H. Wilson and S. K. Atreya. Current state of modeling the photochemistry of Titan's mutually dependent atmosphere and ionosphere. Journal of Geophysical Research (Planets), 109:E06002, June 2004. doi: 10.1029/ 2003JE002181.

A.-S. Wong, A. Y. T. Lee, Y. L. Yung, and J. M. Ajello. Jupiter: Aerosol Chemistry in the Polar Atmosphere. Astrophysical Journal Letters, 534: L215-L217, May 2000. doi: 10.1086/312675.

A.-S. Wong, Y. L. Yung, and A. J. Friedson. Benzene and Haze Formation in the Polar Atmosphere of Jupiter. Geophysical Research Letters, 30:1447, April 2003. doi: 10.1029/2002GL016661.

R. V. Yelle and S. Miller. Jupiter's thermosphere and ionosphere. In F. Bagenal, T. E. Dowling, and W. B. McKinnon, editors, Jupiter. The Planet, Satellites and Magnetosphere, pages 185-218, 2004.

X. Zhang, R.A. West, D. Banfield, and Y.L. Yung. Stratospheric aerosols on jupiter from cassini observations. Icarus, 226(1):159 - 171, 2013. doi: http://dx.doi.org/10.1016/j.icarus.2013.05.020.

X. Zhang, R. A. West, P. G. J. Irwin, C. A. Nixon, and Y. L. Yung. Aerosol influence on energy balance of the middle atmosphere of Jupiter. Nature Communications, 6:10231, December 2015. doi: 10.1038/ncomms10231.

V. Zubov, E. Rozanov, A. Shirochkov, L. Makarova, T. Egorova, A. Kiselev, Y. Ozolin, I. Karol, and W. Schmutz. Modeling of the Joule heating influence on the circulation and ozone concentration in the middle atmosphere. Journal of Atmospheric and Solar-Terrestrial Physics, 67:155-162, January 2005. doi: 10.1016/j.jastp.2004.07.024.

\section{Appendix A. Synthetic spectra and test retrievals}

\section{Appendix A.1. Test retrievals of synthetic observations}

We adopted the synthetic spectra computed using the auroral-220K temperature profile. At all spectral resolutions, random noise was added to the synthetic spectra in order to simulate an observation. For each spectral point, a random number of a gaussian distribution using $\sigma=1$, was computed and scaled by the noise on the coadded measurements of the appropriate dataset on the auroral region (Voyager-NA, MIRMAP-NA, COMPSIT-NA). Thus, these noisy synthetic spectra exhibit approximately the same signal-to-noise ratio as the true observations.
The $600-625 \mathrm{~cm}^{-1}, 640-665 \mathrm{~cm}^{-1}$ (both collision-induced absorption regions for tropospheric temperature but avoiding the emission features of $\mathrm{C}_{3} \mathrm{H}_{4}, \mathrm{C}_{4} \mathrm{H}_{2}$ and $\left.\mathrm{C}_{6} \mathrm{H}_{6}\right), 710-750$ $\mathrm{cm}^{-1}\left(\mathrm{C}_{2} \mathrm{H}_{2}\right.$ emission), $770-890 \mathrm{~cm}^{-1}\left(\mathrm{C}_{2} \mathrm{H}_{6}\right.$ emission $)$ and $1230-1380 \mathrm{~cm}^{-1}\left(\mathrm{CH}_{4}\right.$ emission) regions of the noisy synthetic spectra were then adopted as the observation and the vertical temperature profile and vertical profiles of the concentrations of $\mathrm{C}_{2} \mathrm{H}_{2}$ and $\mathrm{C}_{2} \mathrm{H}_{6}$ were retrieved. In the temperature retrieval, the goal is to retrieve the vertical temperature profile that was initially used to compute the synthetic spectra. Any differences between the initial modelled temperature profile and that retrieved will highlight limitations in the observations in characterising the auroral heating. These discrepancies in the temperature will also induce errors in the retrieval of $\mathrm{C}_{2} \mathrm{H}_{2}$ and $\mathrm{C}_{2} \mathrm{H}_{6}$ since their observed emission depends on both the temperature of the line-forming region and their concentration. Since the synthetic spectra were computed assuming the reference compositions of $\mathrm{C}_{2} \mathrm{H}_{2}$ and $\mathrm{C}_{2} \mathrm{H}_{6}$ (Section 3.2) and since these reference profiles were also adopted as the $a$ priori, any deviation of the retrieved vertical profiles of $\mathrm{C}_{2} \mathrm{H}_{2}$ or $\mathrm{C}_{2} \mathrm{H}_{6}$ from the a priori profiles directly indicates the discrepancy in their retrieved concentrations as a result of the discrepancy in the temperature retrieval. We explore the robustness of the temperature retrievals and the effect on the retrieved hydrocarbon abundances in Appendix A.1.1 and Appendix A.1.2. In addition, we also explored the robustness of the hydrocarbon retrievals in Appendix A.1.3 starting from different vertical profiles of $\mathrm{C}_{2} \mathrm{H}_{2}$ and $\mathrm{C}_{2} \mathrm{H}_{6}$ as a priori.

\section{Appendix A.1.1. Using nominal a priori}

Figure A.16 compares the observed (the synthetic spectra with random noise) and modelled spectra and the retrieved profiles of temperature, acetylene and ethane profiles. The acetylene and ethane retrievals are shown as the fractional difference from the correct profile. The CIRS-COMPSIT simulated spectra, the highest spectral resolution tested, provides the best correspondence between the modelled and retrieved temperature profile with agreement within error bars in both the $10-0.1$-mbar region and the 10- $\mu$ bar level. Only at pressures lower than $10-\mu$ bar do the retrieved and modelled vertical temperature profiles differ, which is a result of the retrieval tending back to the a priori temperature profile in an altitude range where there is no sensitivity in the spectra. Thus, when an a priori temperature profile is chosen that is cooler than the true temperatures at the $10-\mu$ bar level, the retrieved profile will indicate a temperature maximum at this pressure level when in fact the temperatures may be isothermal as they are in this case. This artefact is also observed in the retrievals of the real observations shown in Section 5.

In the lower spectral resolution datasets, the agreement between modelled and retrieved temperature profiles was poorer. In the CIRS-MIRMAP test, the correct temperatures are retrieved at the 10- $\mu$ bar level: however, there is a discrepancy of approximately $5-10 \mathrm{~K}$ in the $1-0.1$-mbar range. In the Voyager-IRIS test, the agreement is poorest of all the 

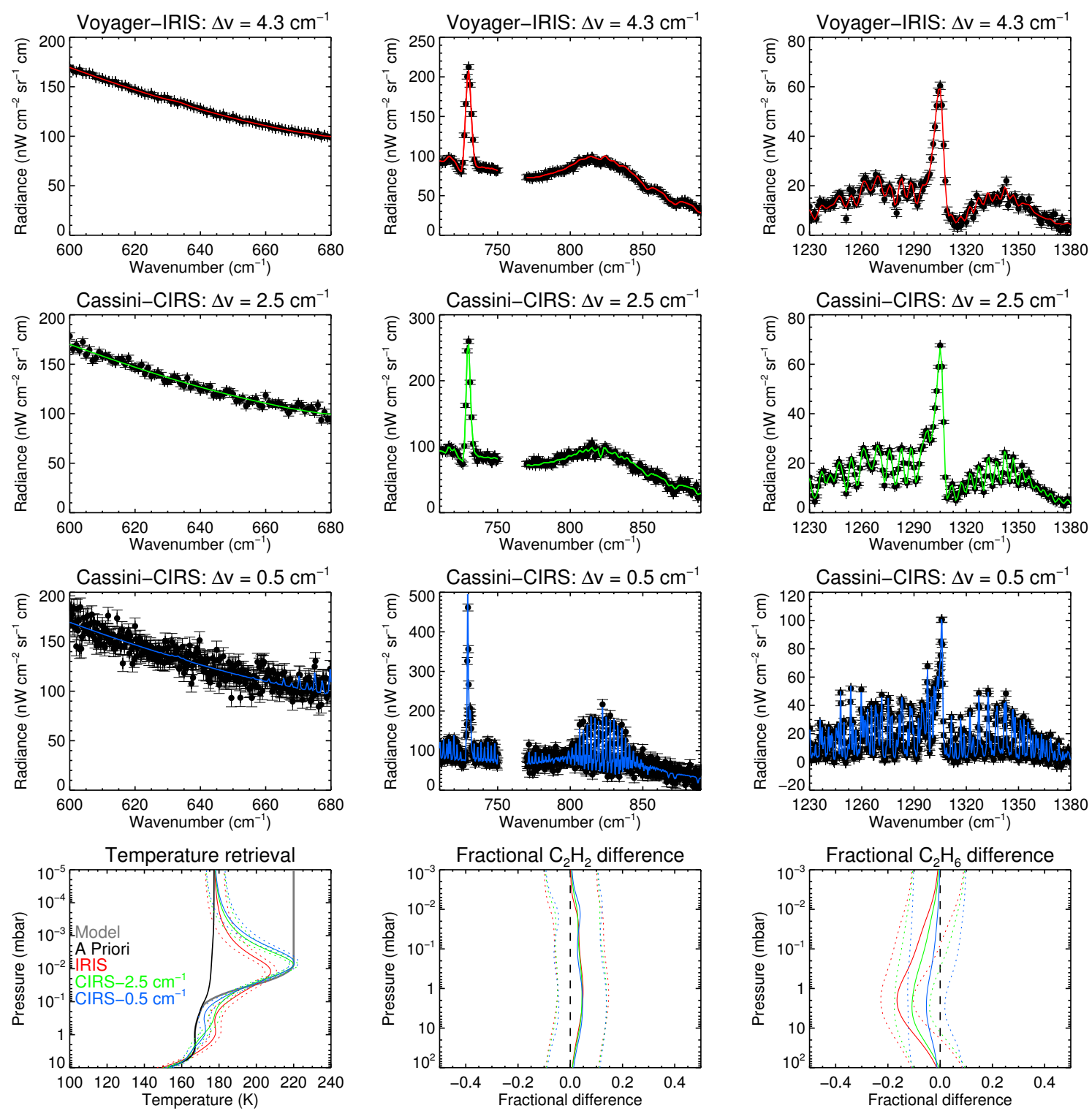

Figure A.16: Test retrievals of the vertical profiles of temperature, $\mathrm{C}_{2} \mathrm{H}_{2}$ and $\mathrm{C}_{2} \mathrm{H}_{6}$ from synthetic Voyager 1-IRIS, Cassini-CIRS spectra ( $\Delta \tilde{v}$ $\left.=2.5 \mathrm{~cm}^{-1}\right)$ and Cassini-CIRS $\left(\Delta \tilde{v}=0.5 \mathrm{~cm}^{-1}\right)$ spectra. The first three rows show comparisons of observed (the synthetic spectra with random noise, shown as points with error bars) and modelled (solid, coloured) spectra for Voyager 1-IRIS (1st row, red), Cassini-CIRS $\left(\Delta \tilde{v}=2.5 \mathrm{~cm}^{-1}\right.$ spectra, 2nd row, green) and Cassini-CIRS $\left(\Delta \tilde{v}=0.5 \mathrm{~cm}^{-1}\right.$ spectra, 3rd row, blue). The first figure in the last row compares the vertical profiles of temperature: the correct temperature profile (the profile used to compute the synthetic spectra, dark grey), the $a$ priori temperature profile (black) and the retrieved vertical temperature profiles (solid) and associated 1- $\sigma$ error bars (dotted) coloured as indicated. The 2nd and 3rd figures show the fractional difference in the retrieved vertical profiles of $\mathrm{C}_{2} \mathrm{H}_{2}$ and $\mathrm{C}_{2} \mathrm{H}_{6}$ with the correct vertical profiles.

datasets tested with retrieved temperatures approximately 10 $\mathrm{K}$ warmer in the $5-0.1$-mbar range and $10-15 \mathrm{~K}$ cooler at the 10- $\mu$ bar level than the modelled (correct) temperature profile. These results demonstrate the benefits of a higher spectral resolution in resolving both lower ( $\sim$-mbar) and upper (10- $\mu$ bar) stratospheric heating associated with the aurora. At higher spectral resolutions such as the $\Delta \tilde{v}=0.5 \mathrm{~cm}^{-1}$ CIRS-COMPSIT spectra, both stronger and weaker lines of $\mathrm{CH}_{4}$ are separated more, which provides a sensitivity to temperature over a larger altitude range in the stratosphere. However, in Voyager-IRIS spectra, which are poorer in spectral resolving power by approximately a factor of 8 , the retrieval struggles to discriminate between upper and lower stratospheric heating and appears to overestimate temperatures at the former level but underestimate temperatures at the latter level.

Figure A.16 also demonstrates the effect of the error in the temperature retrieval on the retrieved vertical profiles of $\mathrm{C}_{2} \mathrm{H}_{2}$ and $\mathrm{C}_{2} \mathrm{H}_{6}$. Retrievals of acetylene at all spectral resolutions are in agreement with the correct profile within the $1-\sigma$ uncertainty. The retrieval of ethane from synthetic CIRS-COMPSIT spectrum agrees with the correct profile within the $1-\sigma$ uncertainty, which again demonstrates the 
benefits of a higher spectral resolution. However, for the Voyager-IRIS and Cassini-CIRS-MIRMAP retrievals, the disagreement between retrieved and correct concentrations exceeds the $1-\sigma$ level between 0.3 and 10 mbar. This discrepancy on the lower spectral resolution retrievals results from the error in the temperature retrieval. However, these results are specific only for the nominal temperature a priori tested in this Section: in the next section (Section Appendix A.1.2), we test alternative temperature a priori profiles and their effect on the retrieved $\mathrm{C}_{2} \mathrm{H}_{2}$ and $\mathrm{C}_{2} \mathrm{H}_{6}$ profiles.

\section{Appendix A.1.2. Using alternative temperature a priori}

We also performed similar retrievals of the synthetic observed spectra but starting from different temperature a priori profiles. This demonstrates the robustness of retrieved temperatures and the effect of the temperature a priori on the hydrocarbon retrievals. Figure A.17 shows the results of retrievals of the vertical profile of temperature, $\mathrm{C}_{2} \mathrm{H}_{2}$ and $\mathrm{C}_{2} \mathrm{H}_{6}$ starting from four a priori temperature profiles: 1) the first is the nominal reference profile (the same profile used in the previous Section for comparison), 2) the reference profile with an isotherm of $160 \mathrm{~K}$ imposed above the level where this temperature is reached, 3) as with (2) but with an isotherm of $200 \mathrm{~K}$ instead and 4) the auroral-200K profile. Figure A.17 also shows the reduced $\chi^{2}$ values for each retrieval to demonstrate how well the noisy, synthetic spectra are fit using different temperature $a$ priori profiles.

Using the $160 \mathrm{~K}$ isotherm a priori, the correspondence between the correct and retrieved vertical temperature profile and the profiles of $\mathrm{C}_{2} \mathrm{H}_{2}$ and $\mathrm{C}_{2} \mathrm{H}_{6}$ is poorest, which is expected since the true, modelled temperature profile and the a priori in this case differ the most. This is also reflected in the degraded fit to the spectra, as indicated by the reduced $\chi^{2}$ values. While the Cassini-CIRS simulations (at both spectral resolutions) continue to match the correct temperature at the 10- $\mu$ bar level, the retrieved temperatures exhibit higher disagreement with the correct temperatures in the 10 -0.1-mbar range in comparison to the standard apriori. This, in turn, leads to larger errors in the concentrations of $\mathrm{C}_{2} \mathrm{H}_{2}$ and $\mathrm{C}_{2} \mathrm{H}_{6}$, with retrieved $\mathrm{C}_{2} \mathrm{H}_{2}$ concentrations being overestimated and $\mathrm{C}_{2} \mathrm{H}_{6}$ concentrations being underestimated.

Using the $200 \mathrm{~K}$ isotherm a priori throughout the stratosphere, the correspondence between the correct and retrieved vertical profiles of temperature, $\mathrm{C}_{2} \mathrm{H}_{2}$ and $\mathrm{C}_{2} \mathrm{H}_{6}$ is comparable with those using the reference temperature profile as the a priori. The $\chi^{2} / n$ values are also very comparable with those of the nominal a priori, which indicates there was negligible difference in the fit to the synthetic observations.

Using instead the auroral-200K profile as the a priori, the correspondence between the retrieved and correct vertical profiles of $\mathrm{C}_{2} \mathrm{H}_{2}$ and $\mathrm{C}_{2} \mathrm{H}_{6}$ is best out of all temperature $a$ priori profiles tested. In using this a priori, the fit to the synthetic observations does improve with reduced $\chi^{2} / n$ values being the lowest out of the four a priori temperature profiles tested. This is intuitive given this isotherm - $200 \mathrm{~K}$ isotherm above $10-\mu$ bar - is most similar to the initial model temperature profile that was assumed. The retrievals from all simulated datasets exhibit good agreement with the true profile in both the 10-0.1-mbar region and the 10- $\mu$ bar level. This in turn improves the retrieval of the concentration of the hydrocarbons: the retrieved concentrations agree with the correct profile within the $1-\sigma$ uncertainty.

\section{Appendix A.1.3. Using alternative hydrocarbon a priori}

Retrievals in the previous Section demonstrated how errors in the temperature retrieval in turn induced errors in the retrieval of $\mathrm{C}_{2} \mathrm{H}_{2}$ and $\mathrm{C}_{2} \mathrm{H}_{6}$. This presented the optimal scenario where the correct profiles of $\mathrm{C}_{2} \mathrm{H}_{2}$ and $\mathrm{C}_{2} \mathrm{H}_{6}$ were also adopted as the a priori. In this Section, we have tested the retrievability of $\mathrm{C}_{2} \mathrm{H}_{2}$ and $\mathrm{C}_{2} \mathrm{H}_{6}$ using different a priori profiles of their vertical profiles.

Alternative a priori of the profiles of $\mathrm{C}_{2} \mathrm{H}_{2}$ and $\mathrm{C}_{2} \mathrm{H}_{6}$ were computed by scaling their vertical profiles (from Moses et al. (2005)) by factors of 0.4 and 2 . These profiles will henceforth be described as the depleted and enriched respectively. The vertical temperature retrieved using the auroral-200K temperature a priori and the associated uncertainty was set as the temperature profile (since retrievals using this a priori yielded the best fit to the synthetic observations) and kept constant. Retrievals of the vertical profiles of $\mathrm{C}_{2} \mathrm{H}_{2}$ and $\mathrm{C}_{2} \mathrm{H}_{6}$ were performed starting from these alternative hydrocarbon $a$ priori and for comparison, the reference profiles of $\mathrm{C}_{2} \mathrm{H}_{2}$ and $\mathrm{C}_{2} \mathrm{H}_{6}$ (the correct profiles).

Figure A.18 shows the results of these retrievals. Intuitively, the best correspondence between the retrieved and correct concentrations occurs when the correct profile was adopted as the a priori. For $\mathrm{C}_{2} \mathrm{H}_{6}$, in adopting the depleted and enriched a priori, retrieved concentrations at 5 mbar exhibit agreement with the correct concentration with uncertainties. This is true for all datasets/spectral resolutions. While larger discrepancies exist at pressures higher and lower than 5 mbar, this is expected given there is less sensitivity to $\mathrm{C}_{2} \mathrm{H}_{6}$ in these pressure regions (Figure 5) and so the retrieved profile tends back to the a priori value. Retrieved concentrations of $\mathrm{C}_{2} \mathrm{H}_{2}$ exhibit greater variation depending on the choice of a priori and the performance is also dependent on the dataset/spectral resolution. For example, using the $\mathrm{C}_{2} \mathrm{H}_{2}$-enriched profile as the a priori (the reference profile scaled by a factor of 2), the retrieval of $\mathrm{C}_{2} \mathrm{H}_{2}$ from the synthetic CIRS-COMPSIT observation returns the correct concentration within $30 \%$ whereas the same retrieval from the synthetic Voyager-IRIS spectrum is inaccurate by greater than $30 \%$. Nevertheless, the magnitude of this discrepancy in $\mathrm{C}_{2} \mathrm{H}_{2}$ retrieved concentrations is considerably larger than the discrepancy introduced into the retrieval of $\mathrm{C}_{2} \mathrm{H}_{2}$ by errors in the retrieved temperature profile (Appendix A.1.1, Figure A.17). Thus, in particular for lower spectral resolutions, these results advocate for the need to test retrievals of $\mathrm{C}_{2} \mathrm{H}_{2}$ and $\mathrm{C}_{2} \mathrm{H}_{6}$ from different a priori and use the reduced $\chi^{2}$ to determine which result lies closer to the true 

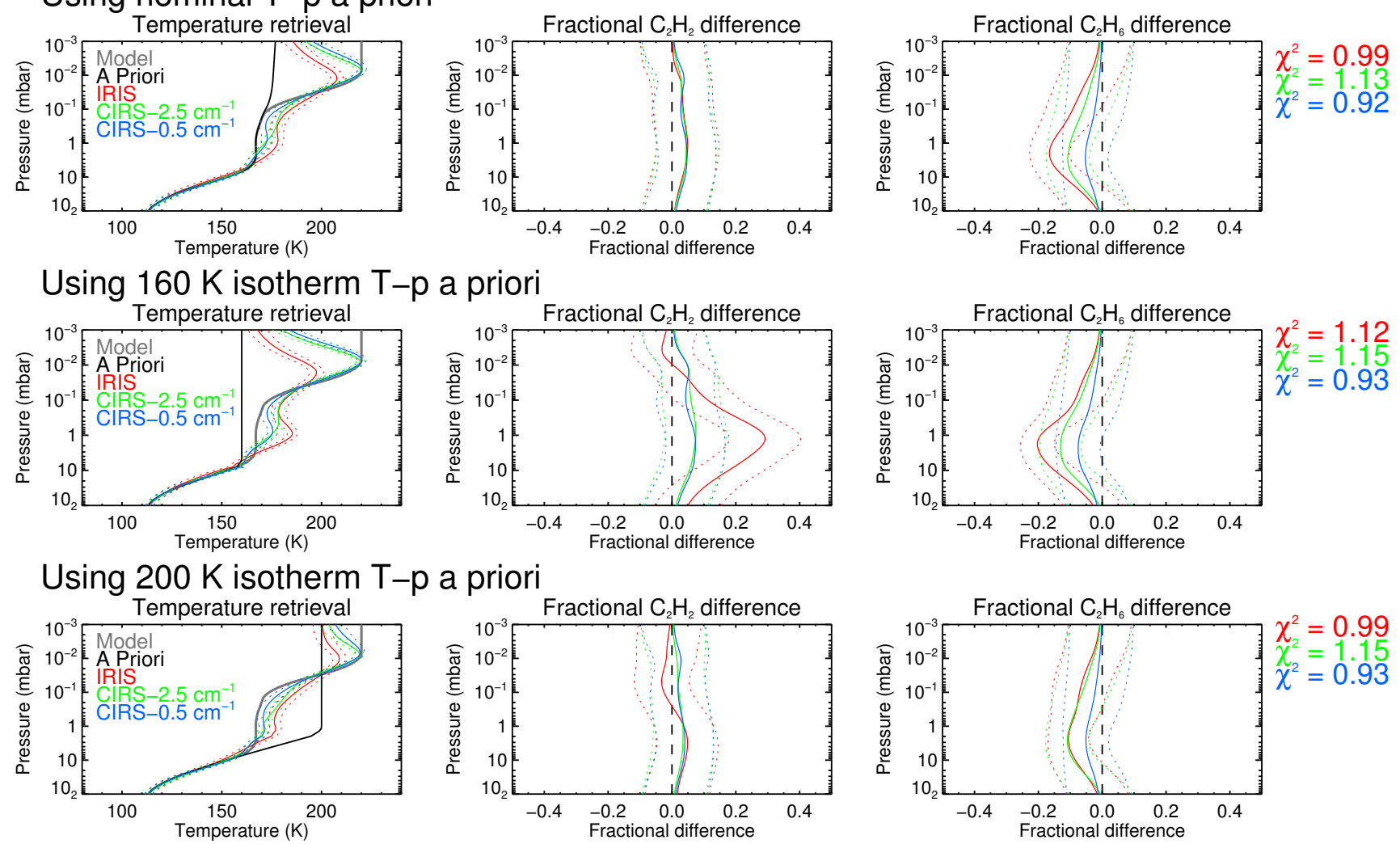

\section{Using $200 \mathrm{~K}$ isotherm above $10-\mu$ bar T-p a priori}
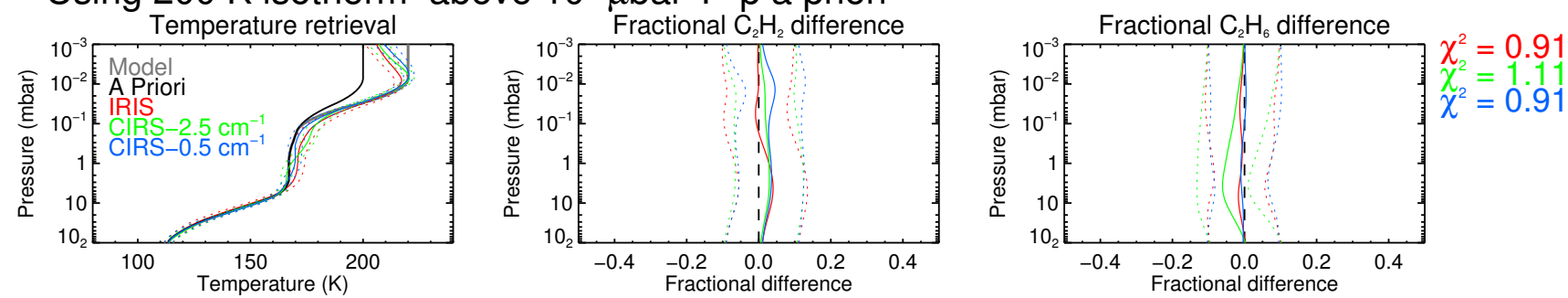

Figure A.17: Test retrievals of the vertical profiles of temperature, $\mathrm{C}_{2} \mathrm{H}_{2}$ and $\mathrm{C}_{2} \mathrm{H}_{6}$ from synthetic observations, as in Figure A.16, but starting from different temperature a priori. Solid lines show the retrieved profiles and dotted lines show the associated uncertainty. $\mathrm{C}_{2} \mathrm{H}_{2}$ and $\mathrm{C}_{2} \mathrm{H}_{6}$ results are shown as a fractional difference between the retrieved and correct profiles. The first row of panels show the results using the nominal temperature profile (identical to Figure A.16, repeated again here for comparison), an isotherm of $160 \mathrm{~K}$ in the stratosphere (2nd row), an isotherm of $200 \mathrm{~K}$ in the stratosphere (3rd row) and an isotherm of $200 \mathrm{~K}$ above the 10 - $\mu$ bar level (the auroral-200K profile). The reduced $\chi^{2} / \mathrm{n}$ values are shown on the right-hand side of each plot for each retrieval in the same colour.

solution. 

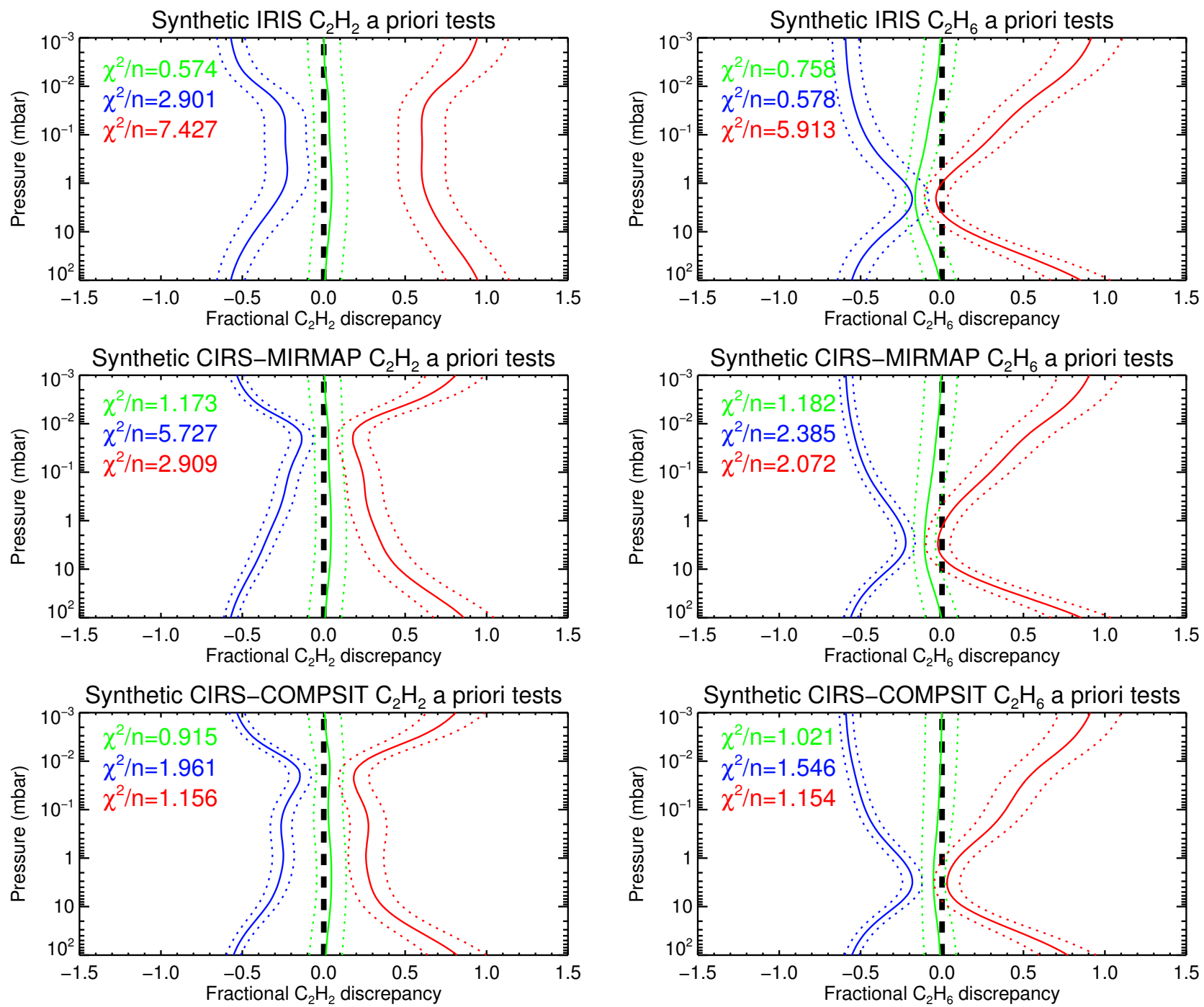

Figure A.18: Test retrievals of $\mathrm{C}_{2} \mathrm{H}_{2}$ (left) and $\mathrm{C}_{2} \mathrm{H}_{6}$ (right) from synthetic Voyager-IRIS spectra (top row), Cassini-CIRS MIRMAP $(\Delta \tilde{v}=2.5$ $\mathrm{cm}^{-1}$, 2nd row) and Cassini-CIRS COMPSIT $\left(\Delta \tilde{v}=0.5 \mathrm{~cm}^{-1}\right.$, 3rd row) spectra. Solid, coloured profiles show the fractional difference of the retrieved result from the correct result and dotted, coloured profiles show the associated uncertainty. Green results used the reference profiles of $\mathrm{C}_{2} \mathrm{H}_{2}$ and $\mathrm{C}_{2} \mathrm{H}_{6}$ as a priori, blue and red results respectively used the depleted and enriched a priori of each hydrocarbon. The reduced $\chi^{2} / n$ values for each retrieval are shown. 